\title{
EFEITO FISIOLÓGICO DO BORO SOBRE O TEOR DE AÇÚCARES EM FOLHAS E COLMOS DE CANA-DE-AÇÚCAR (SachHarun SPP)
}

\author{
JOSE FIGUEIREDO PEDRAS
}

Orlentador: DR. ANDRE M. L. NEPTUNE

Tese apresentada à Escola Superior de Agricultura «Luiz de Queiroz», da Universidade de São Paulo, para obtenção do título de Doutor em Agronomia. Área de Concentração: Solos e Nutrição de Plantas.

PIR A C I C A B A

Estado de Sào Paulo - Brasil

Novembro $=1982$ 
A Marcia, Marcio, Marcelo, Marli

NADA EXISTE NO MUNDO MAIS BELO QUE A FLOR; NEM MAIS ESSENGIAL QUE UMA PLANTA. Peter Tompkins e Cristopher Bird 
A G R A D E C I M E N T O S

o Autor consigna seus agradecimentos sinceros::

ao Professor Dr. ANDRE MARTIN LOUIS NEPTUNE, pela orientação e incentivo na execução deste trabalho;

ao Dr. João Domingos Rodrigues, pelo estímulo e auxílio em todas as fases deste trabalho;

às Professoras Selma Dzimidas Rodrigues e Maria Elena Aparecida Delachiave, pelo auxilio e incentivo;

à Dra. Sheila Zambello de Pinho, pela orientação no delí ' neamento e análise estatística, e ao Dr. Gil Eduardo Serra, pela valiosa colaboração nas análises químicas;

à Sra. Sônia Maria Guimarães Gasparini, pela amizade, além da dedicada colaboração profissional;

ao Sr. José Emilio de Oliveira, pelo auxílio e colaboração; aos Srs. Valdir Factori e Josē Eduardo Costa, pelo auxílio;

à todos aqueles que de uma forma ou de outra, concorreram' para a realização deste trabalho. 


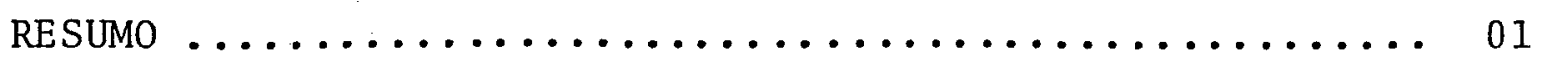

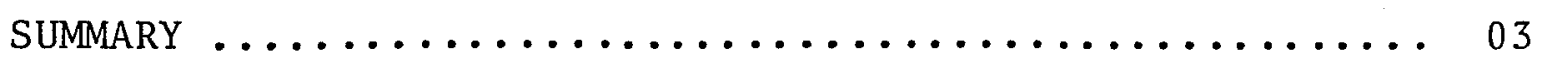

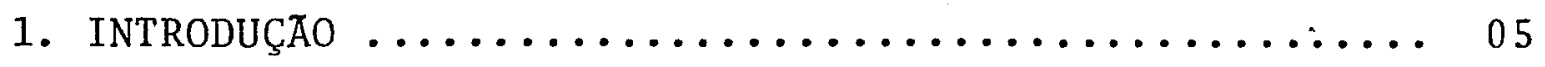

2. REVISAo DE LITERATURA ................... 08

3. MATERIAL E METODOS $\ldots \ldots \ldots \ldots \ldots \ldots \ldots \ldots \ldots \ldots \ldots \ldots$

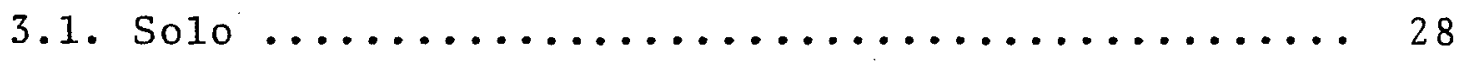

3.2. Delineamento experimental $\ldots \ldots \ldots \ldots \ldots \ldots \ldots 29$

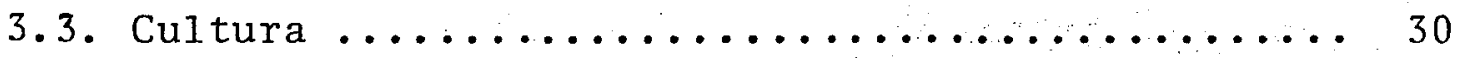

3.4. Variāveis estudadas $\ldots \ldots \ldots \ldots \ldots \ldots \ldots \ldots \ldots \ldots \ldots$

3.5. Coleta das amostras $\ldots \ldots \ldots \ldots \ldots \ldots \ldots \ldots \ldots \ldots \ldots$

3.6. Mëtodos estatísticos $\ldots \ldots \ldots \ldots \ldots \ldots \ldots \ldots \ldots, 35$

3.7. Métodos analíticos ................ 36

4. RESUltados E discussao ................. 38

4.1. Adaptação de método para determinação de açúcar redutor.. 38

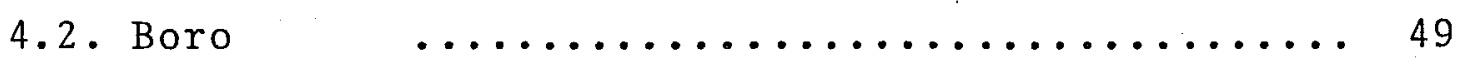

4.3. Açücares redutores ...................... 69

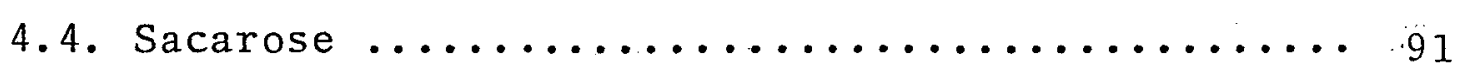

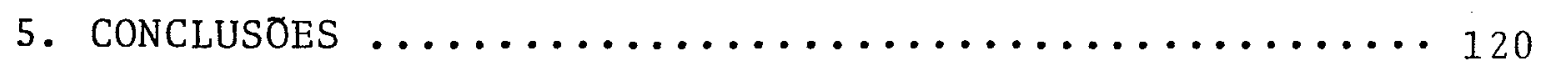

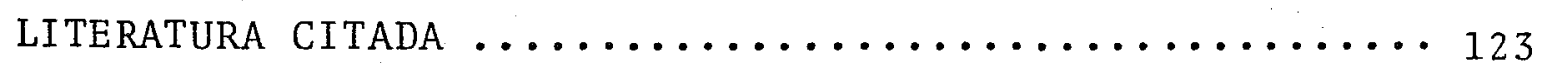


EFEITO FISIOLOGICO DO BORO SOBRE O TEOR DE AÇOCARES EM FOLHAS E COLMOS DE CANA-DE-AÇDCAR (Saccharum spp)

José Figueiredo Pedras

Oriẹtador - Dr. Andrē M. L..Neptune

RESUMO

0 presente trabalho teve por finalidade estudar os efeitos do boro, sobre os teores de açúcares e de boro, em folhas e colmos das variedades IAC 48-65 e IAC 50-14 (cana planta), cultivadas em dois tipos de solo, dos grandes grupos LR e LVa.

As variedades de cana-de-açúcar foram plantadas em outubro e colhidas no período de abril a outubro do ano se guinte. 
Os tratamentos consistiram em doses crescentes de Bórax de $0,10,20$ e $40 \mathrm{~kg} / \mathrm{ha}$, aplicado via foliar dois meses após o plantio e $0,20,40$ e $80 \mathrm{~kg} / \mathrm{ha}$ aplicado via so 10 no plantio, com o experimento instalado em delineamento ex perimental de parcelas :sub-sub-divididas.

Da análise dos resultados obtidos, pode-se destacar as seguintes conclusões:

1. Não foram verificados efeitos conclusivos da adição de Bórax, no teor de boro em limbos, bainhas e colmos.

2. Os dois solos, nas condiçōes de ensaio, apresentaram boro disponível em quantidades suficientes, para atender as necessidades da cana-de-açücar.

3. Não foram obtidas respostas conclusivas a respeito dos efeitos do boro sobre os teores de açúcares redutores em folhas.

4. Não foram verificados efeitos da aplicação de boro sobre o teor de sacarosé em limbos e bainhas, pois a testemunha' aproximou-se dos tratamentos de doses mais elevadas, com exceção do $40 \mathrm{~kg} / \mathrm{ha}$ via solo em bainhas de LVa. Para colmos, também não ocorreram efeitos de tratamento, restrin ' gindo-se as diferenças apenas às coletas.

5. Os teores foliares de boro, foram iguais ou maiores que o nível crítico para cana-de-açūcar. 
PHYSIOLOGICAL EFFECTS OF BORON. ON SUGARS LEVELS IN SUGARCANE (Saccharum spp) IN!LEAVES AND STALKS

$$
\text { Josē Figueiredo Pedras }
$$

Adviser - Dr. André M. L. Neptune

SUMMARY

The purpose of this work is to study the effects of boron on sugars, and boron levels on leaves and on stalks of varieties IAC 48-65 and IAC 50-14 cultivated in Latossol' Roxo (LR) and Latossol Vermelho and Amarelo (LVa).

The sugarcane varieties were planted in October and harvested from April till october of the following year. 
The rates of Borax as follow were: $0,10,20$ and $40 \mathrm{~kg} / \mathrm{ha}$ which were applied in the leaves after planting, and $0,20,40$ and $80 \mathrm{~kg} / \mathrm{ha}$ applied in the soil at the planting; it was utilized the split-split-plot.

From the results, the following conclusion can be drawn:

1. There was no conclusive effects of the applied Bórax on the boron levels in the blades, sheats and stalks.

2. There was no conclusive answers to the boron effects on the reducing sugar levels in the leaves.

3. There were no effects of the applied boron on the sucrose levels in the blades and sheats, because the control has reached results in treatments of high quantities, except $40 \mathrm{~kg} / \mathrm{ha}$ in the soil, in the sheats of LVa. In the stalks there were no treatments effects either and the difference obtained was only in the collects.

4. The two soils, in the conditions of the experiment, present avaiable boron in enough quantities to fill the necessities of the sugarcane.

5. The boron levels in the leaves were similar or bigger than the critical level to the sugarcane. 
1. INTRODUÇAOO

A cultura de cana-de-açúcar, experimenta ainda, no Brasil, incrementos significativos em termos de ärea plantada, em virtude da implantação do Proálcool, apesar das baixas cotações de açūcar no merçado. Este fato faz necessário' a expansão da cultura mesmo em regiōes sem tradição canavieira, invadindo inclusive, solos anteriormente não utilizados, ou considerados inadequados para sua implantação.

Além, do aumento da ārea, faz-se necessārio tam bém a procura de técnicas que possibilitem uma melhor produti vidade, quer para a produção de colmos, quer para melhor qualidade industrial. Neste sentido, insere-se a preocupação' dos pesquisadores que desenvolvem trabalhos de nutrição e fer tilidade.

Algumas evidências, relatadas na literatura, le 
vantam a possibilidade do boro atuar sobre a síntese, movimen tação e acúmulo de carboidratos, inclusive sacarose, em órgãos' de reserva.

0 efeito deste elemento no metabolismo de açúcares tem merecido, hā algum tempo, a atenção de GAUCH e DUGGER ' (1953), que acreditam estar o boro envolvido na translocação de sacarose; de DUGGER e HUMPHREYS (1960), propondo que a ação do elemento prende-se à biossintese de sacarose; de POLLARD et alii (1977), em que o micronutriente atua a nivel de membrana, modificando a translocação; ou ainda de BONILLA et alii (1980) que relatam efeitos benéficos ou tóxicos, sobre o conteúdo de açưcares na seiva e órgãos de reserva.

Sinais de carência de boro no Estado de São Pau 10, tem sido detectados por GALLO et alii (1968); BRASIL S?. et alii (1976); BRASIL S: e FREIRE (1980), utilizando-se de métodos químicos e biológicos, em alguns solos de cultivo tra dicional de cana, e em outros, onde a cultura começa a se ex :" pandir.

Alguns resultados para cana-de-açūcar, embora' não conclusivos, tem sido obtidos em pesquisas desenvolvidas' nas nossas condições, a partir de experimentos desenvolvidos' em diferentes tipos de solo. Estes dados, mais os obtidos pa ra outras culturas, sugerem a necessidade de mais trabalhos, no sentido de se verificar as respostas da cana-de-açúcar à aplicação do boro como fertilizante. 
Assim, o objetivo deste trabalho é verificar em solos LVa e LR, considerados como muito deficientes e não deficientes (BRASIL S\%. e FREIRE, 1980), o efeito fisológico da aplicação de boro, em diferentes doses e formas de aplicação' sobre o teor de açücares em folhas e colmos, das variedades.' IAC 48-65 e IAC 50-14. 
.08 .

2. REVISAO DE LITERATURA

A presente revisão, procurou dentro da extensà literatura sobre o boro, demonstrar os vários aspectos em que - elemento está envolvido, mormente aqueles que possam esclare cer as funções fisiológicas ligadas à translocação e acưmulo' de açúcares. Procurou-se tambēm, evidenciar aspectos de trans locação em plantas de cana-de-açücar, bem como a resposta da cultura à aplicação de boro.

Depois de comprovada a essencialidade do boro por WARINGTON (1923), verificou-se que o elemento está relacionado com várias atividades fisiológicas, nas mais diferentes espēcies, e värias hipóteses tem sido sugeridas para esclare ' cer o seu modo de ação no metabolismo.

A hipötese mais persistente é a de GAUCH e DUGGER (1953), onde sugerem que o elemento está relacionado com a faci 
lidade do movimento de açūcar para dentro das células.

Reforçando a hipótese, GAUCH e DUGGER (1954), sugerem que o boro atuaria facilitando o transporte de açúca : res através de membranas. Ela è baseada na tendência conhecida do $\mathrm{H}_{3} \mathrm{BO}_{3}$ complexar glicídios "in vitro", embora, não hajam provas dessa complexação nas células.

PRICE et alii (1972), fizeram uma revisão das funçōes do boro em plantas e concluiram, que embora esse micro nutriente seja essencial para plantas superiores, um papel bio químico para ele ainda não foi estabelecido. Éstả claro, que o boro é relatiyamente imóvel em plantas e que a divisão celular e o desenvolvimento são alterados na deficiência do mine : ral; a diminuição no crescimento ocorre incidentalmente, antes que qualquer diminuição de reservas de carboidratos seja detec tada. Existe também a hipótese, do envolvimento do elemento' no metabolismo de auxinas, principalmente ao se considerar a redução do alongamento de raízes, que poderia mimetizar níveis supra-ōtimos de äcido indolil-3-acëtico. As variações nos níveis de auxinas em raízes carentes em boro, podem ser uma resposta' secundāria aos efeitos do boro, sobre compostos que afetam a utilização ou síntese de auxinas ou através de um efeito inibi tório do boro sobre o sistema de oxidação de ạ́cido indolil-3-acêti co. Os autores referem tambēm, que äpices de plantas omissas em boro tem células que maturam mais rapidamente.

0 micronutriente tambēm interfere na sintese pro teica, diminuindo a incorporação de aminoācidos na utilização' de fosfato, aumentando a atividade da ATPase (ALBERT, 1965). 
MCILRATH e SKOK (1964), referem que o boro afeta! a produção de lignina, em girassol e fumo, quando carentes nes se micronutriente, porém não existindo estabelecimento do 1ocal onde esse elemento atua, embora haja a sugestão de que o boro esteja envolvido na polimerização de precursores da ligni na. E tambēm sugerido por O'KELLEY (1959), de que o elemento' está relacionado com a síntese de material de parede celular, provavelmente materiais pécticos.

WITTINGTON (1959), relata que na ausência de boro, cessa a divisão celular, devido a anormalidade na formação de parede celular, que impede a organização de célula para mitose. Já BUSSLER (1960), relata que o boro afeta o desenvolví mento de raízes, fazendo com que estas se tornem espessadas, com ápices necrōticos.

o boro seria essencial para o desenvolvimento de raízes e manutenção dos pontos de crescimento, segundo ANDREW (1962), e na carência desse micronutriente, ocorre o acúmulo de carboidratos e restrição na formação de parên quima lacunoso nas folhas. O autor ressalta, que o papel do boro, em especial em feijoeiro, seria na formação de paredes' celulares, havendo cessação de divisões celulares, não por falta de açúcares disponiveis ou de sintese de ācidos nucleicos, porém devido a falta de organização do fuso mitōtico. Re fere também, que as espécies vegetais que são sensỉveis à ca ' rência de boro também o são à de cālcio.

KOUCHI e KUMAZAWA (1975a), citam as observações de Takashi (1975), segundo o qual, as necessidades de boro em 
plantas superiores diferem nas espécies, porém são geralmente altas.

A continuação dos trabalhos de KOUCHI e KUMAZAWA (1976), relatam que na omissão de boro, em tomateiro e girassol, hā uma certa aceleração do processo de senescência. das células do āpice radicular, que sofrem dano irreversível; o que provoca um crescimento anormal a nível sub-celular.

o boro seria capaz de formar complexos com compostos essenciais, influir na respiração, fotossintese, mitose, crescimento e desenvolvimento. Provavelmente, atuaria nometabolismo como regulador onde sua presença permitiria a formaçāo de complexos, além de agir a nível de metabolismo do ácido indoli1-3-acético; são essas as conclusões de AUGSTEN e EICHLORN (1976).

Mais recentemente, foi sugerido por BOHNSACK e ALBERT (1977), que o boro estaria associado ao metabolismo de auxina, mas em orientação contrária a BAKER et alii (1956).

Tem sido também mencionada a relação entre boro e a integridade do tecido condutor. Assim, SKOK (1941) ve rificou desintegração de câmbio e floema em rabanete quando o elemento era ausente. Em Vicia faba, Warington (1962), citado por RIBEIRO (1978), mencionou que a deficiência de boro provoca degeneração das células cambiais, desintegração do pa rênquima e floema, bem como lento desenvolvimento do xilema e, às vezes, sua desintegraçăo. 
STRUCKMEYER (1968), verificou que ocorria enruga mento do tecido internerval, clorose e pequenas lesões; ocorriam também modificações do floema, com células hipertrofia-' das e, consequentemente, colapso do tecido adjacente.

SWANSON (1965), assegura que a translocação è consideravelmente diminuida em plantas em estágios incipiente de carência em boro, mesmo na ausencia de sintomas foliares morfológićos correspondentes. Em estágio mais avançado de' carência de boro, o floema entra em colapso,tornando-se não funciona1.

Os mecanismos envolvidos na sintese,transloca ' ção e acúmulo de açũcares em cana-de-açúcar e outras espécies, tem merecido a atenção de muitos pesquisadores, procurando' comprovar as värias possibilidades.

BUCHANAN (1953), refere que a sintese de sacaro se em plantas é um problema para os bioquímicos. Examinando' hexoses monofosfatos produzidos durante a fotossíntese em atmosfera com ${ }^{14} \mathrm{CO}_{2}$, o autor observou e caracterizou um fosfa to de sacarose como um intermediärio na síntese.

Foi demonstrado por ROREM et alii (1959) que tecidos foliares de beterraba contém sistemas ativos para a sintese, tanto de sacarose como de sacarose-fosfato conforme o esquema:

UDPG + frutose $\rightarrow$ sacarose + UDP

UDPG + frutose-6-fosfato $\rightarrow$ sacarose fosfato + UDP 
HARTT (1940), relata.que folhas isoladas de cana -de-açúcar podem "sintetizar" sacarose, quando suplementadas com glicose e frutose,no escuro. As folhas destacadas podem formar sacarose por aproximadamente 2 semanas, alcançando taxas de $16 \%$ de açūcar-de-cana em base de matéria seca. A temperatura afeta a absorção de monossacarideos, a interconversão de gluco se e frutose e a formaçāo de sacarose,girando a temperatura ' ótima para absórção em tợno de $20^{\circ}-40^{\circ} \mathrm{C}$, para a intercon . versão em torno de $30^{\circ}-40^{\circ} \mathrm{C}$ e a de formação de sacarose é de $30^{\circ} \mathrm{C}$.

O mecanismo de síntese de sacarose em cana - deaçücar, de acordo com outro relato de HARTT (1943a), inclui fosforilação e aeração. Frutose è tão boa quanto glicose como substrato para sintese de sacarose; esse processo tem lugar' obedecendo a um mecanismo que pode ter tanto glicose quanto' frutose como ponto de partida. A única diferença é que ambos os reagentes devem ser formados, quando o substrato ini- ' cial é frutose e que somente um reagente se forma quando a adição é de glicose. A formação de sacarose em plantas não' resulta somente em um armazenamento de açúcares, que podem não ser quebrados de imediato, mas se combinar com fosfa to, o qual pode ser usado novamente.

Os experimentos de HARTT (1943b), levam à con clusão de que a formaçāo de sacarose obedece ao esquema geral de metabolismo de carboidratos, sendo que a inibição de fruto se difosfato diminui essa formação, enquanto que a diminuição da 
quebra desse produto aumenta a sintese. Assim, a frutose difosfato é a pedra angular do processo de formação de sacarose por cana-de-açúcar. A formação de sacarose a partir de glico se tem lugar em folhas destacadas, bainhas, caules e raízes. de cana-de-açücar, além de colmos inteiros. Mais sacarose' acumula-se em colmos com folhas do que naqueles cujas folhas' foram removidas, indicando que tanto a síntese "in situ" quan to a translocação a partir da folha podem estar envolvidas ' no acúmulo de sacarose no caule. Além disso, de acordo com a autora,formação de sacarose a partir de glicose ou frutose po de ter lugar no escuro, não requerendo clorofila e sendo um processo distinto da fotossintese. Nos estudos conduzidos' em folhas supridas com glicose ou frutose, as porcentagens ' de sacarose foram maiores do que de açúcares redutores. Em fó Thas suplementadas com glicose, as porcentagens de sacarose' aumentaram por-quase 2 semanas, ainda que as porcentagens de açúcares redutores flutuassem pouco. Algum componente do mecanismo de conversão de glicose à frutose e formação de sacarose parece ser menos ativo em folhàs destacadas, à noite do que naquelas que o foram durante o dia; esse componente é ativo em folhas destacadas logo após a alvorada. Para a inter-' conversão de glicose à frutose e formação de sacarose, aera-' ção è requerida, bem como também para a absorção de açúcar. 0 terço inferior da folha foi o mais efetivo na síntese e o ter ço superior absorveu mais açūcar, ao passo que o terço médio.' foi o menos eficiente em ambos processos. A țâmima foliar em si è mais eficiente que a região da nervura central em todos' os processos. 
A seiva exsudada por'16 espécies de árvores,pex tencentes a 11 famílias, foi analisada por ZIMMERMANN (1957); somente oligossacarídeos não redutores foram encontrados;a sa carose parece ser a principal forma de transporte, mas os tubos crivosos de muitas espécies também contiveram rafinosí deos (rafinose, estaquiose e verbascose) os quais são os açúcares de translocação.

Suprindo cana-de-açūcar com sacarose marcada com frutose ${ }^{14} \mathrm{C}$ e examinando a distribuição de radioatividade em compostos translocados, HATCH e GLASZIOU (1964) obtiveram evidências de que a molécula de sacarose permanece intacta du rante o transporte ao longo dos tubos crivosos de folhas, bai nhas e caules. A sacarose foi demonstrada ser o componente principal da corrente de transporte, sendo no entanto, quebra da e ressintetizada durante o movimento para armazenamento.

HARTT, et alii (1962), relatam que a sacarose é o principal composto translocado em colmos de cana: da folha para o colmo, basipetamente através deste até as raízes, acro petamente para nutrir a inflorescência e os dois sentidos para outros colmos, quando do perfilhamento. Não hã evidência definitiva de outro componente movimentado. As velocidades ' de translocação da folha nutriz em direção ao colmo é de 42 a $150 \mathrm{~cm} / \mathrm{h}$, sendo que os fatores que afetam esse fenômeno são: temperatura do ar, luz, umidade e deficiência de nitrogênio ou fósforo.

Em base radioquímicas, SWANSON e EL-SHISHINY (1958), concluiram que a sacarose è a única forma de trans- 
porte de açūcares em videiras. Introduziram isōtopos de ${ }^{14} \mathrm{C}$, suprindo uma ünica folha com ${ }^{14} \mathrm{CO}_{2}$, em condições favoräveis à fotossintese. Quantidades de glicose e frutose marcadas isotopicamente foram encontradas no caule, mas parecem ser produ tos hidroliticos de sacarose translocada, como pode ser inferido pela relação de glicose para frutose marcadas. Os resul tados obtidos, provêem evidência suplementar de que a translo cação de açũcares ocorre primariamẹte nos tubos ou células do tecido floemático.

Usando sacarose marcada, SERVAITES e GEIGER (1974), afirmam que os resultados obtidos suportam a teoria, que a taxa de transferência de massa de translocação, sob con dições de suficiente demanda consumidora é limitada pela taxa de fotossintese líquida, ou mais especificamente,pela sintese de sacarose, sendo esta limitação independente da intensidade luminosa "per se".

GEIGER et alii (1973), sustentam que parte do transporte de açúcar, a partir de folhas "fornecedoras" até regiões consumidoras pode ser efetuado por mecanismo ativo. Este fato, parece sugerir a existência de mecanismos de trans porte afetados pela presença de substâncias que ativem a translocação. Esta idéia é sustentada por SOVONICK et alii (1974), que estudando o fluxo no floema, concluem que algumas fases do movimento de açücares, são mediadas por um carreador.

De acordo com TRIP e GORHAN (1968), açúcares ra dioativos foram introduzidos em plantas de soja. Após 5 a 180 minutos, determinou-se que sacarose, glicose e manitol fo 
ram translocados no caule via xilema e passaram através do ! cambio, contrariamente aos resultados previamente relatados. Quando se introduziu a glicose marcada por via lateral em nervuras, esse açūcar era metabolizado como sacarose, por via floemática, de maneira semelhante a dos fotossintetizados. BURR et alii (1957), referem que o transporte de açúcares, ocorre tanto de dia quanto de noite; o armazenamento temporārio dé polissacarídeos nas bainhas durante a noite.' auxilia no transporte de açúcar da lâmina para o caule.

GLASZIOU (1961), relata que há duas vias de en $*$ trada de sacarose em tecidos jovens, uma predominante em baixas e outra em altas concentrações de sacarose. Um precursor ou derivado de sacarose é transferido através das bainhas. que separam os espaços internos e externos dos tecidos e a sa carose é levada para o espaço interno. A maturação de tecido de armazenamento é acompanhada por um aumento relevante no conteúdo de sacarose e diminuiçāo concomitante em glicose e frutose. O autor sugere que a inversão da sacarose ocupa uma posiçāo chave no armazenamento de sacarose no espaço interno' e que a taxa de inversão declina conforme o tecido maduro.

A entrada de açúcares em discos de tecidos de reserva de cana de açúcar, segundo BIELESKI (1960a), apresenta dois estágios. Inicialmente a entrada alcança um equilíbrio' dentro de 1 hora, sendo o nível proporcional à concentraçāo ' externa de açúcar, independente do açúcar e não é afetada por condições anaeróbicas. Esse açūcar difunde-se rapidamen te quando o tecido é colocado em água; tal composto orgânico' 
aparentemente se localiza no espaço livre, constituindo 10-20 $\because$ do volume tissular. Uma segunda fase de entrada continua' após 60 horas, apresentando uma taxa lenta e constante, independente da concentração de açúcar, dependente do açúcar' e inibida por condiçōes de anaerobiose. Esse açūcar não saí do tecido quando colocado em água; esse segundo processo seria ativo.

o conteúdo de sacarose do tecido aumenta durante o acúmulo, que ocorre cnntra gradientes de concentração 10 a 200 vezes maiores. Não ocorre síntese de amido,mas o acúmu 10 é associado com um aumento de 30-40: de respiração. A sacarose não è hidrolizada antes do acúmulo e quando as fatias de tecido armazenam açücar de soluções mistas, a entrada de sacarose inibe a de glicose. Os internós mais ativos em armazenar açúcar em condições de campo revelaram o: mesmo comportamento em laboratório, sendo que fatias de tecidos maduros mostraram pouca ou nenhuma capacidade de acumular açūca.' res.

BIELESKI (1960b), em outra comunicação, revela qué ò compartimento de reserva da cana-de-açúcar,frente a inibidores,é similar a outros mecanismos de transporte, tornando-se mais sensivel que outros processos em vegetais e menos do que certos processos em animais. O autor sugere que os açúcares' contidos em células imaturas de reserva são acumulados por operação contínua, de um mecanismo próprio de acúmulo e não sọ mente por difusāo de açūcares. 
Conforme o relato: de SACHER et alii (1963), há 3 compartimentos distintos através dos quais os açūcares movem-se quando acumulados por discos de tecido de armazenamento; esses compartimentos denominados espaço externo, compartimento metabólico e compartimento de reserva sāo' caracterizados metabolicamente e por seu comportamento com relação a açúcares e anions. A sacarose é invertida ao passar do meio para o compartimento de reserva,onde reaparece co mo sacarose; essa inversão é mediada por uma invertase ácida'. no espaço externo e aparentemente é um passo integrado no acúmulo de sacarose. A invertase no espaço externo é somente uma parte da atividade de invertase ácida total do tecido;uma parte dessa atividade permanece no compartimento de reserva.. Hā esquema cíclico,no qual os açúcares movem-se para o compa timento de reserva por um processo ativo que é denominado ciclo de acūmulo de açūcares.

Estudando o armazenamento de açūcares em colmos de cana-de-açúcar, GLASZIOU e GAYLER (1972) reportam que durante o transporte floemático, moléculas de sacarose marcadas com ${ }^{14} \mathrm{C}$ na metade concernente à frutose, mantēm sua assime , tria; enquanto ${ }^{14} \mathrm{C}$-glicose e ${ }^{14} \mathrm{C}$-frutose, são ambas transloca das, porém rapidamente convertidas em sacarose marcada assime tricamente. Assim,a sacarose move-se através do floema sem quebra ou ressintese; o movimento real de um novo assimilado' e produto de armazenamento parece ser um sistema combinado de bomba que puxa e empurra, mais sistemas dependentes de movi- * mento difusivo e talvez fluxo de pressāo. 
GLASZIOU (1960), reláta que a taxa de sacarose e glicose em discos de tecido jovem internerval de cana é 6 a 15 vezes maior do que em tecidos maduros. Quando discos de tecido jovem são colocados em àgua destilada, as proporçōes relativas de açúcares (sacarose, glicose e frutose) no tecido, são diferentes dos açúcares encontrados no meio; esse tipo de tecido é 8 a 10 vezes mais permeável a açúcares redutores do que a sacarose, sendo que frutose è o açúcar que mais sai para o meio.

MANSON e MASKELL (1928), citam vārios autores que verificaram que a porcentagem de hexoses na folha permane ce praticamente constante ao longo do dia, ao passo que a sacarose flutua marcadamente, aumentando durante o dia e diminuindo durante a noite. Alēm disso, o acúmulo de sacarose re sultante da iluminação, proveniente da condensação de hexoses em sacarose que seria estocada no vacủolo. Também são citados pelos autores Davis et alii (1916), segundo os quais, as nervuras e pecíolos não sō possuem uma alta quantidade de açú car total relativo a matéria seca, como também apresentam a maior relação hexose/sacarose. Outra citação dos autores é a de Strakosh (1907), segundo o qual, em beterraba, o limbo contem 6 vezes mais sacarose que hexose.

o boro, em muitos trabalhos, tem sua ação associada ao metabolismo de carboidratos, podendo atuar quer na síntese, quer na translocação ou na utilização de açūcares de muitas espécies. 
De acordo com MITCHELl et alii (1953) , a translocação de substâncias reguladoras de crescimento como o ácido 2,4-diclorofenoxiacético e seus sais e ésteres, das fothas para outras partes das plantas, está associada com translocaçāo de assimilados. Os autores,citam Stark e Mathew (1949), que relatam que há aumento de sólidos solúveis, entre os quais muitos açúcares; se houver aspersão de ácido bórico' em soluções diluidas, Continuando, os autores a partir, de experimentos sucessivos, verificaram que a translocaçāo de ácido 2,4-diclorofenoxiacético aumentou cerca de 43, 47 e 50\%, na aplicação de boro, conjuntamente à soluções de açũcares, ao passo que o boro por si só nāo afetou o fenômeno.

Os autores concluiram que o efeito acelerador' nesse caso relacionou-se diretamente com o movimento de açúca res e a translocaçāo de reguladores de crescimento foi acelerada indiretamente.

Face às reações bem conhecidas do boro com com postos ricos em $\mathrm{OH}$, e sua recente aplicação em formar complexos boratos com açúcares, de forma que possam ser separados' por colunas de trocas iônicas, GAUCH e DUGGER (1953), concebe ram a hipótese de essencialidade do boro em plantas. Assim,o boro combinar-se-ia com açúcares, formando um complexo açúcar-borato (ionizável), que seria translocado com maior facilidą de do que moléculas não boradas e não ionizáveis. Uma vez ' que muitos estudos indicam que a sacarose não se move rapidamente através de membranas celulares, quantidades da ordem de 5 a $10 \mathrm{ppm}$ de boro afetam a translocação, e sugerem que o 
complexo formado entre boro e certios carboidratos varia com condições como mudanças nas concentrações e pH.

Folhas de feijão foram infiltradas por DUGGER et alii (1957), com 4\% de glicose, após um período de escuro' e verificou-se que as mesmas, sintetizaram mais amido, do que folhas infiltradas com $4 \%$ de glicose e vários niveis de boro. Os estudos "in vitro" da reação glicose-1-fosfato $\vec{\leftarrow}$ amido: , mostram que o boro influencia à taxa de reação, mas não o equi líbrio final. Os autores demonstraram que em baixos niveis de substrato, o boro combina-se com ele e influencia a taxa de síntese de amido. Esse fato pode explicar porque a translocação de açũcares em plantas aumenta quando o elemento está presente.

DUGGER e HUMPHRYES (1960), relatam que o boro pro move a biossintese de sacarose em homogenatos de plântulas de cana-de-açúcar e ervilha. Em uma preparação enzimätica de sementes de ervilha, contendo UDPG pirofosforilase, UDPG ' transglicosilase e UDP quinase, o boro inibe a sintese de sa carose a partir de UTP, G-1-P e frutose. Na reação acoplada, - ATP é essencial e o boro de alguma maneira permite a concen tração de UDPG. No entanto, UDPG pirofosforilase e UDPG ' transglicosilase são inibidas por ATP em experimentos individuais; UDPG pirofosforilase é promovida por boro, enquanto' UDPG transglicosilase é inibida.

De acordo com MOGILNER (1960), vários trabalhos demonstram que o boro influi positivamente na síntese e trans locaçāo de carboidratos. Um mecanismo através do qual o boro 
afeta os fenomenos supracitados, sẹia a faculdade do $\mathrm{H}_{3} \mathrm{BO}_{3}$ ' em formar complexos com açūcares, que dessa forma teriam maior mobilidade que os açūcares por si só; o boro também seria capaz de atuar nos processos de óxido redução e assim haveria maior quantidade de energia disponível para o transporte de açúcares nos tubos crivosos.

De acordo com SAAKOV (1965), o boro associado a Mn acentua a velocidade de translocação de substâncias nutri tivas a partir das folhas; a maior parte dessas substâncias ' dirigesse as partes novas, incluindo o sistema radicular, sen do menor o afluxo a porçōes jā maduras.

SARIN e SADGOPAL (1965), concluem que a omissão' de boro tem um efeito direto no crescimento e que as mudanças nos conteúdos de carboidratos e nitrogênio são secundários.

SISLER et alii (1956), trabalhando com tomate $\underline{i}$ ros em cultivo hidropônico, pulverizam solução de açūcares em plantas deficientes em boro, porém, tal medida nāo evitou a morte da gema apical, no entanto, observou-se que sacarose ra dioativa foi translocada mais rapidamente em plantas carentes, porém que nāo mostravam ainda sintomas. Quando o sintoma morfológico da deficiência era visível, a entrada de sacarose e sua translocaçāo era reduzida e o boro aplicado não auxiliaya, na:distribuição de açúcares aplicados.

De acordo com SWANSON (1965), na sua revisão so bre translocação de solutos orgânicos, o boro afeta o fenomeno,sendo que hã diminuição de fluxo em plantas em estágio incipiente de carência de boro, mesmo sem existir sintomatolo-' 
gia visível. O mecanismo pelo qual o boro acelera o traspor te poderia ser entendido, ao considerarmos a intensidade com a qual o ion borato se complexa com compostos polihidroxili-' cos, como os açūcares, onde a formação de um complexo açūcar-borato seria mais facilmente transportado através de membranas celulares.

LEE e ARONOFF (1967), relatam que o boro, como bo rato, parece desempenhar um papel no metabolismo de partição' entre os esquemas glicolíticos e o desvio das pentoses. Esse efeito é resultante da associação do borato com o ācido-6-fos foglucônico, formando uma substância virtual que inibe a desidrogenase-6-fosfoglucônica. Na falta de borato,ooor re a inibiçāo enzimätica e forma-se um excesso de ácidosfenóIicos.

VENTER e CURRIER,(1977), verificando o efeito do boro tanto em feijoeiro quanto em algodoeiro, observaram que em carência formou-se calose nas placas crivosas, os quais poderiam obstruir a translocação de assimilados, no entanto,os autores consideraram que o declínio da translocaçāo era excessivo para ser atribuído a esse tipo de impedimento, e sugeriram que' outros fatores devem contribuir para a redução de transloca. . ção em plantas carentes em. boro.

Por sua vez, HULl e LERMANN (1972), analisando' a distribuição de produtos fotossintéticos em folhas de feijo eiro deficiente em boro, notaram que baixas concentraçōes de boro deprimiram o crescimento das plantas, afetando mais as raīzes que a parte aérea. O conteúdo de açúcares solúveis foi maior em folhas de plantas carentes em boro do que em." plantas normais. 
POLLARD et alii ( 1977 ), empregando Vicia faba e zea mays, relatam que o boro influe na atividade de componentes específicos da membrana, provavelmente através de uma interação entre esse elemento e compostos polihidroxila-' dos (glicoproteinas e glicolipídeos), e modificando também a translocação de carboidratos.

BONILLA et alii (1980), estudando o efeito do. bo ro sobre o metabolismo de açūcar, afirmam que condições de deficiência e toxidez, resultam num substancial decréscimo dos níveis de açúcar na seiva e na raiz. Isto confirma que o boro tem um papel importante na fotossintese ou em algum estágio' inicial deste caminho metabólico, como também nos processos' de transporte. Finalmente, consideram a possibilidade de exis tir um controle na qualidade inicial de beterraba açucareira, baseado nó fato de que o efeito dos níveis de boro sobre os ": níveis de açúcar da raiz é muito similar àquele observado na seiva. Afirmam ainda, que nível de açúcares redutores na se va é um parâmetro útil para determinar a qualidade da cultura nos estágios iniciais, antes da planta atingir seu pico de a cumulação.

Rabanetes carentes em boro, apresentam cresci-' mento reduzido, diminuição do conteúdo de clorofila e alteraçāo na produção e distribuição de açūcares. (BIBLE e CHONG , 1981).

Outros trabalhos jā reportados por PEDRAS (1981), demonstram que o boro participa da síntese e translocação de 
açúcares, destacando-se: BAKER et alii (1956), para tomateiro e feijoeiro; SISLER et alii (1956), em tomateiro; KISE (1966), em cenoura e repolho; MARTIN et alii (1966); TANAKA (1967a), em girassol e GJUL'AHMEDOV e PEJSAHOV (1969) em videira.

Para beterraba açucareira, em que a reserva é feita como na cana-de-açūcar, na forma de sacarose, citam-se: IVANOVA (1965); KIBALENCO (1966 e 1970); VLASYUK (1967); RAB (1969); NELYUBOVA e DOROZHKINA (1969 e 1970); LUIT (1970).

0 conteūdo de boro disponível no solo, varia em função de vários fatores, tais como: calagem e pH, reportadas respectivamente por TANAKA (1967) e BOWEN (1969); deficits hídricos (BUCKMAN e BRADY, 1967) e óxidosde ferro e alumínio, reportado por SIMS e BINCHAM (1968); além da pobreza ou rique za natural da rocha de origem ou ainda da maior ou menor solubilidade destas, como reportado por MENGEL e KIRKBY (1978).

A absorção de boro por plantas de cana, ocorre preferencialmente na forma de $\mathrm{B}(\mathrm{OH})_{4}$, e parece não existir di ferenças de eficiência em relação as folhas e raízes, através de mecanismos ativos ou passivos (BOWEN 1968 e 1969 ). Por outro lado, em cevada foi encontrada só absorção passiva (BIN GHAM et alii, 1970).

Verifica-se que o boro apresenta imobilidade, e OERTLI e RICHARDSON (1970) estabeleceram mecanismos para explicar o fenömeno. Este fato, sugere que o elemento deve ser fornecido continuamente, tornando válidas as assertivas 
de KOUCHI e KUMAZAWA (1975) e RIBEIRO (1978), de que deficiên cias do elemento mesmo por pequenos periodos, podem afetar o desenvolvimento das plantas.

o teor de boro nos solos do Estado de São Paulo, tem sido levantados por LOTT et alii (1961); BRASIL S $^{\circ}$ et alii (1976); ESPIRONELO et alii (1976a e 1976b); BRASIL S\%. e FREIRE (1979 e 1980), onde se verifica observações de carên cia do micronutriente em värias culturas e espécies hortíco laṣ, demonstrando que alguns solos nāo contēm quantidades ade quadas do elemento na forma disponivel.

Os sintomas de caréncia bem como os teores normais do elemento para plantas de cana-de-açúcar, tem sido reportado por vārios autores, destacando-se MARTIN (1934); CLEMENTS et a1ii (1941); EVANS (1959); van DILLEWIJN (1960);MALA VOLTA et alii (1964); HAAG (1965); ORTIZ (1968); BOWEN (1969 e 1977); HUMBERT (1974); ORLANDO Fo e RUGAI (1974) e SULTANUM (1974); onde se observa que os valores são por vezes discor-' dantes, em função da variedade e tipo de solo.

As respostas da cana-de-açúcar à aplicação do micronutriente, não tem sido consistentes, variando de acordo com o parâmetro observado, variedades e tipos de solo. Res-' postas positivas foram encontradas por MARTIN-LEAKE (1949) ; LAL e SHRIVASTAVA (1949); MITCHELL et alii (1953); DE e SINGH' (1960); KANWAR (1960): MUKHERJEE (1968). As respostas negati vas foram reportadas, entre outros, por WALLACE (1947); SAMUELS et alii (1952), NEPTUNE et alii (1965) e ESPIRONELO et alii (1976) . Por outro lado ALVAREZ e WUTKE (1963)e PEDRAS (1981) encontraram respos ' tas não conclusivas. 
3. MATERIAL E METODOS

3.1. Solo

No presente trabalho, foram utilizados dois tipos de solo, classificados comó Latossolo Roxo (LR), por ESPINDOLA (1979), localizado no município de Barra Bonita, em terras da Usina da Barra S/A e Latossolo Vermelho Amarelo fa se arenosa (LVa), pela COMISSÃO DE SOLOS (1960), localizado' em terras da Usina Santa Adelaide, no município de Dois Corre gos.

A anālise química dos solos, mostra os resultą dos abaixo:

\begin{tabular}{lcc|ccccc} 
& & & \multicolumn{4}{|c}{ Teor Trocavel em meg/100 $\mathrm{g}$ de terra } \\
\cline { 2 - 8 } & $\mathrm{pH}$ & $\mathrm{MO} \%$ & $\mathrm{PO} \overline{\overline{0}}$ & $\mathrm{~K}^{+}$ & $\mathrm{Ca}^{++}$ & $\mathrm{Mg}^{++}$ & $\mathrm{Al}^{++}$ \\
\hline $\mathrm{LR}$ & 6,3 & 2,74 & 0,38 & 0,17 & 3,30 & 0,80 & 0,08 \\
\hline $\mathrm{LVa}$ & 5,5 & 1,24 & 0,06 & 0,07 & 1,19 & 0,70 & 0,40 \\
\hline
\end{tabular}


3.2. Delineamento experimental

Foi instalado um ensaio em cada solo, em blocos ao acaso com parcelas sub-sub-divididas, com três repetições para cada tratamento, num total de 21 parcelas por ensaio. Cada parcela constituida de dez linhas de cinco metros lineares ' cada, espaçadas de 1,4 metros (BRIEGER e PARANHOS, 1964) divi dida em duas sub-parcelas, perfazendo uma ärea de $35 \mathrm{~m}^{2}$ por sub-parcela, $70 \mathrm{~m}^{2}$ por parcela, $490 \mathrm{~m}^{2}$ por bloco e $1470 \mathrm{~m}^{2}$ para cada ensaio, excluidos os espaçamentos que foram de 3 me tros entre parcelas e 4,2 metros entre blocos.

Os tratamentos foram diferenciados pela aplicação de boro, na forma de Bōrax (Tetraborato de södio), via solo (no plantio) e via foliar (dois meses após plantio); com as dosagens e formas de aplicação abaixo:

1. Testemunha

2. $10 \mathrm{~kg}$ de Börax por hectare, via foliar

3. $20 \mathrm{~kg}$ de Bórax por hectare, via foliar

4. $40 \mathrm{~kg}$ de Bórax por hectare, via foliar

$5.20 \mathrm{~kg}$ de Börax por hectare, via solo

6. $40 \mathrm{~kg}$ de Bórax por hectare, via solo

7. $80 \mathrm{~kg}$ de Bórax por hectare, via solo 


\subsection{Cultura}

No presente trabalho, o material vegetal, cons:tou de colmos e folhas (bainhas e limbos), de cana-planta das variedades IAC 48-65 e IAC 50-14.

A primeira apresenta como caracteristicas, alto teor de sacarose, baixo teor de fibra, bom crescimento e perfilhamento, aqui denominada VI; a segunda com baixo teor de sacarose, a1to teor de fibra e vegetação vigorosa, denominada V2, o que em condições normais de cultivo,são consideradas respectivamente, como rica e pobre em sacarose. Os colmos utilizados no plantio, foram fitossanitariamente tratados pelos métodos usuais, antes do plantio, que ocorreu em setembro.

o plantio foi efetuado em solo utilizado para cultivo convencional, convenientemente preparado, em sulcos de aproximadamente $30 \mathrm{~cm}$ de profundidade, utilizando-se 15 toletes de cana, com 3 gemas por tolete, dando um total de 45 gemas em 5 metros 1 ineares ou 9 gemas por metro, acompanha do de heptacloro, pára combate à pragas.

A adubação básica foi diferenciada por tipo de solo, tendo todas as parcelas recebido a mesma, aplicada. normal e individualmente nas laterais dos sulcos, abertos pa ra o plantio e que baseada na análise de solos, constou de: 
Latossolo Roxo:

1. Superfosfato simples - $280 \mathrm{~g}$ por linha, correspondendo' a $80 \mathrm{~kg}$ de $\mathrm{P}_{2}{ }^{0}{ }_{5} / \mathrm{ha}$,

2. Cloreto de potássio - 50 g por linha, correspondendo a $43 \mathrm{~kg}$ de $\mathrm{K}_{2} \mathrm{O} / \mathrm{ha}$,

3. Sulfato de amoneo - $210 \mathrm{~g}$ por linha, em cobertura, correspondendo a $60 \mathrm{~kg}$ de $\mathrm{N} / \mathrm{ha}$; como recomendado por ESPIRONELO e OLIVEIRA (1972).

Latossolo Vermelho Amarelo - fase arenosa:

1. Calcario - $220 \mathrm{~kg}$ no ensaio, correspondente a $1500 \mathrm{~kg} / \mathrm{ha}$, 2. Sulfato de Amoneo - $140 \mathrm{~g}$ por Iinha, correspondendo a 40 : $\mathrm{kg}$ de $\mathrm{N} / \mathrm{ha}$ no plantio è $210 \mathrm{~g}$ por linha, correspondendo $60 \mathrm{~kg}$ de $\mathrm{N} / \mathrm{ha}$ em cobertura,

3. Superfosfato simples - $490 \mathrm{~g}$ por linha, correspondendo' a $140 \mathrm{~kg}$ de $\mathrm{P}_{2}{ }_{5} / \mathrm{ha}$,

4. Cloreto de potássio - $70 \mathrm{~g}$ por linha, correspondendo a $60 \mathrm{~kg}$ de $\mathrm{K}_{2} \mathrm{O} / \mathrm{ha}$,

5. DAP - $210 \mathrm{~g}$ por linha, correspondendo a $54 \mathrm{~kg}$ de $\mathrm{N} / \mathrm{ha}$ e $138 \mathrm{~kg}$ de $\mathrm{P}_{2} \mathrm{O}_{5} / \mathrm{ha}$.

o campo experimental foi mantido isento de ervas daninhas, as quais poderiam competir com a cultura, com aplicação de herbicidas, utilizando-se pulverizador motorizado e bico 80-02, com diferentes dosagens, em função do tipo de solo, das misturas abaixo: 
Latossolo Roxo:

1. Fórmula $40(2,4-\mathrm{D}) 662 \mathrm{ml}$, correspondendo a $4,5 \mathrm{l} / \mathrm{ha}$,

2. Karmex (Diuron) $441 \mathrm{~g}$, correspondendo a $3,0 \mathrm{~kg} / \mathrm{ha}$. Latossolo Verme1ho Amare1o - fase arenosa.

1. Fórmula $40(2,4-\mathrm{D}) 515 \mathrm{ml}$, correspondendo a $3,51 / \mathrm{ha}$,

2. Karmex (Diuron) $368 \mathrm{~g}$, correspondendo a $2,5 \mathrm{~kg} / \mathrm{ha}$.

0 boro foi aplicado como Bórax, com $99,5 \%$ de Tetraborato de sódio', contendo $11 \%$ do elemento, da seguinte ' maneira:

A. Via Solo

o tratamento no solo, foi feito juntamente com a adubação basica, aplicando-se $14 \mathrm{~g}$ por linha ou $140 \mathrm{~g}$ por parcela, o que corresponde a $20 \mathrm{~kg} / \mathrm{ha} ; 28 \mathrm{~g}$ por 1 inha ou $280 \mathrm{~g}$ por parcela, correspondendo a $40 \mathrm{~kg} / \mathrm{ha}$; e $56 \mathrm{~g}$ por linha ou $560 \mathrm{~g}$ por parcela, para o tratamento $80 \mathrm{~kg} / \mathrm{ha}$.

B. Via Foliar

Com pulverizações efetuadas dois meses após o plantio, foram aplicadas $7 \mathrm{~g}$ por linha ou $70 \mathrm{~g}$ por parcela pa ra o tratamento $10 \mathrm{~kg} / \mathrm{ha} ; 14 \mathrm{~g}$ por linha ou $140 \mathrm{~g}$ por parcela no tratamento $20 \mathrm{~kg} / \mathrm{ha}$ e $28 \mathrm{~g}$ por linha ou $280 \mathrm{~g}$ por parcela para o tratamento $40 \mathrm{~kg} / \mathrm{ha}$.

A aplicação da solução, de modo a que cada plan ta fôsse fornecida a mesma quantidade, numa distribuição o mais uniforme possive1, feita com um dispositivo de pulverização de xazão constante, constituido de uma câmara para solução com saida para uma barra com bicos tipo X 4 . A pressão 
era controlada por um manômetro na saida da barra, e estabele cida por um recipiente com $\mathrm{CO}_{2}$ comprimido, que tinha sua vazão também controlada por um manômetro, de modo que a pressão interna na câmara permanecesse constante. Assim,em determina do intervalo de tempo, a mesma quantidade de produto era apli cada, e o controle era feito pelo tempo que o operador utilizava na aplicação, igual para todas as linhas (CHRISTOFOLETI, 1972).

\subsection{Variäveis estudadas}

Do material coletado, foram feitas análíses visando determinar a variação do teor de boro em folhas (1imbo': e bainha) e colmos, em duas épocas. Foi determinado também a variação do teor de açúcares redutores e sacarose no mesmo material, mas em sete meses, visando estebelecer a flutuação destes açúcares no decorrer da curva anual de maturação.

\subsection{Coleta das amostras}

As amostras de folhas e colmos de cana-deraçứcar foram coletados, em cada tipo de solo, a intervalos de trinta dias, durante os sete meses, com intervalo de 15 dias entre um solo e outro. Portanto foram feitas coletas nos meses relatados adiante, com as respectivas idades e denominaçōes, 
(Epocas) como serão tratados no desenvolvimento do trabalho.

\begin{tabular}{lcl}
\hline \multicolumn{1}{c}{ MES } & IDADE & COLETA \\
\hline Abril & 7 & Primeira \\
Maio & 8 & Segunda \\
Junho & 9 & Terceira \\
Julho & 10 & Quarta \\
Agosto & 11 & Quinta \\
Setembro & 12 & Sexta \\
Outubro & 13 & Sétima \\
\hline
\end{tabular}

Cada amostra constou de dez colmos de cana por sub-parcela, obtidos através da retirada de dois colmos por linha de cana, com o cuidado de não se coletarem colmos com maior espaçamento que os demais, a fim de não se verificar interferências de competição, quer em relação a nutrientes, quer em relação a luz. Os colmos tiveram sua base cortada o mais próximo do solo, sendo o desponte feito normalmente, despre ' zando-se o palmito, seguindo-se ó comportamento utilizado em cultivos convencionais.

$\mathrm{Na}$ coleta de amostras de folhas para obtenção' do teor de boro, foi utilizado o sistema de amostragem de foThas de Kuijper, citado por van DILLEWIJN (1960), e utilizado' por GALLO et alii (1968), em que se usa as folhas de posição +3. As épocas de coletas de amostras foi a preconizada por 
CLEMENTS et alii (1941), que tambëm coincide com a utilizada' por GALLO et alii (1968), sendo a primeira amostra retirada ' aos 6 meses e a segunda no final do ciclo, com 13 meses.

Os dados do teor de sacarose e açūcares redutores foram coletados mensalmente (abril à outubro), com o intui to de se obter uma curva de maturação. As amostras, depois de coletadas, eram transportadas para laboratório, sob condições' de controle térmico, entre 0 e $5{ }^{\circ} \mathrm{C}$, a fim de diminuira ativida de metabolica, para que pudessem ser preservadas as concentra ções de açúcar originais. No laboratōrio,o material foi se parado (limbos, bainhas e colmos) e rapidamente desidratado' em estufa de circulação forçada de ar, em torno de $70^{\circ} \mathrm{C}$.

Após a secagem, todo o material foi moido,homogeneizado e dai retiradas amostras para anālise.

\subsection{Métodos estatisticos}

Para interpretação dos parâmetros determinados, foi utilizado o esquema de análise de variância abaixo, bem como o Teste de Tukey para comparação das médias, segundo PIMENTEL GOMES (1976). 


\begin{tabular}{lc}
\hline Causas da Variação & GL \\
\hline Blocos & 2 \\
Tratamentos (T) & 6 \\
Residuo A & 12 \\
\hline Parcelas & 20 \\
\hline Variedades (V) & 1 \\
Interação T x V & 6 \\
Resíduo B & 14 \\
\hline Sub-Parcelas & 61 \\
\hline Coletas (C) & 36 \\
Interação T x C & 36 \\
Interação V x C & 168 \\
Interação V x T x C & 293 \\
Residuo C & \\
\hline Total & \\
\hline
\end{tabular}

3.7. Métodos analíticos

As ... anälises realizadas neste experimento, envol veram técnicas já conhecidas e estabelecidas para determina ção de boro, que consistiu no método colorimetrico da Curcumina, segundo DIBLE et alii (1954), a partir de material cal cinado a seco, em mufla a $550^{\circ} \mathrm{C}$ durante $2-4$ horas. A este material, adiciona-se ácido clorídrico e posterior seca- 
gem a $55 \pm 3^{\circ} \mathrm{C}$, em banho-maria, coṃ solução de curcumina, ácí do oxalico, e ao resíduo junta-se álcool etílico e faz-se le tura a 540 nanometros.

o teor de sacarose de colmos foi determinado pe 10 método de LOPEZ HERNANDES (1961).

No entanto a determinaçāo de sacarose e açúca: : res redutores de bainhas e limbos torna-se mais dificil, para um grande nưmero de determinações, jā que métodos cromatogrâa ficos são trabalhosos e demorados e os métodos volumétricos. não se prestam, pois o material de análise não é zona de acumulo e portanto apresenta pequena concentração o que não é sạ tisfatorio para a sensibilidade dos métodos.

Em vista das dificuldades, foi procurado um método que apresentasse a vantagem de rapidez e sensibilidade,e se possível com a formação de composto estāvel e colorido que permitisse a leitura por espectrofotómetro. Foi então utilir zado o método de SOMOGYI (1937), modificada por NELSON (1944) para determinação de açúcares redutores em sangue, e adaptado para extratos vegetais. 
4. RESULTADOS E DISCUSSÃO

Baseado nos resultados analíticos e nas anālises de variância, pode-se fazer as seguintes observações a tí tulo de discussão, sobre o efeito do boro nas duas variedades' de cana, e nos dois tipos de solos.

Em vista das adaptações introduzidas no método; utilizado para a determinação de açúcares, decidiu-se apresen tar nesta discussão as modificaçōes executadas.

4.1. Adaptação do método

A. Princípios do método

Açūcares redutores, como a glicose, reduzem wo reagente cupro-alcalino, produzindo óxido cuproso, que em pre sença de reativo arsenomolibdico de Nelson, forma um complexo de óxido de molibdênio, de cor azul e estável, passivel de ser 
medido em espectrofotômetro. Este mëtodo, como a maioria dos métodos para determinação de açūcares, baseia-se na capacidade redutora dos açūcares, o que faz necessária uma previa hidrólị se, quando pretendemos analisar açūcares não redutores, como a sacarose.

B. Extração

Apesar da maioria dos mëtodos usarem,para extração ùma mistura de água e álcool, usualmente álcool $70 \%$ ou $80 \%$, foi testado a extração com āgua, pois os açúcares são altamente solúveis, e dispensam extratores mais fortes. Usou -se um esquema de extração proposto por LINSKENS (1974) que consiste em:

0 material depois de coletado e transportado em recipientes térmicos, era transferido para freezer a $-18^{\circ} \mathrm{C}$ on de ficava por alguns dias. Durante este tempo ocorria rompimento celular, por congelamento e expansão do suco celular. De pois o material era colocado, em pequenas porções, em estufa de circulação forçada a $70-80^{\circ} \mathrm{C}$,visando uma rápida secagem e perdas mínimas, evitando também a caramelização, que ocorria' acima desta temperatura, como sugerido por BURR (1974). Uma grama deste material era homogeneizado, a $16.000 \mathrm{rpm}$ por $3 \mathrm{mi}-$ nutos em $30 \mathrm{ml}$ de solução tampão de acetato de sódio de $\mathrm{pH}$ 4,7 para extração. 
Feito um teste de confronto entre extração aquo sa em soluçāo tampāo de acetato de sódio e extração alcoolica (extração com álcool $80 \%$, evaporação e posterior diluição em solução tampão) verificou-se que os resultados são semelhan ' tes, como mostram os resultados médios abaixo, provenientes de 100 leituras.

TESTE - Entre extração aquosa e alcoolica.

\begin{tabular}{lll}
\hline & Extrato & Absorbância a $535 \mathrm{~nm}$ \\
\hline Sem Hidrólise & aquoso & 0,075 \\
& alcoólico & 0,050 \\
\hline \multirow{2}{*}{ Com Hidrólise } & aquoso & 0,230 \\
& alcoólico & 0,210 \\
\hline
\end{tabular}

Em vista destes resultados, decidiu-se pela uti lização da extração aquosa, jā que este procedimento apresenta uma vantagem significativa, pois poucos pigmentos e subs ' tancias orgânicas são extraidos,o que facilita o trabalho,em virtude de uma só clarificação deixar ó extrato pronto para leitura,o que não ocorre com o extrato alcoolico, que : requer precipitações, evaporação do álcool e diluições em āgua ou então sistemas de separação por resinas ou com tetracloreto' de carbono. 
Em relação ao volume de solução e quantidade de material vegetal, foram testadas várias alternativas, na procura da relação que apresentasse leitura dentro da melhor fai xa de resolução. A melhor proporção foi com $1 \mathrm{~g}$ de folhas em $30 \mathrm{ml}$ de solução tampão e $1 \mathrm{~g}$ de bainha em $60 \mathrm{ml}$ de solução ' tampão. No entanto, para facilidade e padronização de trabalho na extração, optamos por 1 grama de limbo e $0,5 \mathrm{~g}$ de bainha em $30 \mathrm{ml}$ de solução tampão.

0 tempo necessário para extração no homogeinizą dor, foi testado entre 2,5 e 5 minutos. Verificou-se que com 2,5 minutos $\mathfrak{j a}$ ocorria o máximo de retirada de açúcares, pois separando-se a fase líquida, e aplicando nova extração ao re síduo sólido, em igual volume, não se recuperou quantidades' significativas de açücares. Em vista disto, e levando em consideracão os resultados médios de 100 amostras entre extra çāo por 2,5 e 5 minutos, visto no quadro abaixo, optou-se por uma extração durante 3 minutos, por facilidade de padronização.

TESTE - Para tempo de extração

\begin{tabular}{ccc}
\hline Açúcares & Tempo,minutos & Absorbância a $535 \mathrm{~nm}$ \\
\hline \multirow{2}{*}{ Sem Hidrölise } & 2,5 & 0,076 \\
& 5,0 & 0,070 \\
\hline \multirow{2}{*}{ Com Hidrólise } & 2,5 & 0,215 \\
& 5,0 & 0,240 \\
\hline
\end{tabular}


.C. Inversão da sacarose

Como o método éscolhido, só determina o teor de açúcares redutores, mas como tambēm desejava-se dosar sacarose, procedeu-se a inversāo.

Inicialmente tentou-se trabalhar com hidrólise em meio ácido, mas por surgirem muitos problemas, passou-se a testar a hidrólise enzimätica, atravês de uma enzima específi: ca, a Beta-Fructofuranosidase ou Invertase. Esta enzima, específica para sacarose, tem características de apresentar sem pre a mesma velocidade de reação, nas seguintes condições:

1. Temperatura de $37^{\circ} \mathrm{C}$, a qual foi conseguida com a utiliza : ção de uma estufa histológica;

2. $\mathrm{pH} 4,7$, conseguido com a utilização de solução tampão de acetato de södio, onde era feita a extração e

3. Tempo de reação de vinte minutos.

Faltava então determinar a quantidade de enzima a ser adicionada ao extrato, e para tanto procedeu-se a alguns testes, cujas médias dos resultados são mostrados a se guir.

Partindo-se de uma solução mãe de enzima, contendo $0,1 \mathrm{~g}$ de Invertase em $100 \mathrm{~m} 1$ de solução tampão de aceta to de sódio, aplicada em várias quantidades a tubos de ensaio contendo quantidades variáveis de soluções de sacarose, gliço se e frutose, utilizando-se o método de NELSON (1944). Ver $\underline{i}$ ficou-se no final, que $0,2 \mathrm{ml}$ da soluçāo "mãe" de Inverta 
se era suficiente para provocar completamente a hidrólise de altas concentrações de sacarose, como se pode ver nos testes abaixo com medidas provenientes de 100 amostras. Como medida prätica para a rotina, diluiu-se a solução mãe da enzima para uma solução de $0,2 \mathrm{~g} / 1.000 \mathrm{ml}$; usando-se assim $1 \mathrm{ml}$ da nova solução para a inversão.

TESTES - De inversão de sacarose

19 TESTE - Sacarose $(50 \mu \mathrm{g} / \mathrm{ml})$ e Enzima $(0,1 \mathrm{~g} / 100 \mathrm{~m} 1)$

\begin{tabular}{cccc}
\hline $\begin{array}{c}\text { Sacarose } \\
\mathrm{m} 1\end{array}$ & $\begin{array}{c}\text { Enzima } \\
\mathrm{m} 1\end{array}$ & $\begin{array}{c}\text { Tampão } \\
\mathrm{m} 1\end{array}$ & Absorbância \\
\hline 1 & 0,1 & 0,9 & 0,221 \\
1 & 0,2 & 0,8 & 0,229 \\
1 & 0,4 & 0,6 & 0,220 \\
1 & 0,6 & 0,4 & 0,229 \\
1 & 0,8 & 0,2 & 0,221 \\
1 & 1,0 & 0,0 & 0,220 \\
\hline
\end{tabular}

2० TESTE - Sacarose $(80 \mu \mathrm{g} / \mathrm{m} 1)$ e Enzima $(0,1 \mathrm{~g} / 100 \mathrm{ml})$

\begin{tabular}{cccc}
\hline $\begin{array}{c}\text { Sacarose } \\
\mathrm{m} 1\end{array}$ & $\begin{array}{c}\text { Enzima } \\
\mathrm{m} 1\end{array}$ & $\begin{array}{c}\text { Tampão } \\
\mathrm{m} 1\end{array}$ & Absorbância \\
\hline 1 & 0,1 & 0,9 & 0,370 \\
1 & 0,2 & 0,8 & 0,390 \\
1 & 0,4 & 0,6 & 0,380 \\
1 & 0,6 & 0,4 & 0,385 \\
1 & 0,0 & 1,0 & 0,000 \\
0 & 0,0 & 2,0 & 0,000 \\
\hline
\end{tabular}


$3^{\circ}$ TESTE - Sacarose $(100 \mu \mathrm{g} / \mathrm{ml})$, Giicose $(50 \mu \mathrm{g} / \mathrm{m} 1)$, Frutose : $(100 \mu \mathrm{g} / \mathrm{ml})$ e Enzima $(0,1 \mathrm{~g} / 100 \mathrm{ml})$

\begin{tabular}{cccccc}
\hline $\begin{array}{c}\text { Sacarose } \\
\mathrm{m} I\end{array}$ & $\begin{array}{c}\text { GIicose } \\
\mathrm{mI}\end{array}$ & $\begin{array}{c}\text { Frutose } \\
\mathrm{ml}\end{array}$ & $\begin{array}{c}\text { Enzima } \\
\mathrm{ml}\end{array}$ & $\begin{array}{c}\text { Tampão } \\
\mathrm{mI}\end{array}$ & $\begin{array}{c}\text { Absor- } \\
\text { bãncia }\end{array}$ \\
\hline 0,25 & 0,50 & 0,25 & 0,20 & 0,80 & 0,395 \\
0,25 & 0,50 & 0,25 & 0,20 & 0,80 & 0,395 \\
0,25 & 0,50 & 0,25 & 0,00 & 1,00 & 0,250 \\
0,25 & 0,50 & 0,25 & 0,00 & 1,00 & 0,251 \\
$0,00 !$ & 0,00 & 0,50 & 0,00 & 1,50 & 0,270 \\
0,00 & 0,00 & 0,50 & 0,00 & 1,50 & 0,260 \\
0,50 & 0,00 & 0,25 & 0,20 & 1,05 & 0,360 \\
0,00 & 0,00 & 0,00 & 0,00 & 2,00 & 0,000 \\
\hline
\end{tabular}

Vale ressaltar, a importância de uma perfeita' inversão da sacarose, pois o teor dêste açúcar nos limbos e bainhas serā dado pela diferença entre o material que sofre a inversāo e aquele que não sofre, o'que significa ser a sacarose determinada pela diferença de leitura de açúcares reduto ' res totais, antes e depois do tratamento com invertase.

D. Interferentes

o método utilizado, prevé em sua marcha analítica,uma clarificação ou desproteinização do extrato, antes do trate mento com o reativo de Somogyi (Sulfato de Cobre em solução alcalina de Tartarato duplo de Sódio e Potássio), tornando-se necessário a remoção de proteinas e outras substâncias, antes de submetermos a extrato à ação dos reativos para determina ' çāo de açúcares. 
Esta necessidade foi ${ }^{\prime}$ sentida, pois verificou-se que as leituras obtidas variavam intensamente, poucas horas ' depois da extração, para mais ou para menos, mesmo que o ex trato ficasse acondicionado em refrigerador em temperatura de $0-2^{\circ} \mathrm{C}$. Após algumas análises, notou-se que o extrato, apesar de aquoso, ainda continha alguns pigmentos e outras substân ' cias, que provocavam interferências, visto que também possuiam proprịiedades, ou mesmo grupos redutores, sendo então determinados por mëtodos redutores ou precipitando-se com os reativos cupro-alcalinos. Passou-se imediatamente então após a extração, a executar a primeira fase do mëtodo, ou seja, a clarificação do extrato, e então, se necessário, guardado' para anālises posteriores, visto estar agora isento de outras substâncias,as quais poderiam comprometer as leituras.

A clarificação foi feita, usando-se como precipitante o hidróxido de zinco, obtido por dupla troca entre sulfato de zinco e hidróxido de bário; o bārio possui tambèm' a propriedade de formar sais com os esteres fosfóricos, precí pitando-os. O extrato então livre de interferentes è guardado, para posterior anālise, ou análisado imediatamente. Foram feitos testes, onde se procurou verificar as alterações ' no extrato guardado após a clarificação; vārios dias após a extração, fazendo uma comparação com extrato não clarificado, verificou-se que o extrato clarificado não variava, enquanto' que o não clarificado apresentou variações de leitura com o passar do tempo, como mostra o quadro seguinte o que nos levou 
a proceder a clarificação logo após a extração.

TESTE - de Interferentes - Leituras em Absorbância

\begin{tabular}{cccccc}
\hline Tempo após ex & \multicolumn{2}{c}{ CLARIFICADO } & \multicolumn{2}{c}{ NAO CLARIFICADO } \\
tração(horas) & S/Hidrölise & Hidrolizado & S/Hidrólise & Hidrolizado \\
\hline \multirow{2}{*}{0,0} & 1 & 24,8 & 36,0 & 24,0 & 35,4 \\
& 2 & 31,0 & 39,5 & 30,9 & 38,5 \\
& 3 & 28,2 & 39,0 & 28,0 & 39,6 \\
\hline \multirow{2}{*}{24} & 1 & 24,8 & 36,0 & 27,9 & 33,8 \\
& 2 & 31,0 & 39,0 & 30,1 & 39,5 \\
& 3 & 28,2 & 39,0 & 29,6 & 38,0 \\
\hline \multirow{3}{*}{48} & 1 & 24,0 & 35,0 & 32,0 & 42,1 \\
& 2 & 31,0 & 39,5 & 40,0 & 42,1 \\
& 3 & 27,9 & 39,0 & 31,0 & 44,5 \\
\hline \multirow{2}{*}{96} & 1 & 25,0 & 35,0 & 35,5 & 40,0 \\
& 2 & 32,0 & 39,5 & 35,9 & 45,0 \\
\hline
\end{tabular}

E. Estudo da curva padrão e do melhor comprimento de onda

A bibliografia é discordante quanto ao compri. ' mento de onda a ser usado na leitura do método aqui utilizą do, e este ' problema foi tambēm observado na forma de testes' preliminares.

Vários autores, ao se utilizarem do método, fizeram leituras em $535 \mathrm{~nm}, 540 \mathrm{~nm}, 530 \mathrm{~nm}$ e mesmo NELSON (1944) 
no trabalho original, fez suas anáiises em $500 \mathrm{~nm}$; mas $j \bar{a}$ dìzia que outros comprimentos de onda poderiam ser usados. No entanto, o autor escolheu o comprimento de onda de $500 \mathrm{~nm}$, por que apresentava uma boa relação entre a sensibilidade desejada e a vantagem em reduzir o efeito da variação, tais como o branco devido a reagentes, reoxidação de óxido cūprico outros.

Nos testes realizados, verifica-se que no com ' primento de onda de $500 \mathrm{~nm}$, temos uma mëdia das diferenças.' igua1 a 7,2 , tendo 5 pontos abaixo e 7 acima da média. A $510 \mathrm{~nm}$, a média das diferenças é igual a 8,0 , existindo exata mente a metade dos valores abaixo e metade acima da média... A $520 \mathrm{~nm}$, a média é igual a 8,7, existindo 4 valores abaixo é 7 acima da média; $535 \mathrm{~nm}$, temos uma média das diferenras igua1' a 10,3 sendo 4 pontos abaixo e 5 acima da média. Em $535 \mathrm{~nm}$, apenas 10 pontos caem dentro da faixa de resolução do mêtodo, onde podemos determinar concentraçōes de até $225 \mu \mathrm{g}$ de açúcar. A $660 \mathrm{~nm}$, apenas 4 pontos são determinados, e a concentração' māxima seria perto de $75 \mu \mathrm{g}$ de açücar.

Então, restava a escolha do melhor comprimento' de onda, bem como executar o traçado da curva padrão, dentro' desse comprimento de onda. Assim, escolheu-se a leitura em comprimento de onda de $510 \mathrm{~nm}$, onde se verificaram as mais. constantes mẻdias das diferenças e onde, dos $1 \overline{3}$ pontos da cur va, metade dos valores ficaram abaixo e metade acima da diferença média dos valores da leitura; a $510 \mathrm{~nm}$ também foi obtida a melhor regressão, com $\underline{r}$ igual a 0,9989 . 
TESTE - do Comprimento de onda

\begin{tabular}{crrrrr}
\hline $\begin{array}{c}\text { Conc. Glicose } \\
\mu \mathrm{g}\end{array}$ & \multicolumn{5}{c}{ LEITURA EM ABSORBANCIA } \\
\hline 0,0 & 0,0 & 0,0 & 0,0 & 0,0 & 0,0 \\
25,0 & 4,5 & 5,0 & 5,5 & 6,2 & 16,0 \\
50,0 & 12,5 & 13,7 & 15,3 & 18,0 & 48,0 \\
75,0 & 19,9 & 21,8 & 25,0 & 29,0 & 76,8 \\
100,0 & 28,9 & 31,6 & 35,5 & 41,6 & 100,0 \\
125,0 & 37,0 & 41,2 & 45,8 & 53,8 & 100,0 \\
150,0 & 43,3 & 48,5 & 54,1 & 65,3 & 100,0 \\
175,0 & 52,5 & 58,4 & 64,8 & 76,0 & 100,0 \\
200,0 & 59,6 & 66,0 & 73,5 & 85,0 & 100,0 \\
225,0 & 64,3 & 72,0 & 80,0 & 93,0 & 100,0 \\
250,0 & 71,5 & 79,5 & 88,0 & 100,0 & 100,0 \\
275,0 & 77,8 & 87,0 & 96,0 & 100,0 & 100,0 \\
300,0 & 86,5 & 96,0 & 100,0 & 100,0 & 100,0 \\
\hline
\end{tabular}

TESTE - de Regressão

\begin{tabular}{ccccc}
\hline $\begin{array}{c}\text { Comprimento de } \\
\text { Onda }\end{array}$ & $\hat{\mathrm{n}}$ & $\hat{\mathrm{m}}$ & $\hat{\mathrm{r}}$ & $\begin{array}{c}\mu \mathrm{g} / \text { Aç.Redutores } \\
\text { (Fórmu1a) }\end{array}$ \\
\hline 500 & 3,5918 & 3,4051 & 0,9988 & $3,4051 \times \mathrm{A}+3,5918$ \\
510 & 4,0170 & 3,0565 & 0,9989 & $3,0565 \times \mathrm{A}+4,0170$ \\
520 & 3,6614 & 2,7525 & 0,9985 & $2,7525 \times \mathrm{A}+3,6614$ \\
535 & 5,6710 & 2,2920 & 0,9985 & $2,2920 \times \mathrm{A}+5,6710$ \\
\hline
\end{tabular}


4.2. Boro

Os resultados dos teores de boro em ppm nos col mos, encontram-se na tabela 01 , para canas cultivadas em so1o LVa.

Neste solo, a análise estatística não apresenta significância em relação a tratamentos, variedades ou coletas. A distribuição dos resultados verificada na tabela, mostra não haver constância nos teores de boro, para nenhuma das va riedades, refletindo no estudo um menor teor de boro na coleta final, com exceção para os tratamentos testemunha e $80 \mathrm{~kg} / \mathrm{ha}$ via solo para a variedade IAC $48-65$ e os tratamentos testemunha, $10 \mathrm{~kg} / \mathrm{ha}$ via foliar e $40 \mathrm{~kg} / \mathrm{ha}$ via foliar para a varieda de IAC 50-14, que são os de menor quantidade de boro aplicado. Observando-se as interações, verifica-se que, também não ocorreram significâncias, não havendo interaçôes entre tratamentos, variedades e coletas. No entanto, no desdo bramento das causas de variação, são assinaladas diferenças' significativas nas coletas dentro dos tratamentos, detacando-se o aumento do teor de boro da la. para a 2 a. coleta no tra tamento testemunha, e a diminuiçāo do tratamento $40 \mathrm{~kg} / \mathrm{ha}$ via solo, nas duas variedades.

Os resultados para canas cultivadas em LR, encon traram-se na tabela 02 . 
TABELA 01 - Valores de boro em colmos de canas das variedades IAC $48-65$ e IAC 50-14 em LVa (em ppm)

\begin{tabular}{|c|c|c|c|c|c|}
\hline \multicolumn{2}{|l|}{$\begin{array}{l}\text { TRATA- } \\
\text { MLKTOS }\end{array}$} & \multirow{2}{*}{$\frac{\dot{A B R I L}}{3.3}$} & \multirow{2}{*}{$\frac{\text { OUTURRO }}{4.1}$} & \multicolumn{2}{|c|}{ MEDIAS } \\
\hline \multirow[b]{2}{*}{ TEST. } & $V_{1}$ & & & 3,7 & \\
\hline & $y^{\prime \prime 2}$ & 2.8 & 3.9 & 3,3 & 3,5 \\
\hline \multirow[b]{2}{*}{$10 \mathrm{~kg} / \mathrm{F}$} & $v$ & 3,5 & 3.1 & 3,3 & \multirow[b]{2}{*}{3.5} \\
\hline & $v_{2}$ & 3.6 & 3.7 & 3,6 & \\
\hline \multirow{2}{*}{$20 \mathrm{~kg} / \mathrm{F}}$. & vi & 3,9 & 3.8 & 3.8 & \multirow[b]{2}{*}{3,5} \\
\hline & $v_{2}$ & 3.6 & 2.8 & 3.2 & \\
\hline \multirow{2}{*}{$40 \mathrm{~kg} / \mathrm{F}$} & v & 3,0 & 2,8 & 2.9 & \multirow[b]{2}{*}{3.0} \\
\hline & v2 & 3,0 & 3.1 & 3,0 & \\
\hline \multirow{2}{*}{$20 \mathrm{~kg} / \mathrm{s}$} & vu & 3,1 & 2,8 & 2,9 & \multirow{2}{*}{3,1} \\
\hline & $v_{2}$ & 3,3 & 3,1 & 3,2 & \\
\hline \multirow[b]{2}{*}{$40 \mathrm{~kg} / \mathrm{S}$} & $v_{1}$ & 3.8 & 3,0 & 3,4 & \multirow{2}{*}{3,3} \\
\hline & v 2 & 3.8 & 2.4 & 3.1 & \\
\hline \multirow[b]{2}{*}{$B 0 \mathrm{~kg} / \mathrm{S}$} & $v_{1}$ & 3,7 & $4 ., 5$ & 4.1 & \multirow[b]{2}{*}{3,7} \\
\hline & $1{ }^{\prime 2}$ & 3,6 & 3,2 & 3,4 & \\
\hline \multirow{3}{*}{ MEDIAS } & v1 & 3,4 & 3,4 & & \\
\hline & $v_{2}$ & 3,4 & 3,1 & & \\
\hline & $\mathrm{V}_{1} \mathrm{~V}_{2}$ & 3,4 & 3.3 & & \\
\hline
\end{tabular}

\begin{tabular}{|c|c|c|}
\hline Causas da Variaçāo & $\mathrm{GL}$ & $F$ \\
\hline Blocos & 2 & 1.992 \\
\hline Trutamentos & 6 & 1.067 \\
\hline Kesiduo A & 12 & \\
\hline Parcelas & 20 & \\
\hline Variedade & 1 & 0.875 \\
\hline Interaçāo $T \times V$ & 6 & 0,660 \\
\hline Residuo B & 14 & \\
\hline Sub-Parcelas & 41 & \\
\hline Coletas & 1 & 0.380 \\
\hline Interaçāo $I \times C$ & 6 & 1.797 \\
\hline Interaçao $\mathrm{V} \times \mathrm{C}$ & 1 & 0.204 \\
\hline Interação $v \times \quad T \times C$ & 6 & 0,500 \\
\hline Residuo C & 28 & \\
\hline Total & 83 & \\
\hline
\end{tabular}

CV (T) $27,564^{\circ} \quad \mathrm{CV} \quad\left(V^{\prime}\right) 27,349 \% \quad \mathrm{Cl} \quad(\mathrm{C}) 23,6258$ 
.51.

TABELA 01 (Continuação) - Valores de boro em colmos de canas das variedades IAC 48-65 e IAC 50-14 em LVa (em ppm).

\begin{tabular}{|c|c|c|c|c|}
\hline \multicolumn{2}{|c|}{$\begin{array}{c}\text { DESDOBRAMENTOS CAU } \\
\text { SA DA VARIAÇAOO }\end{array}$} & GL & F & \multirow[t]{2}{*}{ DMS } \\
\hline $\mathrm{T}$ dentro $\mathrm{V}$ & 1 & 6 & 1,43 & \\
\hline $\mathrm{T}$ dentro $\mathrm{V}$ & 2 & 6 & 0,31 & \\
\hline $\mathrm{V}$ dentro $\mathrm{T}$ & 1 & 1 & 0,43 & \\
\hline $\mathrm{V}$ dentro $\mathrm{T}$ & 2 & 1 & 0,39 & \\
\hline $\mathrm{V}$ dentro $\mathrm{T}$ & 3 & 1 & 1,49 & \\
\hline $\mathrm{V}$ dentro $\mathrm{T}$ & 4 & 1 & 0,48 & \\
\hline $\mathrm{V}$ dentro $\mathrm{T}$ & 5 & 1 & 0,25 & \\
\hline $\mathrm{V}$ dentro $\mathrm{T}$ & 6 & $I$ & 0,31 & \\
\hline $\mathrm{V}$ dentro $\mathrm{T}$ & 7 & 1 & 1,90 & \\
\hline $\mathrm{T}$ dentro $\mathrm{C}$ & 1 & 6 & 1,08 & \\
\hline $\mathrm{T}$ dentro $\mathrm{C}$ & 7 & 6 & 2,16 & \\
\hline $\mathrm{C}$ dentro $\mathrm{T}$ & 1 & 1 & $4,58 *$ & \\
\hline $\mathrm{C}$ dentro $\mathrm{T}$ & 2 & 1 & 0,84 & \\
\hline $\mathrm{C}$ dentro $\mathrm{T}$ & 3 & 1 & 0,95 & \\
\hline $\mathrm{C}$ dentro $\mathrm{T}$ & 4 & 1 & 0,32 & \\
\hline $\mathrm{C}$ dentro $\mathrm{T}$ & 5 & 1 & 0,25 & 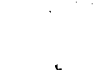 \\
\hline $\mathrm{C}$ dentro $\mathrm{T}$ & 6 & 1 & $5,05^{*}$ & 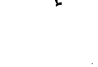 \\
\hline $\mathrm{C}$ dentro $\mathrm{T}$ & 7 & 1 & 0,18 & \\
\hline $\mathrm{V}$ dentro $\mathrm{C}$ & 1 & 1 & 0,19 & \\
\hline $\mathrm{V}$ dentro $\mathrm{C}$ & 7 & 1 & 1,17 & \\
\hline $\mathrm{C}$ dentro $\mathrm{V}$ & 1 & 1 & 0,13 & \\
\hline $\mathrm{C}$ dentro $\mathrm{V}$ & 2 & 1 & 0,57 & \\
\hline
\end{tabular}


Para este solo, as réspostas tiveram tendéncias' diferentes, apresentando-se a coleta final com maior teor, inclusive com significância a $5 \%$, sem no entanto apresentar ' significāncia para tratamentos ou variedades. No entanto, co mo se pode ver na tabela, os comportamentos não foram uniformes, apresentando-se o tratamento $20 \mathrm{~kg} / \mathrm{ha}$ via foliar com um der créscimo na variedade IAC 48-65, diferente dos outros trata ' mentos e os tratamentos $10 \mathrm{~kg} / \mathrm{ha}$ e $40 \mathrm{~kg} / \mathrm{ha}$ via foliar para a variedade IAC 50-14. Vale ainda ressaltar que os incrementos na variedade IAC 48-65 foram maiores que na outra variedade, com exceçāo do tratamento de $40 \mathrm{~kg} / \mathrm{ha}$ via solo, que apresen tou grande incremento no teor final.

Da observaçāo dos resultados para interaçōes, no ta-se que não ocorreram significâncias em qualquer delas. Toda via no desdobramento das causas da variaçāo, verifica-se sig nificância de variedade dentro dos tratamentos $20 \mathrm{~kg} / \mathrm{ha}$ e $80 \mathrm{~kg} / \mathrm{ha}$ com a IAC 48-65 superando a IAC 50-14 na coleta ffinal. Outras significancias ocorreram, tais como: nas coletas, dentro dos tratamentos, quando no tratamento $40 \mathrm{~kg} / \mathrm{ha}$ via solo, a segunda coleta destaca-se da primeira na variedade IAC 50-14 e nas cole tas dentro da variedade IAC 48-65, onde a primeira coleta é menor que a segunda.

Os resultados do teor de boro em ppm nas bainhas, encontram-se na tabela 03, para canas cultivadas em LVa.

A análise estatistica, neste solo apresenta sig nificância para a variável coleta, mas não para as demais va riáveis, seguindo um acúmulo entre a primeira e a segunda coleta. Os tratamentos mostraram comportamentos semelhantes no 
TABELA 02 - Valores de boro em colmos de canas

$$
\begin{aligned}
& \text { das variedades IAC } 48-65 \text { e IAC } \\
& 50-14 \text { em LR(em ppm) : }
\end{aligned}
$$

\begin{tabular}{|c|c|c|}
\hline Causas da Variaçāo & GL & $F$ \\
\hline Blocos & 2 & 1.406 \\
\hline Tratamentos & 6 & 1.100 \\
\hline Resíduo A & 12 & \\
\hline Parcelás & 20 & \\
\hline Variedade & 1 & 0,608 \\
\hline Interaçāo $T \times V$ & 6 & 1.244 \\
\hline Resíduo B & 14 & \\
\hline Sub-Parcelas & 41 & \\
\hline Coletas & 1 & $10.606 *$ \\
\hline Interaçāo $T \times C$ & 6 & 1.258 \\
\hline Interação V x C & 1 & 2,571 \\
\hline Interaçāo $V \times . T \times C$ & 6 & 1.446 \\
\hline Resíduo C & 28 & \\
\hline Total & 83 & \\
\hline
\end{tabular}

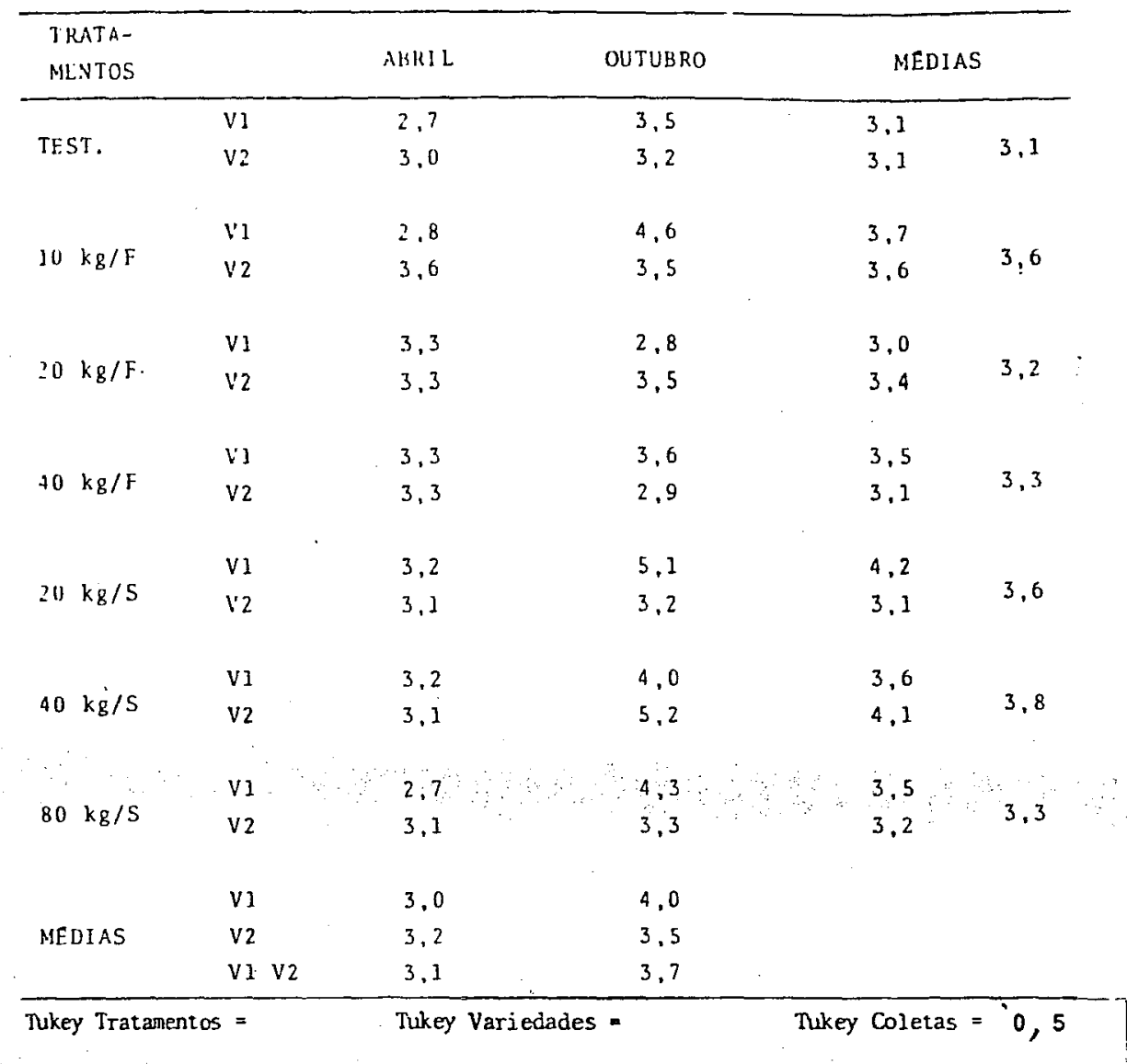


.54 .

TABELA 02 (Continuação) - Valores de boro em colmos de canas das variedades IAC 48-65 e IAC 50-14 em LR (em ppm).

\begin{tabular}{|c|c|c|c|c|}
\hline $\begin{array}{l}\text { DESDOBRAMENTO } \\
\text { SA DA VARIA }\end{array}$ & ${ }_{0}^{\mathrm{CAU}}$ & GL & $\mathrm{F}$ & DMS \\
\hline $\mathrm{T}$ dentro $\mathrm{V}$ & 1 & 6 & 1,30 & \\
\hline $\mathrm{T}$ dentro $\mathrm{V}$ & 2 & 6 & 1,25 & \\
\hline $\mathrm{V}$ dentro $\mathrm{T}$ & 1 & 1 & 0,82 & \\
\hline $\mathrm{V}$ dentro $\mathrm{T}$ & 2 & 1 & 0,80 & \\
\hline$V$ dentro $T$ & 3 & 1 & 0,61 & \\
\hline $\mathrm{V}$ dentro $\mathrm{T}$ & 4 & 1 & 0,55 & \\
\hline $\mathrm{V}$ dentro $\mathrm{T}$ & 5 & 1 & $5,02 *$ & \\
\hline$V$ dentro $T$ & 6 & 1 & 1,29 & \\
\hline $\mathrm{V}$ dentro $\mathrm{T}$ & 7 & 1 & 0,50 & \\
\hline $\mathrm{T}$ dentro $\mathrm{C}$ & 1 & 6 & 0,23 & \\
\hline $\mathrm{T}$ dentro $\mathrm{C}$ & 7 & 6 & 2,11 & \\
\hline $\mathrm{C}$ dentro $\mathrm{T}$ & 1 & 1 & 0,95 & \\
\hline$C$ dentro $\mathrm{T}$ & 2 & 1 & 2,25 & \\
\hline $\mathrm{C}$ dentro $\mathrm{T}$ & 3 & 1 & 0,10 & \\
\hline $\mathrm{C}$ dentro $\mathrm{T}$ & 4 & 1 & 0,10 & \\
\hline $\mathrm{C}$ dentro $\mathrm{T}$ & 5 & 1 & 3,70 & \\
\hline $\mathrm{C}$ dentro $\mathrm{T}$ & 6 & 1 & $8,24^{*}$ & \\
\hline $\mathrm{C}$ dentro $\mathrm{T}$ & 7 & 1 & 2,88 & \\
\hline $\mathrm{V}$ dentro $\mathrm{C}$ & 1 & 1 & 0,39 & \\
\hline $\mathrm{V}$ dentro $\mathrm{C}$ & 7 & 1 & 2,68 & \\
\hline $\mathrm{C}$ dentro $\mathrm{V}$ & 1 & 1 & $11,81^{*}$ & \\
\hline $\mathrm{C}$ dentro $\mathrm{V}$ & 2 & 1 & 1,36 & \\
\hline
\end{tabular}


sentido de acúmulo, para as duas variedades, nas coletas, com exceção do tratamento $40 \mathrm{~kg} / \mathrm{ha}$ via solo, que na variedade IAC 48-65 apresentou um decréscimo da primeira para a segunda coleta. 0 tratamento $80 \mathrm{~kg} / \mathrm{ha}$ via solo, destaca-se por apresen tar a maior concentração na variedade IAC 48-65 na segunda co leta e a menor na variedade IAC 50-14, acompanhando contudo a tendência geral de apresentar maior teor na coleta final.

Apesar de não se observarem significâncias nas interações, verifica-se uma tendência, jâ que no desdobramento das causas de variação,ocorrem diferenças em algumas coletas dentro dos tratamentos, onde nos tratamentos testemunha, $20 \mathrm{~kg} / \mathrm{ha}$ e $40 \mathrm{~kg} / \mathrm{ha}$ via foliar, bem como no $80 \mathrm{~kg} / \mathrm{ha}$ via solo, apresentam a segunda coleta maior que a primeira. Observa-se tambēm variaçōes das coletas nas duas variedades, com a segun da sobrepujando a primeira.

Para canas cultivadas em LR, os resultados são encontrados na tabela 04.

A anālise estatística para este solo apresentou tambêm significância para coleta, com a segunda coleta apre. ' sentando maior teor que na primeira. Neste tipo de solo o comportamento tambèm foi uniforme, com exceção do tratamento' de $20 \mathrm{~kg} / \mathrm{ha}$ via foliar na variedade IAC 50-14, mas com incrementos menores do que no LVa, destacando-se ainda o tratamento testemunha que apresentou, nas duas variedades, teores' bem altos.

As interações analisadas pelo desdobramento' ' das causas de variação, apresentam significâncias para varie- 
TABELA 03 - Valores de boro em bainha de canas das variedades IAC $48-65$ e IAC 50-14 em LVa (em ppm).

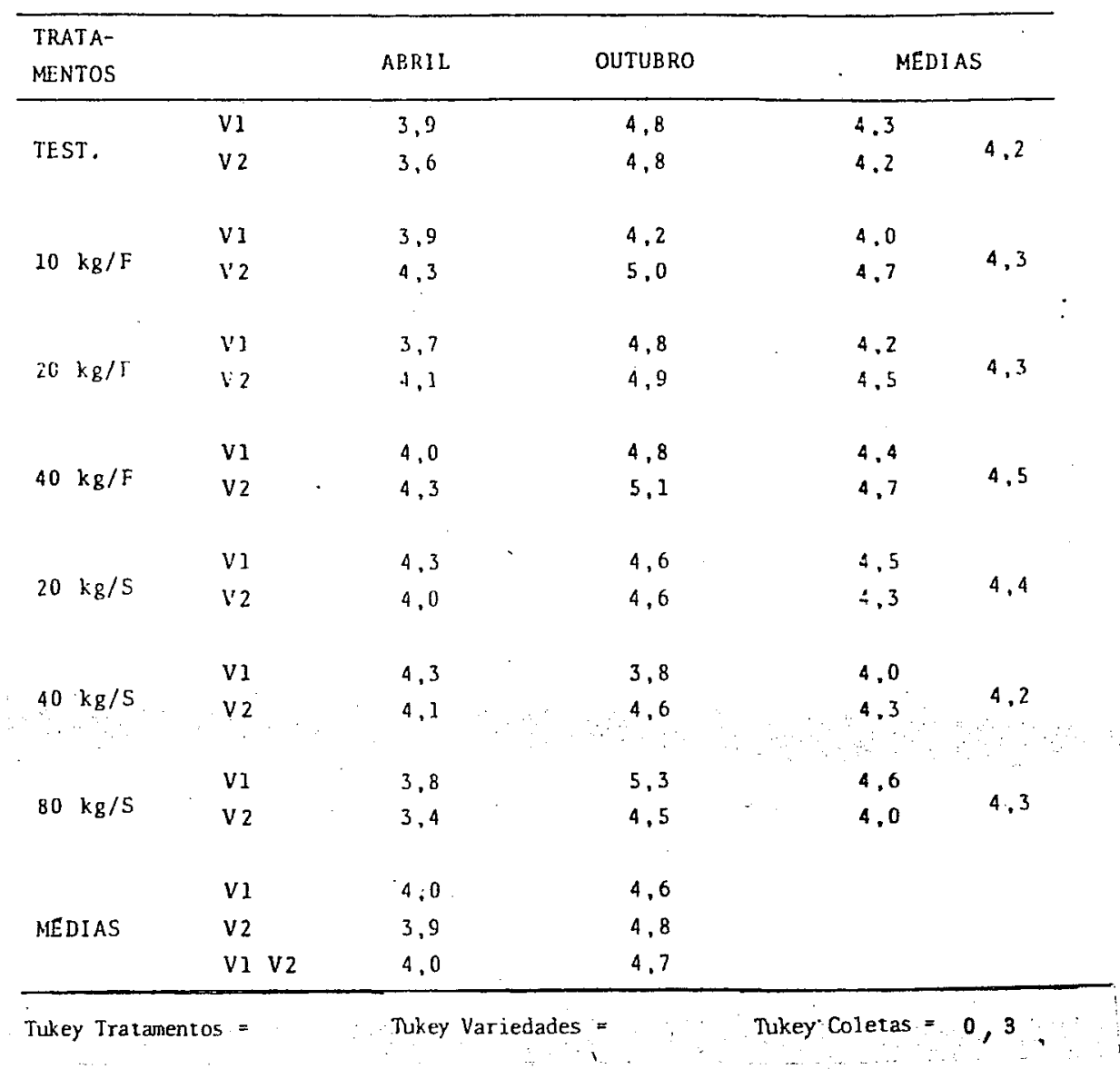

\begin{tabular}{|c|c|c|}
\hline Causas da Variação & GL & $F$ \\
\hline Blocos & 2 & 2.146 \\
\hline Tratamentos & 6 & 0.860 \\
\hline Resíduo A & 12 & \\
\hline Parcelas & 20 & \\
\hline Variedade & 1 & 0.382 \\
\hline Int eraçāo T $\times V$ & 6 & 1.449 \\
\hline Resíduo B & 14 & \\
\hline Sub-Parcelas & 41 & \\
\hline Coleta & 1 & $39,411^{*}$ \\
\hline Interaçāo $T \times C$ & 6 & 1.892 \\
\hline Interaçāo $V \times C$ & 1 & 0.879 \\
\hline Interaçao $\mathrm{V} \times \mathrm{T} \times \mathrm{C}$ & 6 & 0.609 \\
\hline Resíduo $\mathrm{C}$ & 28 & \\
\hline Total & 83 & \\
\hline $\operatorname{CV}(\mathrm{T}) \quad 9,568 \mathrm{CV}(\mathrm{V}) 14,6618$ & $\mathrm{CV}(\mathrm{C})$ & 12.3598 \\
\hline
\end{tabular}


TABELA 03 (Continuação) - Valores de boro em bainha de canas das variedades IAC 48-65 e FAC 50-14 em LVa (em ppm).

\begin{tabular}{|c|c|c|c|c|}
\hline \multicolumn{2}{|c|}{$\begin{array}{c}\text { DESDOBRAMENTOS CAU } \\
\text { SA DA VARIAÇÃO }\end{array}$} & GL & $\mathrm{F}$ & DMS \\
\hline $\mathrm{T}$ dentro $\mathrm{V}$ & 1 & 6 & 0,69 & \\
\hline $\mathrm{T}$ dentro $\mathrm{V}$ & 2 & 6 & 1,11 & \\
\hline $\mathrm{V}$ dentro $\mathrm{T}$ & 1 & 1 & 0,25 & \\
\hline $\mathrm{V}$ dentro $\mathrm{T}$ & 2 & 1 & 3,30 & \\
\hline $\mathrm{V}$ dentro $\mathrm{T}$ & 3 & 1 & 0,59 & \\
\hline $\mathrm{V}$ dentro $\mathrm{T}$ & 4 & 1 & 0,74 & \\
\hline $\mathrm{V}$ dentro $\mathrm{T}$ & 5 & 1 & 0,20 & \\
\hline $\mathrm{V}$ dentro $\mathrm{T}$ & 6 & 1 & 0,82 & \\
\hline $\mathrm{V}$ dentro $\mathrm{T}$ & 7 & 1 & 3,14 & \\
\hline $\mathrm{T}$ dentro $\mathrm{C}$ & 1 & 6 & 1,06 & \\
\hline $\mathrm{T}$ dentro $\mathrm{C}$ & 7 & 6 & 1,34 & \\
\hline $\mathrm{C}$ dentro $\mathrm{T}$ & 1 & 1 & $10,82^{*}$ & \\
\hline $\mathrm{C}$ dentro $\mathrm{T}$. & 2 & 1 & 2,61 & \\
\hline $\mathrm{C}$ dentro $\mathrm{T}$ & 3 & 1 & $10,12^{*}$ & \\
\hline $\mathrm{C}$ dentro $\mathrm{T}$ & 4 & 1 & $6,42^{*}$ & \\
\hline $\mathrm{C}$ dentro $\mathrm{T}$ & 5 & 1 & 2,61 & \\
\hline $\mathrm{C}$ dentro $\mathrm{T}$ & 6 & 1 & 0,11 & \\
\hline $\mathrm{C}$ dentro $\mathrm{T}$ & 7 & 1 & $18,14^{*}$ & \\
\hline $\mathrm{V}$ dentro $\mathrm{C}$ & 1 & 1 & 0,20 & \\
\hline $\mathrm{V}$ dentro $\mathrm{C}$ & 7 & 1 & 1,39 & \\
\hline $\mathrm{C}$ dentro $\mathrm{V}$ & 1 & 1 & $14,25 *$ & \\
\hline $\mathrm{C}$ dentro $\mathrm{V}$ & 2 & 1 & $26,03^{*}$ & \\
\hline
\end{tabular}


TABELA 04 - Valores de boro em bainhas de canas .58 das variedades I IAC 48-65 e IAC 50-14 em LR (em ppm).

\begin{tabular}{|c|c|c|c|c|c|}
\hline \multicolumn{2}{|l|}{$\begin{array}{l}\text { TRITA- } \\
\text { MENTOS }\end{array}$} & \multirow{2}{*}{$\frac{A B R I L}{4.7}$} & \multirow{2}{*}{$\frac{\text { OUTUBRO }}{5,1}$} & \multicolumn{2}{|c|}{ MEDIAS } \\
\hline \multirow{2}{*}{ TEST. } & il & & & 4.9 & \multirow[b]{2}{*}{4.8} \\
\hline & $V_{2}$ & 4.6 & 5,0 & 4,8 & \\
\hline \multirow[b]{2}{*}{$10 \mathrm{~kg} / \mathrm{F}$} & $V_{1}$ & 3.4 & 4.2 & 3,8 & \multirow[b]{2}{*}{3,9} \\
\hline & 12 & 3.7 & 4,5 & 4.1 & \\
\hline \multirow[b]{2}{*}{$20 \mathrm{~kg} / \mathrm{F}$} & VI & 4.0 & 4.2 & 4.1 & \multirow[b]{2}{*}{4,4} \\
\hline & $v_{2}$ & $\cdot 4.7$ & 4.6 & 4.7 & \\
\hline \multirow[b]{2}{*}{$40 \mathrm{~kg} / \mathrm{F}$} & VI & 4.3 & 4.4 & 4,3 & \multirow[b]{2}{*}{4,4} \\
\hline & $v_{2}$ & 4.3 & 4.5 & 4.4 & \\
\hline \multirow{2}{*}{$20 \mathrm{~kg} / \mathrm{s}$} & $V 1$ & 4,4 & 4,9 & 4,7 & \multirow[b]{2}{*}{4,5} \\
\hline & $v_{2}$ & 4,2 & 4,5 & 4,3 & \\
\hline \multirow[b]{2}{*}{$40 \mathrm{~kg} / \mathrm{S}$} & V 1 & 3,4 & 3,9 & 3,7 & \multirow[b]{2}{*}{4,2} \\
\hline & $v_{2}$ & 4,6 & 4,8 & 4,7 & \\
\hline \multirow[b]{2}{*}{$80 \mathrm{~kg} / \mathrm{S}$} & Vl & 3,9 & 5,3 & 4,6 & \multirow[b]{2}{*}{4,4} \\
\hline & $v_{2}$ & 3,5 & 4,8 & 4.2 & \\
\hline \multirow{3}{*}{ MEDI AS } & $V 1$ & 4,0 & 4,6 & & \\
\hline & v2 & 4,2 & 4.7 & & \\
\hline & V2 V2 & 4,1 & 4.6 & & \\
\hline
\end{tabular}

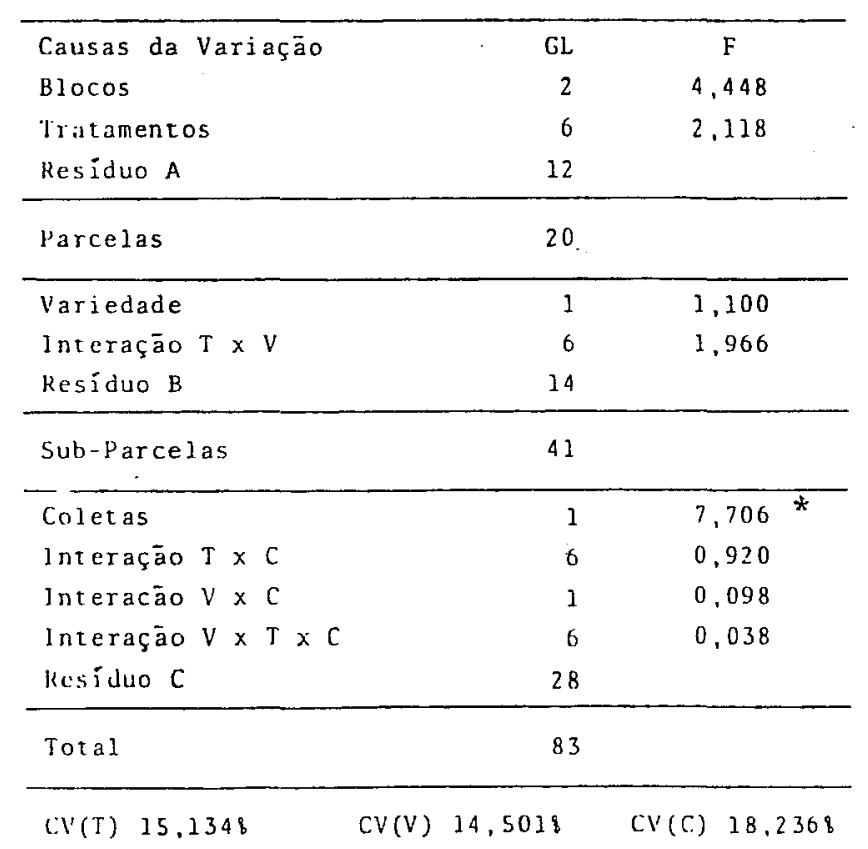


TABELA 04 (Continuação) - Valores de boro em bainhas de canas das variedades IAC 48-65 e IAC 50-14 (em ppm).

\begin{tabular}{lllll}
\hline DESDOBRAMENTOS CAU & GL & F & DMS \\
SA DA VARIAÇAO & & 6 & $3,09^{*}$ & 1,8 \\
\hline T dentro V & 1 & 6 & 1,17 & \\
T dentro V & 2 & 1 & 0,33 \\
V dentro T & 1 & 1 & 0,53 \\
V dentro T & 2 & 1 & 2,25 \\
V dentro T & 3 & 1 & 0,82 \\
V dentro T & 4 & 1 & 0,74 \\
V dentro T & 5 & 1 & $7,70^{*}$ \\
V dentro T & 6 & 1 & 1,62 \\
V dentro T & 7 & 1 & 0,96 \\
T dentro C & 1 & 6 & 0,75 \\
T dentro C & 7 & 6 & 2,77 \\
C dentro T & 1 & 1 & 0,11 \\
C dentro T & 2 & 1 & 0,47 \\
C dentro T & 3 & 1 & 0,69 \\
C dentro T & 4 & 1 & 0,57 \\
C dentro T & 5 & 1 & $8,37^{*}$ \\
C dentro T & 6 & 1 & 0,65 \\
C dentro T & 7 & 1 & 0,13 \\
V dentro C & 1 & 1 & $4,77^{*}$ \\
V dentro C & 7 & 1 & \\
C dentro V & 1 & 1 & \\
C dentro V & 2 & 1 & \\
\hline
\end{tabular}


dades dentro de tratamentos, quando se verifica no tratamento $40 \mathrm{~kg} / \mathrm{ha}$ via solo que a variedade IAC 50-14 é maior que a IAC 48-65. Tambēm as coletas variam dentro do tratamento 80 $\mathrm{kg} / \mathrm{ha}$ via solo, quando a segunda coleta foi sensivelmente' maior que a primeira. Por outro lado, também ocorre significância das coletas dentro da variedade IAC 48-65, com a segun da coleta destacando-se da primeira.

Os resultados do teor de boro em ppm nos limbos, encontram-se na tabela 05 para LVa.

Pela anālise de variância, verifica-se que no LVa obteve-se significāncia para a variável coleta, apresen ' tando-se as duas variedades, visto pela tabela com comporta ' mento semelhante em relação a diminuição pronunciada ao teor de boro, da primeira para a segunda coleta; com exceção dos tratamentos' testemunha, $40 \mathrm{~kg} / \mathrm{ha}$ via foliar e $80 \mathrm{~kg} / \mathrm{ha}$ via solo para a va riedade IAC 48-65. Já a variedade IAC 50-14 apresentou os tra tamentos testemunha, $10 \mathrm{~kg} / \mathrm{ha}$ e $40 \mathrm{~kg} / \mathrm{ha}$ via foliar com aumen tos do teor de boro na segunda coleta, em relaçāo à primeira, salientando-se no entanto, que os tratamentos que aumentaram, tiveram menor variação do que os que diminuiram.

Analisando as interações, verifica-se signifi.' cância para tratamentos e variedades; tratamentos e coletas ; bem como tratamentos, coletas e variedades. Pelo desdobramen to das causas de variação, observou-se ocorrência de significân cia de tratamentos dentro da variedade IAC 50-14, com desta ' que para o tratamento $80 \mathrm{~kg} /$ ha via solo como o maior e $10 \mathrm{~kg} /$ ha via foliar como o menor, ficando os demais como intermedia a 
TABELA 05 - Valores de boro em limbos de canas das variedades IAC $48-65$ e IAC 50-14 em LVa (em ppm).

\begin{tabular}{|c|c|c|c|c|c|}
\hline \multirow{3}{*}{$\begin{array}{l}\text { TRATA- } \\
\text { MENTOS }\end{array}$} & \multirow{3}{*}{$\begin{array}{l}v^{\prime} 1 \\
v_{2}\end{array}$} & \multirow{2}{*}{$\frac{\text { AURIL }}{5,7}$} & \multirow{2}{*}{$\frac{\text { OUTUBRO }}{5.9}$} & \multicolumn{2}{|c|}{ MEDIAS } \\
\hline & & & & 5.8 & \\
\hline & & 5,1 & 6.2 & 5.6 & 5.7 \\
\hline \multirow[b]{2}{*}{$10 \mathrm{~kg} / \mathrm{F}$} & v1 & 8,7 & 4,9 & 6.8 & \multirow[b]{2}{*}{5,7} \\
\hline & v2 & 4,1 & 4,9 & 4,5 & \\
\hline \multirow[b]{2}{*}{$20 \mathrm{~kg} / \mathrm{F}}$. & VI & 7,5 & 5,6 & 6.6 & \multirow[b]{2}{*}{6,2} \\
\hline & $v_{2}$ & 6.8 & 5,0 & 5.9 & \\
\hline \multirow[b]{2}{*}{$40 \mathrm{~kg} / \mathrm{F}$} & $v_{1}$ & 5.3 & 6.1 & 5.7 & \multirow[b]{2}{*}{5.6} \\
\hline & $v_{2}$ & 4,7 & 6.2 & 5,4 & \\
\hline \multirow[b]{2}{*}{$20 \mathrm{~kg} / \mathrm{s}$} & $v_{1}$ & 6,2 & 4.5 & 5.4 & \multirow[b]{2}{*}{5.5} \\
\hline & $1 \cdot 2$ & 6.2 & 4,9 & 5,5 & \\
\hline \multirow[b]{2}{*}{$40 \mathrm{~kg} / \mathrm{s}$} & $v_{1}$ & 7,0 & 6.1 & 6.5 & \multirow[b]{2}{*}{5,8} \\
\hline & $v_{2}$ & 5,2 & 5,2 & 5.2 & \\
\hline \multirow[b]{2}{*}{$80 \mathrm{~kg} / \mathrm{S}$} & VI & 5,4 & 5,4 & 5,4 & \multirow[b]{2}{*}{6,4} \\
\hline & $v_{2}$ & 8,9 & 5.7 & 7.3 & \\
\hline \multirow{3}{*}{ MEDIAS } & $v_{1}$ & 6,5 & 5,5 & & \\
\hline & $v_{2}$ & 5,7 & 5.4 & & \\
\hline & $V_{1} v_{2}$ & 6,2 & 5,5 & & \\
\hline
\end{tabular}

\begin{tabular}{|c|c|c|}
\hline Causas da Variaçāo & GL & $F$ \\
\hline Blocos & 2 & 2,112 \\
\hline Tratamentos & 6 & 1.004 \\
\hline Residuo A & 12 & \\
\hline Parcelas & 20 & \\
\hline Variedade & 1 & 2,518 \\
\hline Interaçāo $\mathrm{T} \times \mathrm{V}$ & 6 & 4,235 \\
\hline Resíduo B & 14 & \\
\hline Sub-Parcelas & 41 & \\
\hline Coletas & 1 & $8,375^{*}$ \\
\hline Interaçāo $T \times C$ & 6 & 3,305 \\
\hline Interação V x C & 1 & 1.511 \\
\hline Interaçào $V \times T \times C$ & 6 & 2.921 \\
\hline Resíduo $C$ & 28 & \\
\hline lotal & 83 & \\
\hline
\end{tabular}

CV (T) $20,525: \quad C V(V) 18,828 \% \quad C V$ (C) $19,744 \%$ 
.62 .

TABElA 05 (Continuação) - Valores de boro em limbos de canas das variedades IAC 48-65 e IAC 50-14 em LVa (em ppm).

\begin{tabular}{|c|c|c|c|c|}
\hline $\begin{array}{l}\text { DESDOBRAMENT } \\
\text { SA DA VARI }\end{array}$ & ${ }_{40}^{\mathrm{CAU}}$ & GL & $\mathrm{F}$ & DMS \\
\hline $\mathrm{T}$ dentro $\mathrm{V}$ & 1 & 6 & 1,75 & \multirow[t]{9}{*}{3,2} \\
\hline $\mathrm{T}$ dentro $\mathrm{V}$ & 2 & 6 & $3,67^{*}$ & \\
\hline $\mathrm{V}$ dentro $\mathrm{T}$ & 1 & 1 & 0,55 & \\
\hline $\mathrm{V}$ dentro $\mathrm{T}$ & 2 & 1 & $12,92 *$ & \\
\hline $\mathrm{V}$ dentro $\mathrm{T}$ & 3 & 1 & 0,99 & \\
\hline $\mathrm{V}$ dentro $\mathrm{T}$ & 4 & 1 & 0,19 & \\
\hline $\mathrm{V}$ dentro $\mathrm{T}$ & 5 & 1 & 0,68 & \\
\hline $\mathrm{V}$ dentro $\mathrm{T}$ & 6 & 1 & $4,74^{*}$ & \\
\hline $\mathrm{V}$ dentro $\mathrm{T}$ & 7 & 1 & $8,94^{*}$ & \\
\hline $\mathrm{T}$ dentro $\mathrm{C}$ & 1 & 6 & $3,11^{*}$ & \multirow{13}{*}{2,1} \\
\hline $\mathrm{T}$ dentro $\mathrm{C}$ & 7 & 6 & 1,27 & \\
\hline $\mathrm{C}$ dentro $\mathrm{T}$ & 1 & 1 & 0,95 & \\
\hline $\mathrm{C}$ dentro $\mathrm{T}$ & 2 & 1 & $5,18^{*}$ & \\
\hline $\mathrm{C}$ dentro $\mathrm{T}$ & 3 & 1 & $7,85^{*}$ & \\
\hline $\mathrm{C}$ dentro $\mathrm{T}$ & 4 & 1 & 2,98 & \\
\hline $\mathrm{C}$ dentro $\mathrm{T}$ & 5 & 1 & $5,07^{*}$ & \\
\hline $\mathrm{C}$ dentro $\mathrm{T}$ & 6 & 1 & 0,39 & \\
\hline $\mathrm{C}$ dentro $\mathrm{T}$ & 7 & 1 & $5,77^{*}$ & \\
\hline $\mathrm{V}$ dentro $\mathrm{C}$ & 1 & 1 & 3,76 & \\
\hline $\mathrm{V}$ dentro $\mathrm{C}$ & 7 & 1 & 0,40 & \\
\hline $\mathrm{C}$ dentro V & 1 & 1 & $8,50^{*}$ & \\
\hline $\mathrm{C}$ dentro $\mathrm{V}$ & 2 & 1 & 1,38 & \\
\hline
\end{tabular}


rios. Por outró lado, ocorrem variaçōes das variedades den ' tro dos tratamentos, assim temos: no tratamento $10 \mathrm{~kg} / \mathrm{ha}$ via foliar e $40 \mathrm{~kg} / \mathrm{ha}$ via solo, a variedade IAC 48-65 sobrepuja a IAC 50-14; enquanto que no tratamento $80 \mathrm{~kg} / \mathrm{ha}$ via solo, esta situação se inverte.

Ocorre também variaçāo dos tratamentos dentro' da primeira coleta, com destaque para os tratamentos $20 \mathrm{~kg} / \mathrm{ha}$ via foliar e $80 \mathrm{~kg} / \mathrm{ha}$ via solo apresentando os maiores valo ' res, os tratamentos testemunha e $40 \mathrm{~kg} / \mathrm{ha}$ via solo apresentan do os menores e os demais em posição intermediāria. As coletas também variam dentro dos tratamentos, apresentando a pri: meira coleta valores maiores que a segunda nos tratamentos:10 e $20 \mathrm{~kg} / \mathrm{ha}$ via foliar e 20 e $80 \mathrm{~kg} / \mathrm{ha}$ via solo.

A variação de coletas dentro da variedade IAC 48-65 também foi observada, com a primeira coleta sobrepujando a segunda.

Os resultados constantes da tabela 06, são refe rentes a canas cultivadas em : LR onde se verifica pela análise de variância que não ocorreram significância para as variáveis, mas verificou-se comportamento parecido com o LVa, apresentan do-se a primeira coleta com um teor maior que a segunda,e que as variações para menos são maiores do que para mais, desta cando-se os tratamentos 10 e $40 \mathrm{~kg} / \mathrm{ha}$ via foliar para a varie dade IAC 48-65 e testemunha, 10 e $40 \mathrm{~kg} / \mathrm{ha}$ via foliar, bem co mo $40 \mathrm{~kg} / \mathrm{ha}$ via solo para a variedade IAC 50-14, como aqueles que tiveram aumentos, embora pequenos, entre as duas coletas. 
TABELA 06 - Valores de boro em limbos de canas das variedades IAC 48-65 e IAC 50-14 em LR (èm ppm).

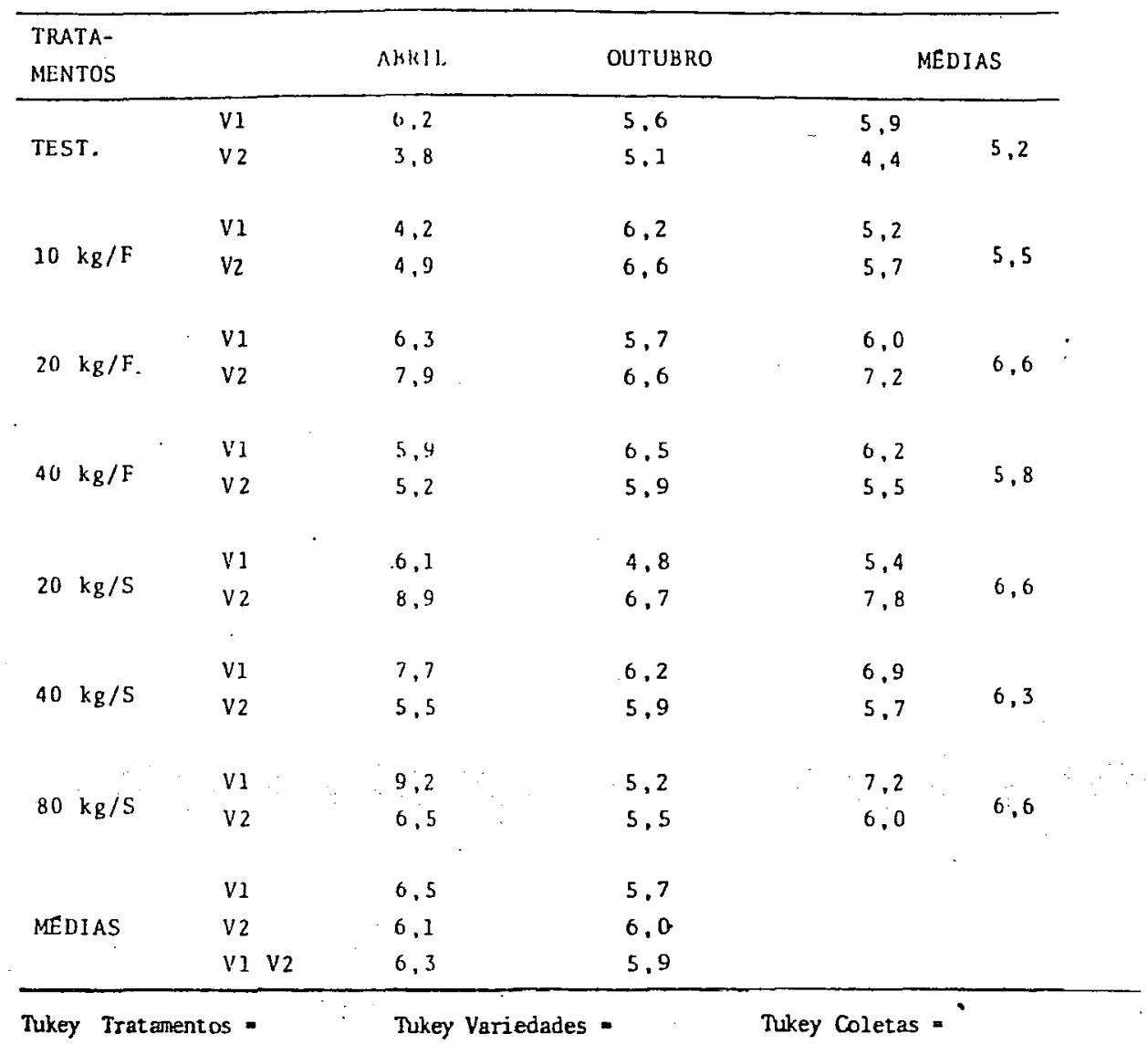

\begin{tabular}{|c|c|c|}
\hline Causas da Variação & GL & F \\
\hline Blocos & 2 & 2,636 \\
\hline Tratamentos & 6 & 1,259 \\
\hline Resíduo A & 12 & \\
\hline Parcelas & 20 & \\
\hline Variedade & 1 & 0,014 \\
\hline Interaçāo $T \times V$ & 6 & 1.106 \\
\hline Resíduo B & 14 & \\
\hline Sub-Patcelas & 41 & \\
\hline Coleta & 1 & 0.864 \\
\hline Interação $T \times C$ & 6 & 1,415 \\
\hline Interaçāo $V \times C$ & 1 & 0.588 \\
\hline Interarāo $V \times T \times C$ & 6 & 0,371 \\
\hline Resíduo $C$ & 28 & \\
\hline Total & 83 & \\
\hline
\end{tabular}


TABELA 06 (Continuação) - Valores de boro em limbos de canas das variedades IAC 48-65 e IAC 50-14 em LR (em ppm).

\begin{tabular}{|c|c|c|c|c|}
\hline $\begin{array}{l}\text { DESDOBRAMENT } \\
\text { SA DA VARI }\end{array}$ & ${ }_{20}^{\mathrm{CAU}}$ & GL & $\mathrm{F}$ & DMS \\
\hline $\mathrm{T}$ dentro $\mathrm{V}$ & 1 & 6 & 0,53 & \\
\hline $\mathrm{T}$ dentro $\mathrm{V}$ & 2 & 6 & 1,31 & \\
\hline $\mathrm{V}$ dentro $\mathrm{T}$ & 1 & 1 & 1,10 & \\
\hline $\mathrm{V}$ dentro $\mathrm{T}$ & 2 & 1 & 0,13 & \\
\hline $\mathrm{V}$ dentro $\mathrm{T}$ & 3 & 1 & 0,76 & \\
\hline $\mathrm{V}$ dentro $\mathrm{T}$ & 4 & 1 & 0,20 & \\
\hline $\mathrm{V}$ dentro $\mathrm{T}$ & 5 & 1 & 2,88 & \\
\hline $\mathrm{V}$ dentro $\mathrm{I}$ & 6 & 1 & 0,80 & \\
\hline $\mathrm{V}$ dentro $\mathrm{I}$ & 7 & 1 & 0,74 & \\
\hline $\mathrm{T}$ dentro $\mathrm{C}$ & 1 & 6 & 2,11 & \\
\hline $\mathrm{T}$ dentro $\mathrm{C}$ & 7 & 6 & 0,22 & \\
\hline $\mathrm{C}$ dentro $\mathrm{I}$ & 1 & 1 & 0,72 & \\
\hline C dentro I & 2 & 1 & 2,06 & \\
\hline C dentro $\mathrm{I}$ & 3 & 1 & 0,58 & \\
\hline $\mathrm{C}$ dentro $\mathrm{I}$ & 4 & 1 & 0,26 & \\
\hline $\mathrm{C}$ dentro $\mathrm{T}$ & 5 & 1 & 2,10 & \\
\hline $\mathrm{C}$ dentro $\mathrm{T}$ & 6 & 1 & 0,19 & \\
\hline $\mathrm{C}$ dentro $\mathrm{I}$ & 7 & 1 & 4,06 & \\
\hline $\mathrm{V}$ dentro & 1 & 1 & 0,40 & \\
\hline $\mathrm{V}$ dentro & 7 & 1 & 0,19 & \\
\hline $\mathrm{C}$ dentro $\mathrm{V}$ & 1 & 1 & 1,43 & \\
\hline $\mathrm{C}$ dentro $\mathrm{V}$ & 2 & 1 & 0,13 & \\
\hline
\end{tabular}


Em relação as interações, não se verificou qual quer significância em todas as possibilidades.

Parece,quando se observa as tabelas,que o teor' de boro nos limbos, bainhas e colmos, não apresentaram com ' portamentos semelhantes nos diferentes tratamentos e tipos de solos, jā que as variações não seguiram qualquer padrão.

Estes resultados no entanto, encontram-se dentro dos valores relatados na literatura, visto que GALLO et alii (1968), encontraram variações de 3 a 37 ppm para o limbo' +3 em canaviais de São Paulo. Teores em torno de 15,1 ppm fo ram encontrados nos limbos +3 ; 16 ppm nas +1 e 13,9 ppm - I' por ESPIRONELO et alii (1976).

Todavia, teores mais baixos são encontrados em condiçōes de campo, em função de local e variedades, o que foi verificado por vários autores. Valores da ordem de 5 ppm foram: estabelecidos como sendo o teor necessārio para uma boa produ çāo por ORTIZ (1968), enquanto MALAVOLTA et alii (1964), estabeleceram valores variando, em função do örgāo analisado, en tre 1,5 ppm para lígula e internós basais e 12 ppm para região meristemātica.

Van DILLEWIJN (1960), no entanto, preconiza valores bem mais elevados, que seriam em torno de $100 \mathrm{ppm}$ de peso seco da cana-planta, para se obter um desenvolvimento normal. Em contraste valores tão baixos quanto, 1 a 2 ppm de boro são dados como normais, citando-se EVANS (1959), com 1 ppm; ORLANDO Fo 
e RUGAI (1974), com 1,9 ppm; RAO (1977), com 1,2 ppm; BOWEN ' (1977), com 1,5 ppm; como sendo valores críticos.

Verifica-se pela observação dos resultados, que ocorre uma variação do teor de boro quando se compara colmos, bainhas e limbos, visto que os maiores teores de boro são encontrados nos meristemas (ESPIRONELO, 1972); BOWEN (1970)' que preconiza variações de 4,2 ppm para Iimbo , 2,9 ppm para bainha e 6,7 ppm para meristemas, em condições moderadas $:$ de deficiência e 2,$0 ; 1,2$ e 4,0 ppm para limbo, bainha e meriste ma respectivamente, em condições severas de deficiência. Já MALAVOLTA et alii (1964), sugerem 4 ppm para o colmo inteiro, $12 \mathrm{ppm}$ na região meristemätica e $1,5 \mathrm{ppm}$ na 1 İgula e internós mais velhos.

Em relação ao teor comparativo do conteúdó de borno nos dois solos, verificam-se poucas variações nos colmos, bainhas e limbos, demonstrando que não houve efeito do tipo de solo sobre o teor de boro. Estes resultados são consisten. tes com a literatura, no sentido de não haver muita variação' entre solos, como observado por ESPIRONELO et alii (1976), em s.olos do município de Piracicaba.

Tomando-se os valores de classe propostos por BRASIL S०. e FREIRE (1980), de que LVa é deficiente e que LR è não deficiente, usando plantas de girassol como padrão, verị fica-se a concordância dos dados, com o proposto por ESPIRONE LO (1972), jă que não se verificaram valores discrepantes entre eles, embora o autor tenha encontrado valores mais altos' 
em suas anālises.

No entanto, os valores encontrados por ORLANDO : $F^{\circ}$. et alii (1980), estão mais próximos, pois foram encontra ' dos nos três solos estudados, valores de 4 à 7 ppm para colmos e 5 à 7 para folhas, entre os 6 e 12 meses de idade das plantas, verificando-se ainda que,como nos resultados encontrados neste trabạ̣ho, os teores das folhas são ligeiramente' mais elevados que nos colmos.

Os mesmos autores citam que no Estado de São Paulo, muitas vezes ocorreram sintomas semelhantes a carência de boro, com algumss variedades mais suscetiveis que outras, comsintomatologia semelhante à doença"pokkah boeng", mesmo não tendo sido encontradas respostas à aplicação do elemento. Parece válida pois, a assertiva de ESPIRONELO: ' (1972), a partir de seus dados, e dos demais, bem como nos resultados deste trabalho, de que a cana-de-açúcar è pouco exigente em boro, sendo suficiente a quantidade de elemento encontrado na muda e eventuais quantidades disponíveis no substrato de areia. Outra possibilidade é a de que arcultura; tenha suficiente habilidade para absorver o elemento, não apresentando portanto,resposta à sua aplicação; eventualmente, pela existência do excelente sistema radicular apresentado' pela cultura, concordando com EVANS (1959), de que a cana- deaçúcar, apresenta sistema radicular de grande capacidade de absorção, resistindo mais que outras culturas à deficien ' cias de micronutrientes. 


\subsection{Açúcares redutores}

Os açücares redutores determinados pelo método proposto por NELSON (1944), adaptados às condições de trabalho' deste ensaio, foram determinados como passo inicial para a determinação do teor de sacarose, mas refletem por si próprios, algumas condições relativas à translocação e armazenamento de reservas na cana-de-açúcar, servindo inclusive como referen..' cial de maturação dos colmos.

Os resultados obtidos referentes a teor, em microgramas de açúcares redutores em limbos, encontram-se na tabela 07 , para LVa.

Verifica-se pela anälise de variância desté solo a ocorrência de significāncia para as variâvies consideradas, bem como para as interações. Destacaram-se as maiores médias gerais como sendo dos tratamentos testemunha, $40 \mathrm{~kg} / \mathrm{ha}$ via fo liar bem como $20 \mathrm{~kg} / \mathrm{ha}$ e $80 \mathrm{~kg} / \mathrm{ha}$ via solo; apresentando ainda a variedade IAC 50-14 como tendo maior média que a IAC $48-65$.

No entanto, ao se analisar as interações, observando-se os valores encontrados no desdobramento das causas de variação, obtem-se melhor visualização destes resultados .

Assim è que da análise da variação de tratamentos dentro das variedades, nota-se significância dentro das duas variedades, com destaque para os tratamentos $40 \mathrm{~kg} / \mathrm{ha}$.' via foliar e $20 \mathrm{~kg} / \mathrm{ha}$ via solo, que apresentam os maiores va- 
TABELA 07 - Valores de açúcares redutores $(\mu \mathrm{g} / \mathrm{g})$ em limbos de canas, das variedades IAC $48-65^{\circ}$ e IAC 50-14, em LVa.

\begin{tabular}{|c|c|c|c|c|c|c|c|c|c|c|}
\hline $\begin{array}{l}\text { IKAIA- } \\
\text { MENTOS }\end{array}$ & & ABRIL & Mio & JUN 10 & JUL 10 & ACOSTO & SETEMBPO & OUTUßКо & \multicolumn{2}{|c|}{ MEDIAS } \\
\hline \multirow[b]{2}{*}{ TEST. } & $v_{1}$ & 35.892 & 23.173 & 5.508 & 14.625 & 13.580 & 17.447 & 16.307 & 18.076 & \multirow[b]{2}{*}{18.870} \\
\hline & v2 & 26.450 & 28.422 & 8.259 & 16.942 & 17.471 & 13.066 & 27.047 & 19.663 & \\
\hline \multirow{2}{*}{$10 \mathrm{~kg} / \mathrm{F}$} & V1 & 26.248 & 21.028 & 5.993 & 16.222 & 14.714 & 18.426 & 22.923 & 37.936 & \multirow[b]{2}{*}{17.935} \\
\hline & V2 & 25.626 & 27.412 & 3.725 & 16.259 & 15.659 & 17.529 & 19.33] & 17.934 & \\
\hline \multirow[b]{2}{*}{$20 \mathrm{~kg} / \mathrm{F}$} & V1 & 36.039 & 26.042 & 3.302 & 17.930 & 8. 123 & 17.667 & 15.865 & 17.861 & \multirow[b]{2}{*}{17.617} \\
\hline & $v_{2}$ & 22.763 & 28.670 & 4.532 & 16.230 & 14.575 & 17.587 & 17.246 & 17.372 & \\
\hline \multirow{2}{*}{$40 \mathrm{~kg} / \mathrm{F}$} & V1 & 34.415 & 26.586 & 6.617 & 15.111 & 10.390 & 13.603 & 27.508 & 19.176 & \multirow[b]{2}{*}{19.376} \\
\hline & $v_{2}$ & 35.767 & 31.236 & 4.805 & 11.858 & 16.212 & 16.934 & 20.217 & 19.576 & \\
\hline \multirow{2}{*}{$20 \mathrm{~kg} / \mathrm{s}$} & VI & 26.858 & 26.947 & 3.974 & 15.935 & 15.635 & 17.734 & 24.188 & 18.753 & \multirow{2}{*}{18.039} \\
\hline & v2 & 16.535 & 23.562 & 6.341 & 23.246 & 16.266 & 22.453 & 21.270 & 18.525 & \\
\hline \multirow{2}{*}{$40 \mathrm{~kg} / \mathrm{s}$} & vi & 27.068 & 22.124 & 5.230 & 13.106 & 10.214 & 14.527 & 18.740 & 15.858 & \multirow[b]{2}{*}{17.656} \\
\hline & $v_{2}$ & 28.978 & 28.519 & 3.564 & 20.209 & 14.688 & 22.655 & 17.566 & 19.454 & \\
\hline \multirow{2}{*}{$50 \mathrm{k} / \mathrm{s}$} & v1 & 31.931 & 23.625 & 7.428 & 15.206 & 8.458 & 18.442 & 23.984 & 18.439 & \multirow{2}{*}{18.919} \\
\hline & $\mathbf{v}_{2}$ & 32.045 & 31.198 & 3.747 & 18.594 & 10.596 & 13.651 & 25.960 & 19.399 & \\
\hline \multirow{3}{*}{ MEUIAS } & V1 & 31.207 & 29.218 & 5.445 & 15.448 & 11.588 & 16.835 & 21.359 & & \\
\hline & $\mathrm{v} 2$ & 26.880 & 28.432 & 4.995 & 17.620 & 15.067 & 17.697 & 21.234 & & \\
\hline & V1 V2 & 29.044 & 26.325 & 5.220 & 16.534 & 13.327 & 17.266 & 21.297 & & \\
\hline
\end{tabular}

\begin{tabular}{lrc}
\hline Causas da Variaçāo & GL & F \\
Blocos & 2 & 0,991 \\
Tratamentos & 6 & $15,482 *$ \\
Resíduo A & 12 & \\
\hline Parcelas & 20 & \\
\hline Variedades & 1 & $23,576 *$ \\
Interaçao T $\times V$ & 6 & 9,712 \\
Resíduo B & 14 & \\
\hline Sub-Parcelas & 41 & \\
\hline Coletas & 6 & $2.011,424 *$ \\
Interaçāo T $\times C$ & 36 & 30,110 \\
Interaçāo V $\times C$ & 6 & 63,925 \\
Interaçāo T $\times$ V $\times$ C & 36 & 23,108 \\
Resíduo C & 168 & \\
\hline Total & 293 & \\
\hline
\end{tabular}

$C V(T) 6,186 \quad C V(V) 7,970 \quad C V(C) 6,310$


.71.

TABELA 07 (Continuaçāo) - Valores de açūcares redutores (ug/g) em limbos de canas das yariedades IAC 48-65 e IAC 50-14, em LVa.

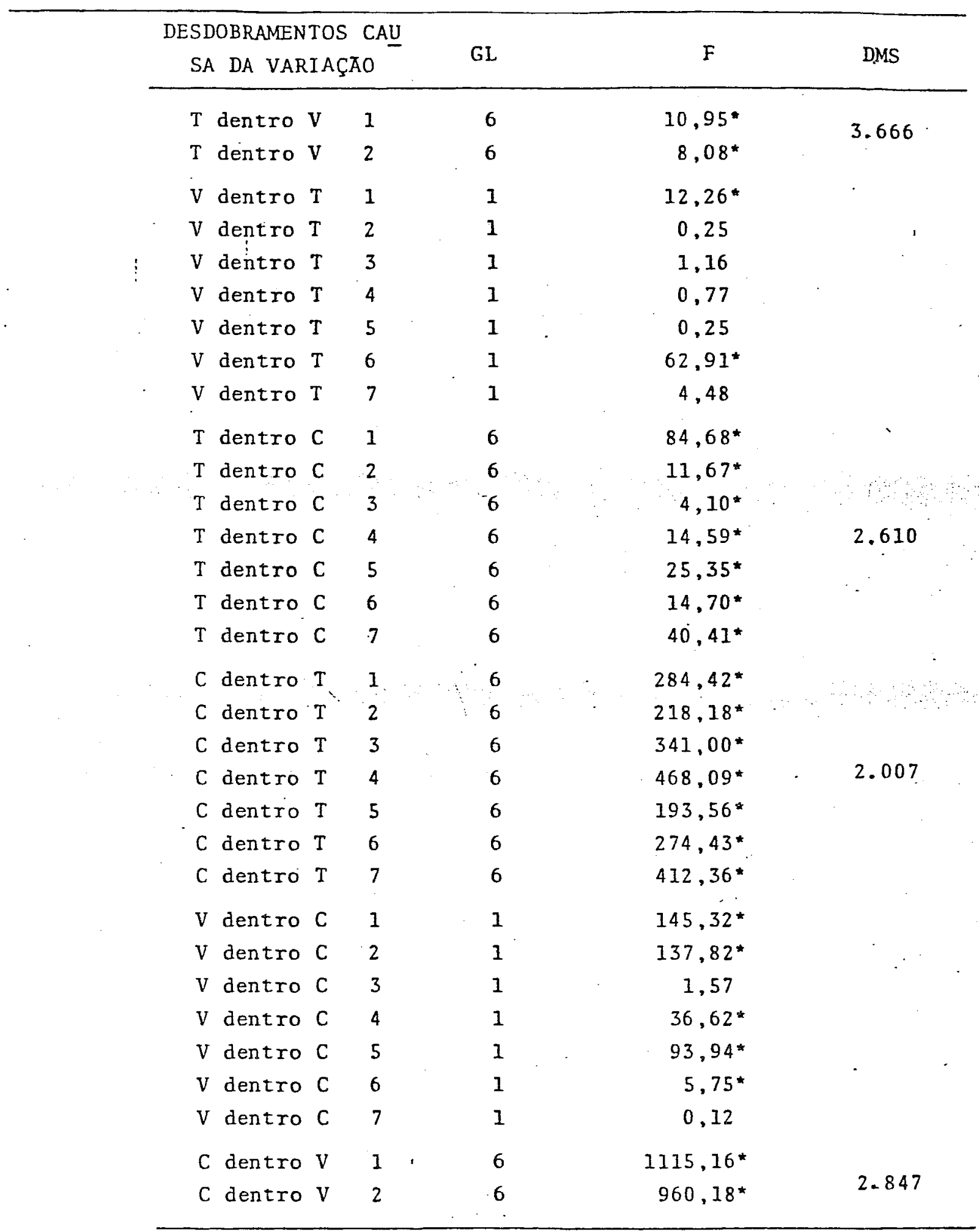


lores e o tratamento $40 \mathrm{~kg} / \mathrm{ha}$ via solo, como sensivelmente me nor na variedade IAC 48-65. Na variedade IAC 50-14, os desta ques são para o tratamento $20 \mathrm{~kg} / \mathrm{ha}$ wia foliar com o menor valor, seguido dos tratamentos $10 \mathrm{~kg} / \mathrm{ha}$ via foliar e $20 \mathrm{~kg} / \mathrm{ha}$ via solo, sendo os outros valores maiores.

Da variação das variedades dentro dos tratamentos, nota-se significância nos tratamentos testemunha, e 40 $\mathrm{kg} / \mathrm{ha}$ via solo, com a variedade IAC: $50-14$ apresentando maiores valores que a IAC 48-65, não havendo significância nos demais tratamentos.

Jā em relação a variação dos tratamentos dentro das coletas, verifica-se significância em todas as coletas com os seguintes destaques: na primeira coleta, o maior valor' è o do tratamento $40 \mathrm{~kg} / \mathrm{ha}$ via foliar, seguido de $80 \mathrm{~kg} / \mathrm{ha}$. via solo e testemunha, ficando o menor valor para o trata mento de $20 \mathrm{~kg} / \mathrm{ha}$ via solo; na segunda coleta, temos o maior valor no tratamento $40 \mathrm{~kg}$ /ha via foliar, seguindo-se os trata mentos $80 \mathrm{~kg} / \mathrm{ha}$ via solo e $20 \mathrm{~kg} / \mathrm{ha}$ via foliar, com os demais semelhantes; na terceira,o tratamento testemunha sobrepuja os demais, aparecendo o tratamento $20 \mathrm{~kg} / \mathrm{ha}$ wa foliar como o de menor valor; na quarta, quinta sexta coleta, o maior valor é obtido pelo tratamento $20 \mathrm{~kg} / \mathrm{ha}$ via solo, que se destaca na quarta e sexta coleta, enquanto que os menores valo res são respectivamente os dos tratamentos $40 \mathrm{~kg} / \mathrm{ha}$ via fós liar, $80 \mathrm{~kg} / \mathrm{ha}$ via solo e testemunha; na sétima coleta,o maior valor é obtido pelo tratamento $80 \mathrm{~kg} / \mathrm{ha}$ via solo, seguido de 
$40 \mathrm{~kg} / \mathrm{ha} \mathrm{via}$ foliar e $20 \mathrm{~kg} / \mathrm{ha}$ via solo, sendo o menor valor: obtido pelo tratamento $20 \mathrm{~kg} / \mathrm{ha}$ via foliar.

As variações das coletas dentro dos tratamentos, tambëm foram todas significativas, mas apresentaram um padrão de comportamento, com a primeira e segunda coletas apresentan do os maiores valores em todos os tratamentos, com exceção. do $20 \mathrm{~kg} / \mathrm{ha}$ via solo, em que os maiores valores foram obtidos ina segunda e sétima coleta ; já os menores valores foram obtí dos pela terceira coleta, seguida da quinta coleta, excetuan do-se o tratamento testemunha, em que aparece a sexta coleta.

$\mathrm{Na}$ interação variedades por̀ coleta, só não ocorre significância da variedade dentro da terceira e da sétima' coleta. Nas demais, o comportamento è o seguinte: na primeira coleta o maior valor $\overline{\mathrm{e}}$ obtido pela IAC 48-65, enquanto nas de mais, a supremacia é da variedade IAC 50-14. Em relação ao comportamento das coletas dentro das variedades, apresenta a variedade IAC 48-65 semelhante ao ocorrido com a maioria das. coleta dentro dos tratamentos, com a primeira e segunda cole ta: apresentando os maiores valores e terceira e quinta os pi ores. Para a variedade IAC 50-14 houve inversão entre a segun da e primeira coleta nos melhores valores.

Os resultados constantes da tabela 09 , corres :pondem aos teores obtidos em limbos da duas variedades no solo LR. Neste solo, observa-se também significância' nas variáveis estudadas para tratamentos, variedades e coletas, com destaque para os tratamentos 20 e $40 \mathrm{~kg} / \mathrm{ha}$ via solo, 
para a primeira coleta e variedade IAC 48-65, pois apresentaram os maiores valores.

Todavia, as interações foram significativas e faz-se necessário o desdobramento das causas de variação, que permitem as observaçōes seguintes:

A interação tratamentos $x$ variedades mostra sig... nificância para variações dos tratamentos dentro da variedade IAC 48-65, onde os maiores valores são observados no tratamen to $20 \mathrm{~kg} / \mathrm{ha}$ via solo, seguido do tratamento $20 \mathrm{~kg} / \mathrm{ha}$ via foli ar e o menor valorino tratamento testemunha, com os outros' ocupando posição intermediāria. Na variedade IAC 50-14,tambēm foi observada significância, destacando-se os tratamentos tes temunha, 40 e $20 \mathrm{~kg} / \mathrm{ha}$ via solo, como os de maior valor e o tratamento $20 \mathrm{~kg} / \mathrm{ha}$ via foliar como o menor. $\mathrm{Na}$ variação das variedades dentro dos tratamentos, observa-se significância.' para todas as interações, com exceção dos tratamentos $10 \mathrm{~kg} /$ ha via foliar e $40 \mathrm{~kg} / \mathrm{ha}$ via solo; nos significativos a varie dade IAC 50-14 foi melhor no tratamento testemunha, enquanto' nas demais predominou a IAC 48-65.

Para tratamentos dentro das coletas, observa-se que na primeira coleta existe significância para o tratamento $20 \mathrm{~kg} / \mathrm{ha}$ via solo sobre as demais e que o tratamento $10 \mathrm{~kg} /$ ha via foliar apresenta o menor valor; na segunda coleta, o mesmo tratamento se destaca, acompanhado de $10 \mathrm{~kg} / \mathrm{ha}$ via foliar, o me nor valor foi observado no tratamento $20 \mathrm{~kg} / \mathrm{ha}$ via foliar, ocupando os demais, posições intermediárias; na terceira e sex ta coleta. os maiores valores são obtidos pelo tratamento 
TABELA 09 - Valores de açūcares redutores $(\mu \mathrm{g} / \mathrm{g})$ em 1 imbos de canas, das variedades IAC 48-65 e IAC 50-14, em LR.

\begin{tabular}{|c|c|c|c|c|c|c|c|c|c|c|}
\hline $\begin{array}{l}\text { TKATA- } \\
\text { MENTOS }\end{array}$ & & ABRIL & MAIO & JUNHO & JULHO & AGOSTO & SETEMBRO & OUTUBRO & \multicolumn{2}{|c|}{ MEDIAS } \\
\hline \multirow[b]{2}{*}{ TEST. } & $v 1$ & 11.509 & 6.192 & 6.519 & 4.270 & 9.559 & 13.987 & 8.614 & 8.664 & \multirow[b]{2}{*}{11.270} \\
\hline & v2 & 29.489 & 9.663 & 4.382 & 15.230 & 4.445 & 11.515 & 22.611 & 13.877 & \\
\hline \multirow[b]{2}{*}{$10 \mathrm{~kg} / \mathrm{F}$} & v1 & 18.489 & 9.346 & 6.892 & 16.345 & 7.698 & 15.008 & 17.635 & 13.059 & \multirow[b]{2}{*}{12.881} \\
\hline & $v_{2}$ & 18.081 & 10.573 & 6.373 & 14.408 & 7.130 & 13.799 & 18.555 & 12.703 & \\
\hline \multirow[b]{2}{*}{$21 \mathrm{~kg} / \mathrm{F}$} & v1 & 24.316 & 5.294 & $9.7^{2} 6$ & 18.127 & 6.162 & 12.966 & 25.281 & 14.553 & \multirow[b]{2}{*}{12.850} \\
\hline & V2 & 14.352 & 6.376 & 4.389 & $13.238 !$ & 6.724 & 14.537 & 18.416 & 11.147 & \\
\hline \multirow{2}{*}{$40 \mathrm{~kg} / \mathrm{F}$} & $\mathrm{v}$ & 22.048 & 7.827 & 4.141 & 11.897 & 12.255 & 15.865 & 13.857 & 12.556 & \multirow[b]{2}{*}{12.166} \\
\hline & $v_{2}$ & 20.491 & 9.166 & 5.346 & 14.193 & 4.918 & 9.387 & 18.934 & 11.777 & \\
\hline \multirow[b]{2}{*}{$20 \mathrm{~kg} / \mathrm{S}$} & $V_{1}$ & 32.160 & 11.671 & 8.421 & 17.897 & 11.964 & 11.146 & 22.836 & 16.586 & \multirow[b]{2}{*}{14.975} \\
\hline & $v_{2}$ & 26.462 & 8.400 & 8.543 & 13.170 & 5.280 & 13.928 & 17.764 & 13.364 & \\
\hline \multirow[b]{2}{*}{$40 \mathrm{~kg} / \mathrm{S}$} & v1 & 18.039 & 7.757 & 8.978 & 13.337 & 12.511 & 14.500 & 18.155 & 13.327 & \multirow[b]{2}{*}{13.519} \\
\hline & $v_{2}$ & 23.116 & 6.425 & 12.224 & 13.236 & 4.788 & 16.521 & 19.670 & 13.711 & \\
\hline \multirow{2}{*}{$\therefore \quad i s / S$} & v1 & 18.857 & 9.087 & 9,555 & 3.451 & 11.044 & 16.014 & 24.468 & 13.215 & \multirow[b]{2}{*}{12.468} \\
\hline & $v_{2}$ & 21.551 & 6.240 & $5.58 ?$ & 13.393 & 6.342 & 10.873 & 18.066 & 11.721 & \\
\hline \multirow{3}{*}{ MEDIAS } & vl & 20.779 & 3.168 & 7.747 & 12.189 & 10.170 & 14.212 & 18.692 & & \\
\hline & V2 & 21.934 & 8.120 & 6.663 & 13.838 & 5.661 & 12.937 & $19.145^{\circ}$ & & \\
\hline & $V_{1} V_{2}$ & 21.358 & 4.144 & 7.205 & 13.014 & 7.916 & 13.575 & 18.919 & & \\
\hline
\end{tabular}

\begin{tabular}{lrc}
\hline Causas da Variação & GL & F \\
Blocos & 2 & 1,073 \\
Tratamentos & 6 & $63,406 *$ \\
Residuo A & 12 & \\
\hline Parcelas & 20 & \\
\hline Variedades & 1 & $17,749 *$ \\
Interaçāo T $\times V$ & 6 & 77,804 \\
Resíduo B & 14 & \\
\hline Sub-Parcelas & 41 & \\
\hline Coleta & 6 & $1.632,597 *$ \\
Interação T $\times$ C & 36 & 32,484 \\
Interaçāo V $\times C$ & 6 & 55,281 \\
Interaçāo T $\times$ V $\times C$ & 36 & 49,364 \\
Resíduo C & 168 & \\
\hline Total & 293 & \\
\hline
\end{tabular}


TABELA 09 (Continuação) - Valores de açücares redutores ( $\mu \mathrm{g} / \mathrm{g}$ ) em limbos de canas, das variedades IAC 48-65 e IAC 50-14, em LR.

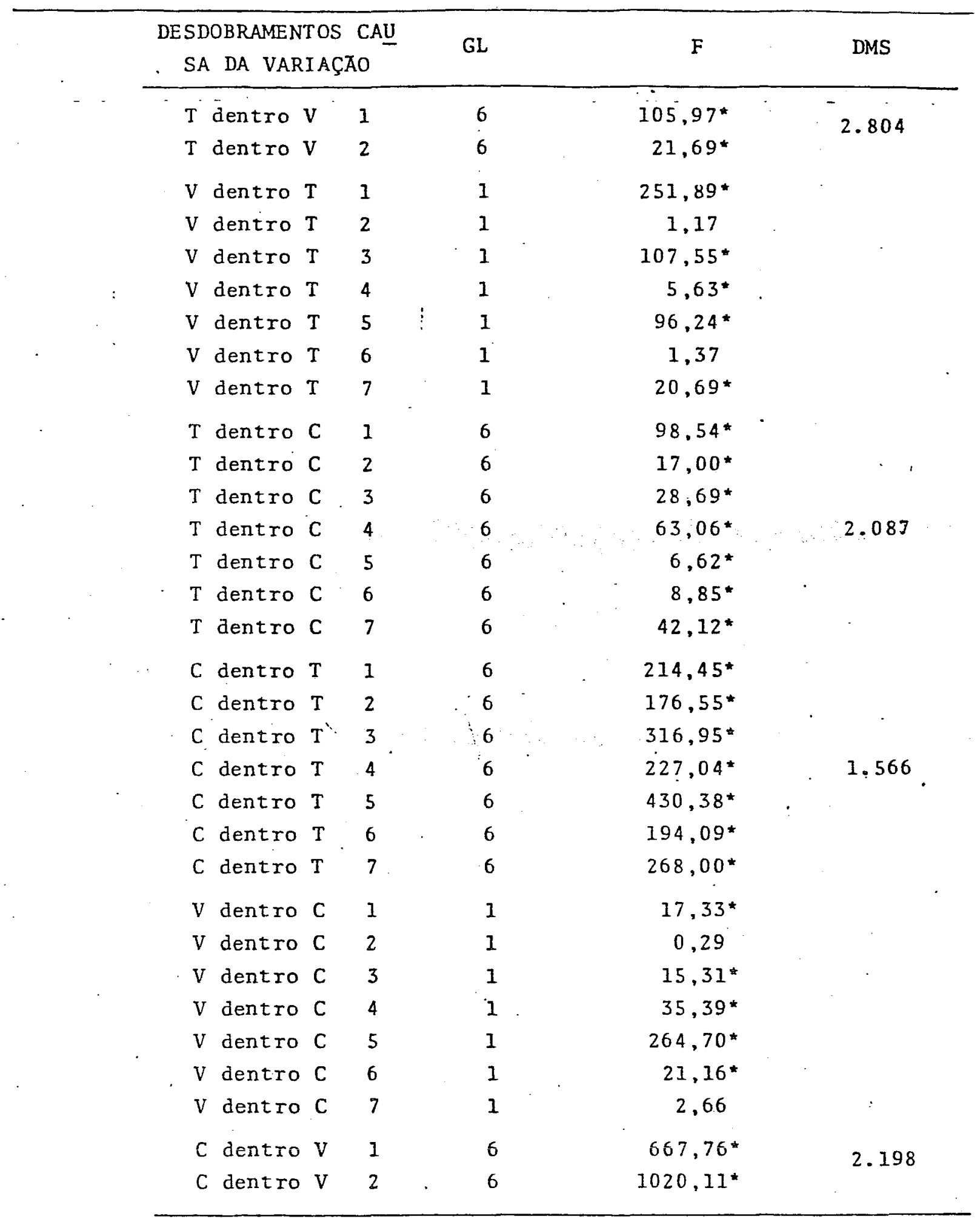


$40 \mathrm{~kg} / \mathrm{ha}$ via solo, embora os piores sejam obtidos, respectiva mente, pelo tratamento $40 \mathrm{~kg} / \mathrm{ha}$ via foliar e $20 \mathrm{~kg} / \mathrm{ha}$ via so1o; na quarta e sétima coleta, temos três tratamentos destacados como melhores, 20 e $10 \mathrm{~kg} / \mathrm{ha}$ via foliar, acompanhado de $20 \mathrm{~kg} / \mathrm{ha}$ via solo na quarta, e $20 \mathrm{~kg} / \mathrm{ha}$ via foliar, acompanhado de 20 e $80 \mathrm{~kg} / \mathrm{ha}$ via solo na sétima, sendo as pizores' respectivamente $\quad 80 \mathrm{~kg} / \mathrm{ha}$ via solo e testemunha; na quinta coleta,os valores são semelhantes, com destaque para o tratamento $20 \mathrm{~kg} / \mathrm{ha}$ via foliar como o menor. Para coletas' dentro dos tratamentos, verifica-se como no LVa, alguma cons tância, destacando-se a testemunha e $80 \mathrm{~kg} / \mathrm{ha} \mathrm{via}$ solo, como maiores valores, ao passo que $20 \mathrm{~kg} / \mathrm{ha}$ via foliar e $20 \mathrm{~kg} / \mathrm{ha}$ ! via solo apresentaram os menores valores.

$\mathrm{Na}$ interação variedades $\mathrm{x}$ coletas, observa-se' significância das variedades dentro das coletas, excetuando--se a segunda e a sétima; dentro dos significativos, a IAC 50-14 predominou na primeira e quarta coleta e a IAC 48-65' nas demais. Por outro lado, na observação de coletas dentro' de variedades, nota-se que essas variedades predominaram na primeira e sétima coleta; enquanto os piores valores foram' na terceira e quinta coleta, para IAC 48-65 e IAC 50-14 res pectivamente.

Os resultados de açūcares redutores, transforma dos para porcentagem, a serem utilizados em possiveis compara ções e que permitem as mesmas interpretações, são apresenta ' dos na tabela 8 para LVa e na tabela 10 para LR. 
TABELA 08 - Valores de açúcares redutores $(\%)$ em limbo de canas. das variedades IAC $48-65^{\circ}$ e IAC 50-14, em LVa.

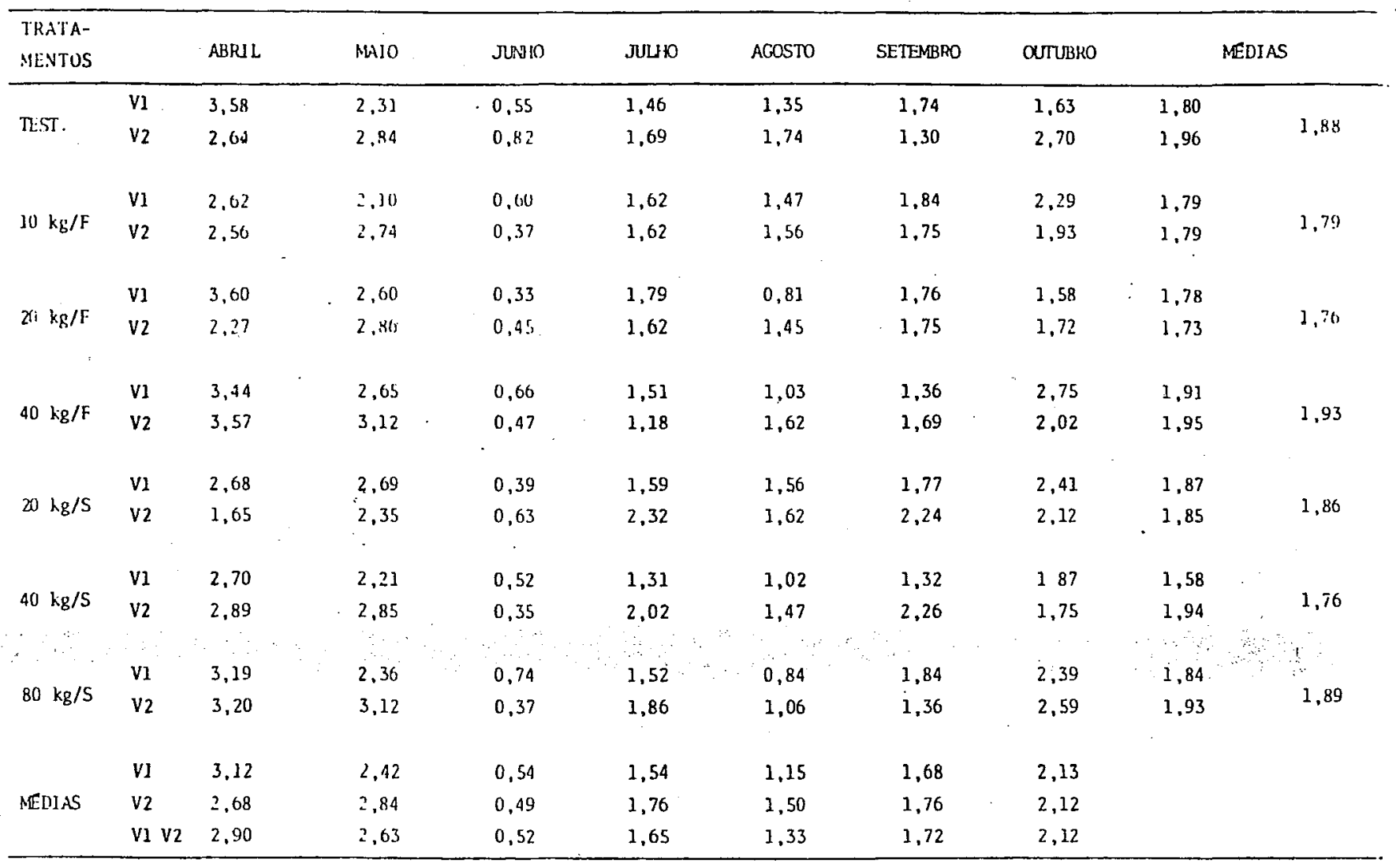

\begin{tabular}{|c|c|c|}
\hline Causas da Variação & GL & $F$ \\
\hline Blocos & 2 & 0,362 \\
\hline Tratamentos & 6 & $14,474 *$ \\
\hline Resíduo A & 12 & \\
\hline Parcelas & 20 & \\
\hline Variedades & 1 & $29,835 *$ \\
\hline Interaçāo $T \times V$ & 6 & 9,898 \\
\hline Resíduo $B$ & 14 & \\
\hline Sub-Parcelas & 41 & \\
\hline Coleta & 6 & $2.557 .826 *$ \\
\hline Interaçāo & 36 & 29.138 \\
\hline Interaçāo $V \times C$ & 6 & 59,521 \\
\hline Interarāo $T \times V \times C$ & 36 & 24,787 \\
\hline Residuo $C$ & 168 & \\
\hline Total & 293 & \\
\hline
\end{tabular}

CV (T) $3.425 \quad$ CV (V) $4.009 \quad$ CV (C) 3.214


TABELA 10 - Valores de açūcares redutores ( $(0)$ ) em limbos de canas, das variedades IAC 48-65 e IAC 50-14, em LR.

\begin{tabular}{|c|c|c|c|c|c|c|c|c|c|c|c|c|c|c|c|c|}
\hline $\begin{array}{l}\text { Th:il }- \\
\text { Mllows }\end{array}$ & & \multicolumn{2}{|l|}{ ABRIL } & MHIO & JU:A II & \multicolumn{2}{|l|}{ JULHO } & \multicolumn{2}{|l|}{ ACOSTO } & \multicolumn{2}{|l|}{ SETLMKIK) } & \multicolumn{3}{|l|}{ OUTUBRO } & \multicolumn{2}{|l|}{ MEDIAS } \\
\hline & Vl & 1.15 & & 0,02 & 0.65 & 0.42 & & 0.95 & & 1.39 & & 0,86 & & 0,86 & \multirow{2}{*}{\multicolumn{2}{|c|}{1.12}} \\
\hline ThSi. & $v_{2}$ & 2,95 & & 0,96 & 0.43 & 1,32 & & 0,44 & & 1.15 & & 2,26 & & 1.38 & & \\
\hline & & - & . & & & & & & & & . & & & & & \\
\hline \multirow[b]{2}{*}{ lo ig/t: } & VI & 1,84 & & 0,93 & $0,(1,0)$ & 1,63 & , & 0,76 & & 1.50 & & 1,76 & . & 1.30 & & \multirow[b]{2}{*}{1.28} \\
\hline & $v_{2}$ & 1,80 & & 1,05 & $0,6.3$ & 1,44 & & 0,71 & & 1,38 & & 1,85 & & 1.27 & & \\
\hline \multirow[b]{2}{*}{20 h.:'s: } & $b$ & 2,43 & & 0,52 & 0,97 & 1,81 & & 0,61 & & 1.29 & & 2,53 & $\vdots$ & 1,45 & & \multirow[b]{2}{*}{1,28} \\
\hline & 12 & 1.45 & . & 6,63 & 0,43 & 1,32 & & 0.67 & & 1,45 & & 1,85 & & 1,11 & & \\
\hline \multirow[t]{2}{*}{ 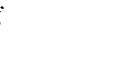 } & & : & & & & . & . & & & & & & & & \multirow{3}{*}{\multicolumn{2}{|c|}{1,21}} \\
\hline & VI & 2.211 & \multirow[t]{2}{*}{$\cdot$} & $U, 7 B$ & 0,41 & 1,19 & \multirow{2}{*}{. } & 1,22 & & 1,58 & & 1,38 & & 1.25 & & \\
\hline $411+k_{k}^{\prime}, j$ & 12 & 2.05 & & 0,91 & 0,53 & 1,42 & & 0,49 & & 0,94 & & 1,89 & & 1,17 & & \\
\hline & & & & & & & & & & & & & & & & \\
\hline \multirow{2}{*}{$20 \mathrm{~kg} / \mathrm{S}$} & VI & 3,21 & & 1,10 & 0,84 & 1,79 & & 1,19 & & 1,11 & & 2,28 & & 1.65 & & \multirow{2}{*}{$1.49^{\circ}$} \\
\hline & $v 2$ & $\therefore 64$ & & 0,33 & 0,85 & 1,32 & & 0,52 & & 1,39 & & 1,61 & & 1.33 & $\cdot$ & \\
\hline \multirow{2}{*}{$40 \mathrm{~kg} / \mathrm{S}$} & V] & 1,80 & & 0,77 & 0,89 & 1,33 & & 1,25 & $\because$ & 1,44 & & 1,81 & & 1,33 & . & \multirow{2}{*}{1,35} \\
\hline & 12 & 2,31 & & 0,64 & 1,22 & 1,32 & & 0.48 & : & $1 ; 65$ & • & 1.96 & & 1,37 & - & \\
\hline \multirow{2}{*}{$80 \mathrm{~kg} / \mathrm{s}$} & VI & 1,88 & & 0.91 & 0,95 & 0,34 & & 1,10 & & 1,60 & & 2,44 & & 1,32 & & \multirow[b]{2}{*}{1,24} \\
\hline & v2 & 2,15 & & 0.62 & 0,55 & 1,34 & & 0.63 & $\therefore$ & 1,09 & & 1,80 & . & 1,17 & & \\
\hline \multirow{3}{*}{ MEDIAS } & VI & 2,07 & & 0,81 & 0,77 & 1,21 & & 1,01 & & 1,42 & & 1,86 & & & & \multirow{3}{*}{ - } \\
\hline & $v_{2}$ & 2,19 & & 0,81 & 0,66 & 1,38 & & 0,56 & & 1,29 & & 1,91 & . & & & \\
\hline & V1 V2 & 2,13 & & 0.81 & 0,72 & 1,30 & & 0,79 & & 1.35 & & 1.89 & & & & \\
\hline
\end{tabular}

Tukev Tratamen'os $=0,24$

. Tukey Variedades $=$

Tukey Coletas $=0,20$

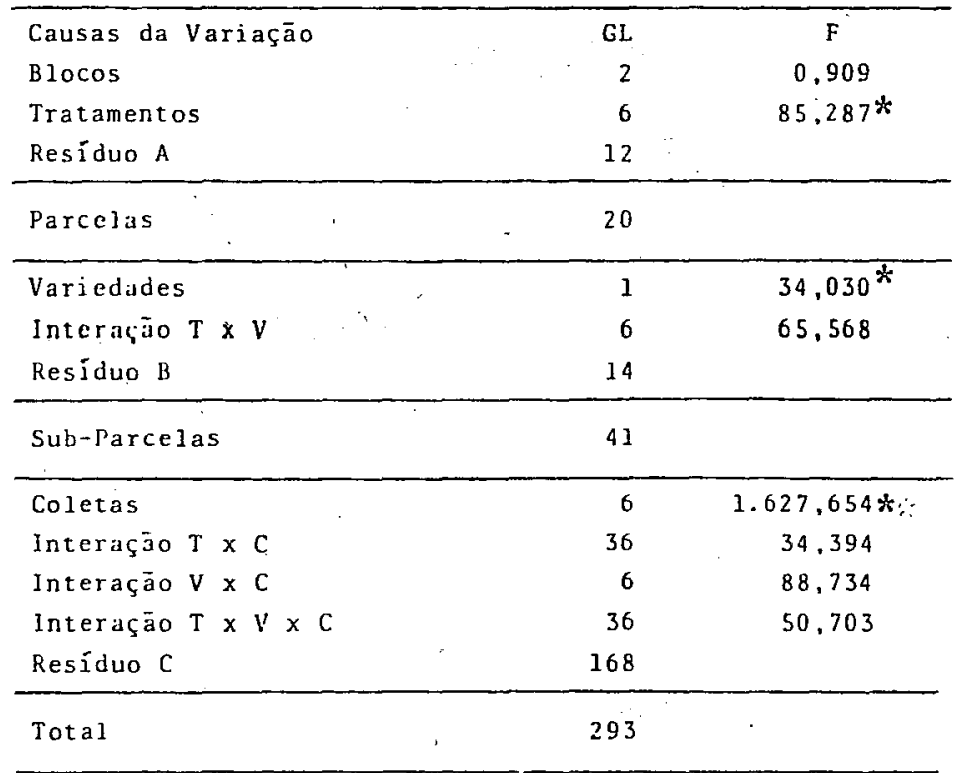

$\mathrm{CV}(\mathrm{T}) 3.520 \quad \mathrm{Cl}(\mathrm{V}) 4.073 \quad \mathrm{CV}$ (C) 3,576


Os resultados para bainhas, referentes a plantas cultivadas em LVa, encontram-se na tabela 11.

Pela anälise de variância, verifica-se haver sig nificância estátística para todas as variāveis, com destaque' para os tratamentos $80 \mathrm{~kg} / \mathrm{ha}$ via solo e $20 \mathrm{~kg} / \mathrm{ha}$ via foliar.' com os maiores valores e $40 \mathrm{~kg} / \mathrm{ha}$ via solo como o de me:-' nor valor. Entre as variedades é a IAC 50-14 que apresenta maior valor; enquanto entre as coletas destacam-se; a primeira e segunda com valores maiores e a terceira com 'menor' valor.

Contudo, ao se observar a anālise de variação, detecta-se significância para as interações, e da anālise des tas atravēs de decomposição das causas de variação, pode-se ' depreender:

$\mathrm{Na}$ interação tratamentos dentro das variedades; observa-se na variedade IAC 48-65 destaque para os tratamen.' tos $20 \mathrm{~kg} / \mathrm{ha}$ via foliar e $80 \mathrm{~kg} / \mathrm{ha}$ via solo com os maiores va lores e o tratamento $40 \mathrm{~kg} / \mathrm{ha}$ via solo como o menor. Jà ina IAC 50-14 verifica-se o maior valor com $80 \mathrm{~kg} / \mathrm{ha}$ e o menor, como na anterior, no tratamento $40 \mathrm{~kg} / \mathrm{ha}$ via solo. Na decompo sição das variedades dentro dos tratamentos, verificou-se pre dominância da IAC 50-14 sobre a IAC 48-65, em todos os trata ' mentos,com exceção de $20 \mathrm{~kg} / \mathrm{ha}$ via foliar.

Ao se analisar a interação tratamentos $x$ coletas, com os tratamentos variando, nota-se que o tratamento $80 \mathrm{~kg} /$ ha via solo foi o melhor na. primeira quinta e sexta cole " 
$\mathrm{ta}$, tendo como menores valores a testemunha, $40 \mathrm{~kg} / \mathrm{ha} v \mathrm{ia}$ solo e $40 \mathrm{~kg} / \mathrm{ha}$ via foliar respectivamente; na segunda coleta, destacou-se como maior valor o $10 \mathrm{~kg} / \mathrm{ha}$ via foliar e menores 40 $\mathrm{kg} / \mathrm{ha}$ via foliar e $20 \mathrm{~kg} / \mathrm{ha}$ via solo; na terceira,o maior valor foi obtido para $40 \mathrm{~kg} / \mathrm{ha}$ via foliar e o menor para $20 \mathrm{~kg} /$ ha via solo; na quarta,o menor foi no tratamento $40 \mathrm{~kg} / \mathrm{ha}$ via solo e o maior na testemunha; jā na sétima coleta,o destaque' ficou no. $20 \mathrm{~kg} / \mathrm{ha}$ via solo, como maior e $40 \mathrm{~kg} / \mathrm{ha}$ via foliar,' como menor.

A variação de coletas dentro dos tratamentos:, apresentou constância nos resultados, com a segunda e primeira coleta revesando-se como melhores valores e a terceira coleta como pior em todos os tratamentos, com exceçãós do 40 $\mathrm{kg} / \mathrm{ha}$ via foliar, que foi a sétima coleta.

A interação variedades $x$ coletas, com variação' das variedades, apresentou a variedade IAC 48-65 como melhor na segunda e quarta coleta; e nas demais,a variedade IAC 50-14; com exceção da quinta e sétima que não apresentaram di ferenças. Jā na variação das coletas,verifica-se que para ' IAC 48-65 existe grande diferença entre a segunda coleta como maior valor e a terceira como menor, ficando as demais em posição intermediäria; na IAC 50-14 existe semelhança, com gran de diferença entre a primeira coleta, que se sobressai das demais, ficando tambẻm com destaque, a terceira com pior re sultado. 
$.82 \cdot$

TABELA 11 - Valores de açūcares redutores $(\mu \mathrm{g} / \mathrm{g})$ em bainhas de canas, das variedades IÁC 48-65 e IAC 50-14, em LVa.

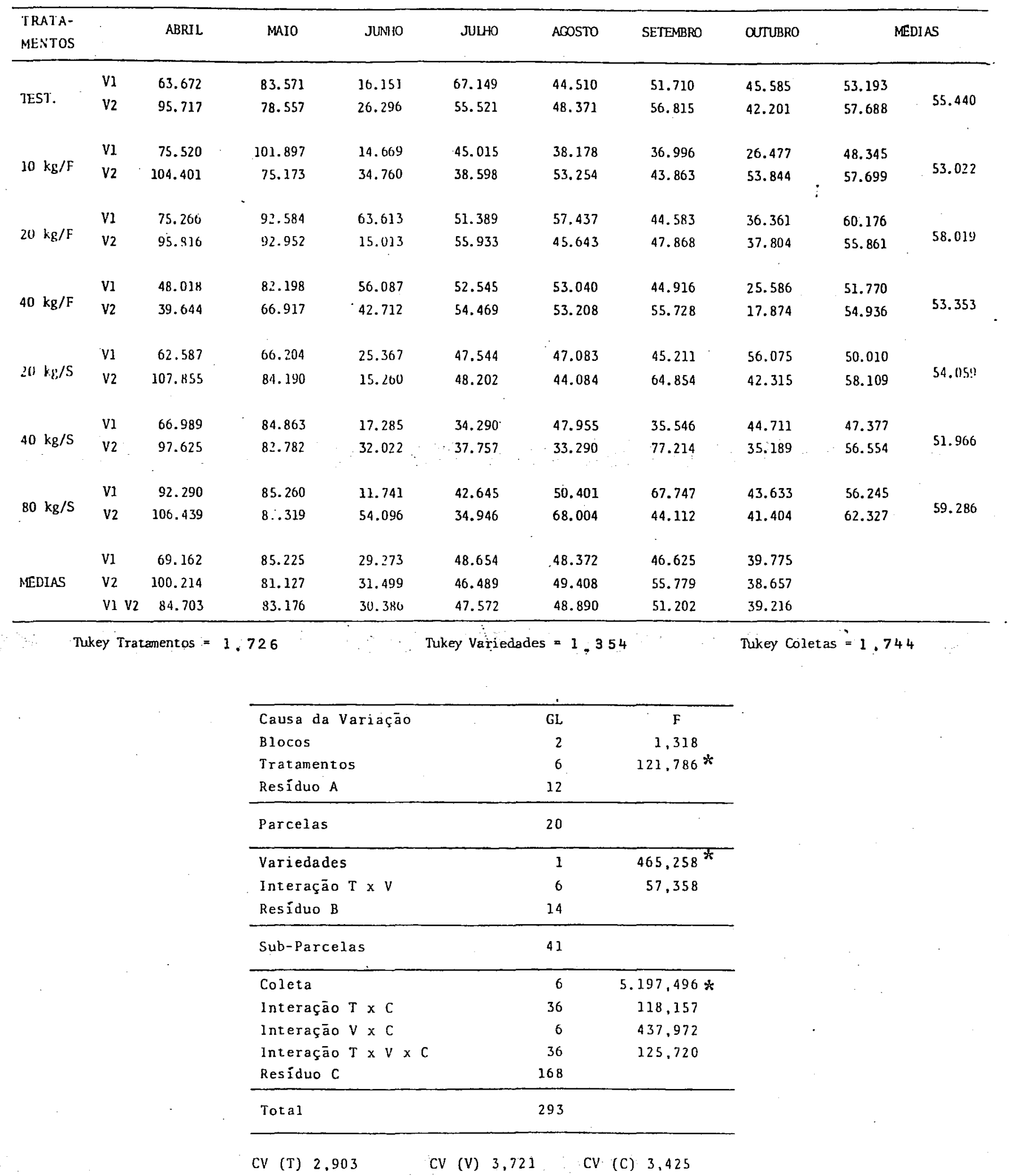


.83.

TABELA 11 (Continuaçāo) - Valores de açūcar redutores $(\mu \mathrm{g} / \mathrm{g}$ ) em bainhas de canas, das variedades IAC 48-65 e IAC 50-14, em LVa.

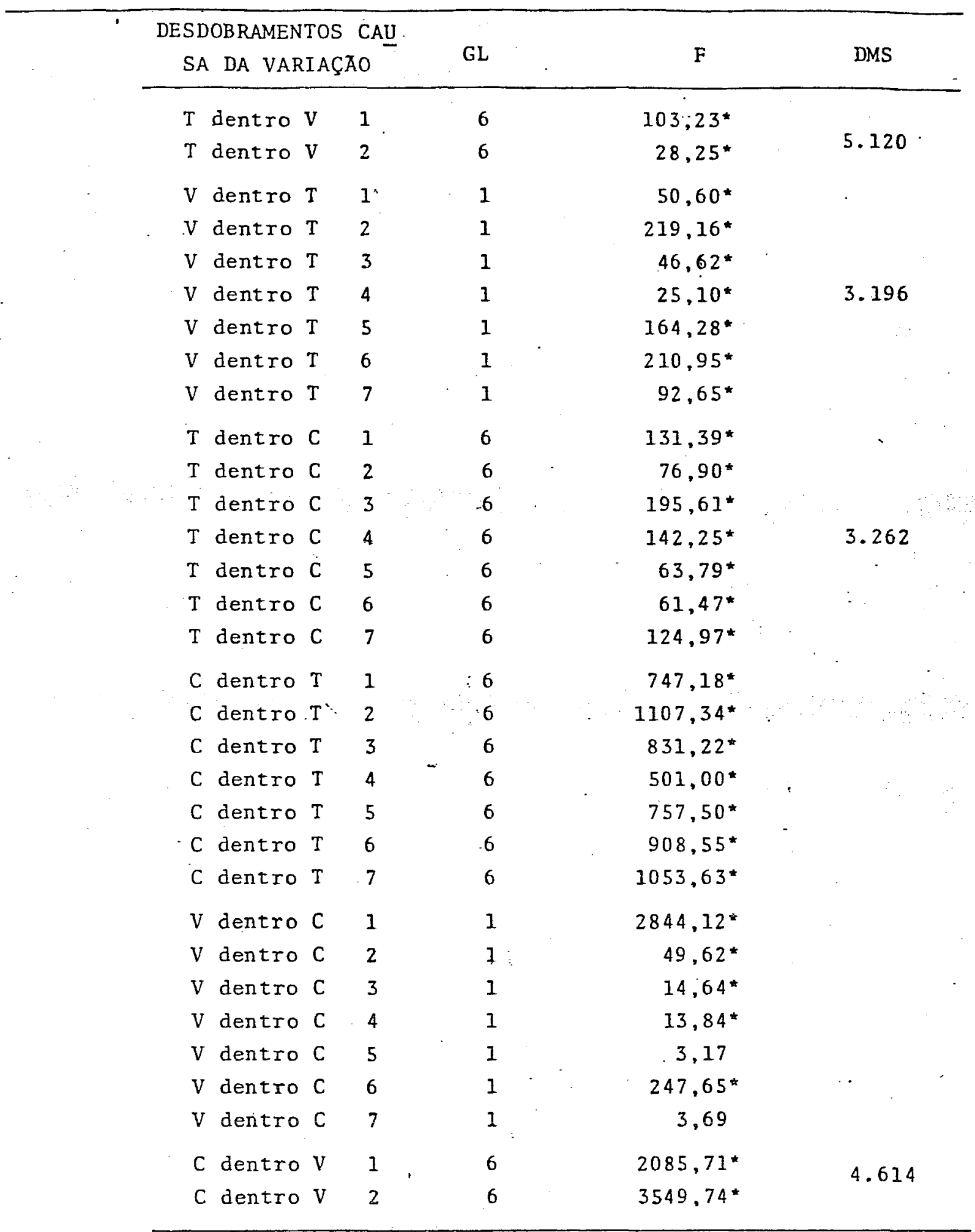


Os resultados referentes ao teor de açúcares rẹ dutores obtidos para bainhas em LR, constam da tabela 13 onde podem ser observadas significância para tratamentos, variedades e coletas, destacando-se o tratamento $20 \mathrm{~kg} / \mathrm{ha}$ via' foliar, como de maior valor, a variedade IAC 48-65 com a maior média, e a sexta e sétima coleta com os maiores resultados. Todavia, como se verificou significância nas interações, obtem -se atravēs do desdobramento das causas de variaçāo, as rrè guintes observações:

$\mathrm{Na}$ interação tratamentos $\mathrm{x}$ variedades, quando se fixa variedades, verifica-se que na variedade IAC 48-65 os meIhores tratamentos são $20 \mathrm{~kg} / \mathrm{ha}$ via solo e $40 \mathrm{~kg} / \mathrm{ha}$ via foliar, enquanto o menor valor foi o do tratamento $10 \mathrm{~kg} / \mathrm{ha}$ via foliar. Na variedade IAC 50-14, os maiores valores foram dos tratamentos $20 \mathrm{~kg} / \mathrm{ha}$ via foliar e $80 \mathrm{~kg} / \mathrm{ha}$ via solo. e o de mais baixo valor o do tratamento $40 \mathrm{~kg} / \mathrm{ha}$ via foliar. Ao se fixar os tratamentos, as variedades tiveram o seguinte compor tamento: a variedade IAC 50-14 apresentou maiores valores nos tratamentos $10 \mathrm{~kg} / \mathrm{ha}$ e $20 \mathrm{~kg} / \mathrm{ha} \mathrm{via}$ foliar e $80 \mathrm{~kg} / \mathrm{ha} \mathrm{via}$ so10; nos demais, a supremacia foi da IAC 48-65.

A decomposição para a interação tratamentos $x$ coletas, mostra que quando se varia o tratamento dentro da coleta, observa-se que na primeira coleta destacam-se os tratamentos $20 \mathrm{~kg} / \mathrm{ha}$ via foliar e $80 \mathrm{~kg} / \mathrm{ha}$ via solo como os de maior valor e $10 \mathrm{~kg} / \mathrm{ha}$ e $40 \mathrm{~kg} / \mathrm{ha}$ via foliar como os de menor; o tratamento $20 \mathrm{~kg} / \mathrm{ha}$ via foliar destaca-se como primeiro,tam bém na terceira e sexta coleta, com os tratamentos $20 \mathrm{~kg} / \mathrm{ha}$ ' 
e $80 \mathrm{~kg} / \mathrm{ha}$ via solo, respectivamente, como os piores; na gunda coleta,formaram-se dois grupos, separados pela testemunha, com os valores mais altos para os tratamentos 80 e 40 $\mathrm{kg} / \mathrm{ha}$ via solo e $40 \mathrm{~kg} / \mathrm{ha}$ via foliar, e o mais baixo para 20 $\mathrm{kg} / \mathrm{ha}$ via foliar; na quarta e sétima coleta, o destaque é para o tratamento $20 \mathrm{~kg} / \mathrm{ha}$ via solo, com os piores para teste munha e $40 \mathrm{~kg} / \mathrm{ha}$ via solo, respectivamente; na quarta coleta, o melhor valor: também é $40 \mathrm{~kg} / \mathrm{ha}$ vảa solo, enquanto o menor è a testemunha.

Ao se fixar o tratamento, verifica-se que as co letas de maior valor são a sexta para os tratamentos' 10 e $20 \mathrm{~kg} / \mathrm{ha}$ via foliar e $40 \mathrm{~kg} / \mathrm{ha}$ via solo, e a sétima cole ta para as demais, Como menores valores encontramos a tercei ra para $20 \mathrm{~kg} / \mathrm{ha}$ via solo e a quinta para as outras.

$\mathrm{Na}$ intéração coletas $\mathrm{x}$ variedades, fixando-se as coletas, obtem-se significância para todas, menos a quinta e a sexta, com a variedade IAC 50-14 apresentando maior valor' só na quarta coleta. Por outro lado, ao se variar as coletas, obtem-se para IAC 48-65 o maior valor na sétima coleta $e$ o menor na quinta coleta; enquanto que na IAC 50-14 o maior é da sexta coleta e o menor da quinta coleta.

Na tabela 12 são encontrados os valores de açúcares redutores em bainhas, transformados para porcentagem em canas cultivadas no LVa e na tabela 14, em LR. 
TABELA 13 - Valores de açücares redutores ( $\mu \mathrm{g} / \mathrm{g}$ ) em bainhas de canas, das variedades IAC 48-65 e IAC 50-14, em LR.

\begin{tabular}{|c|c|c|c|c|c|c|c|c|c|c|}
\hline $\begin{array}{l}\text { TRATA- } \\
\text { MENTOS }\end{array}$ & & ABRIL & MAIO & RNHO & ЈบนК & AGOSTO & SEIEMBRO & QTTUBRO & \multicolumn{2}{|c|}{ MEDIAS } \\
\hline \multirow{2}{*}{ TEST. } & vl & 44.762 & 27.796 & 30.752 & 25.257 & 7.294 & 33.049 & 33.405 & 28.893 & \multirow{2}{*}{27.739} \\
\hline & v2 & 21.266 & 27.701 & 25.480 & 25.513 & 19.300 & 32.144 & 34.700 & 26.585 & \\
\hline \multirow{2}{*}{$10 \mathrm{~kg} / \mathrm{F}$} & VI & 24.865 & 26.268 & 17.549 & 26.641 & 17.289 & 36.250 & 35.906 & 26.395 & \multirow{2}{*}{28.532} \\
\hline & $v_{2}$ & 22.101 & 24.320 & 20.535 & 35.938 & 17.794 & 43.271 & 41.721 & 30.668 & \\
\hline \multirow[b]{2}{*}{$201 \mathrm{~kg} / \mathrm{l}$} & VI & 37.012 & 14.892 & 36.420 & 35.565 & 21.529 & 47.442 & 25.504 & 31.195 & \multirow[b]{2}{*}{32.037} \\
\hline & v2 & 35.738 & 32.713 & 33.718 & 33.017 & 16.622 & 44.493 & 33.712 & 32.859 & \\
\hline \multirow[b]{2}{*}{$40 \mathrm{~kg} / \mathrm{F}$} & VI & 25.189 & 37.385 & 22.450 & 33.705 & 25.828 & 32.617 & 47.226 & $32: 057$ & \multirow[b]{2}{*}{27.200} \\
\hline & $v_{2}$ & 21.933 & 24.273 & 20.985 & 32.543 & 12.289 & 16.816 & 27.557 & .22 .342 & \\
\hline \multirow{2}{*}{$20 \mathrm{~kg} / \mathrm{S}$} & v1 & 38.138 & 35.430 & 17.663 & 35.958 & 20.861 & $33.826^{\circ}$ & 53.840 & 33.673 & \multirow[b]{2}{*}{29.253} \\
\hline & v2 & 26.195 & 13.105 & 19.923 & 30.324 & 23.412 & 32.869 & 27.999 & 24.832 & \\
\hline \multirow{2}{*}{$40 \mathrm{~kg} / \mathrm{S}$} & $\mathrm{n}$ & 35.892 & 28.366 & 30.606 & 25.695 & 16.247 & 41.994 & 26.699 & 29.358 & \multirow{2}{*}{28.374} \\
\hline & $v_{2}$ & 27.181 & 32.840 & 13.234 & 46.100 & 18.196 & 31.611 & 22.569 & 27,390 & \\
\hline \multirow{2}{*}{$80^{\circ} \mathrm{kg} / \mathrm{s}$} & v1 & 36.731 & 34.138 & 34.243 & 26.557 & 17.513 & 13.201 & 36.673 & 28.441 & \multirow{2}{*}{29.776} \\
\hline & V2 & 34.533 & 29.762 & 25.710 & 32.457 & 24.305 & 35.414 & 35.461 & 31.092 & \\
\hline \multirow{3}{*}{ MEDIAS } & v1 & 34.656 & 29.182 & 27.097 & 29.911 & 18.080 & 34.060 & 37.027 & & \\
\hline & $v_{2}$ & 26.992 & 26.388 & 24.083 & 33.699 & 18.845 & 33.802 & 31.959 & & \\
\hline & $v_{1} V_{2}$ & 30.824 & 27.785 & 25.590 & 31.805 & 18.463 & 33.931 & 34.493 & & \\
\hline
\end{tabular}

\begin{tabular}{lrc}
\hline Causas da Variação & GL & F \\
Blocos & 2 & 2,674 \\
Tratamentos & 6 & $62,282 \%$ \\
Pesiduo A & 12 & \\
\hline Parcelas & 20 & \\
\hline Variedades & 1 & $158,885 *$ \\
Interação T $\times \mathrm{V}$ & 6 & 165.176 \\
Residuo B & 14 & \\
\hline Sub-Parcelas & 41 & \\
\hline Coleta & 6 & $638.950^{*}$ \\
Interação T $\times \mathrm{C}$ & 36 & 80.572 \\
Interação V $\times \mathrm{C}$ & 6 & 70,478 \\
Interaçao T $\times \mathrm{V} \times \mathrm{C}$ & 36 & 67.678 \\
Residuo C & 168 & \\
\hline Total & 293 & \\
\hline
\end{tabular}

CV (T) $4.517 \cdots \mathrm{CV}$ (V) $4.775 \quad \mathrm{CV}$ (C) 4,975 
TABELA 13 (Continuaçāo) - Valores de áçúcares redutores ( $\mu \mathrm{g} / \mathrm{g}$ ) em bainhas de canas, das variedades IAC 48-65 e IAC 50-14, em LR.

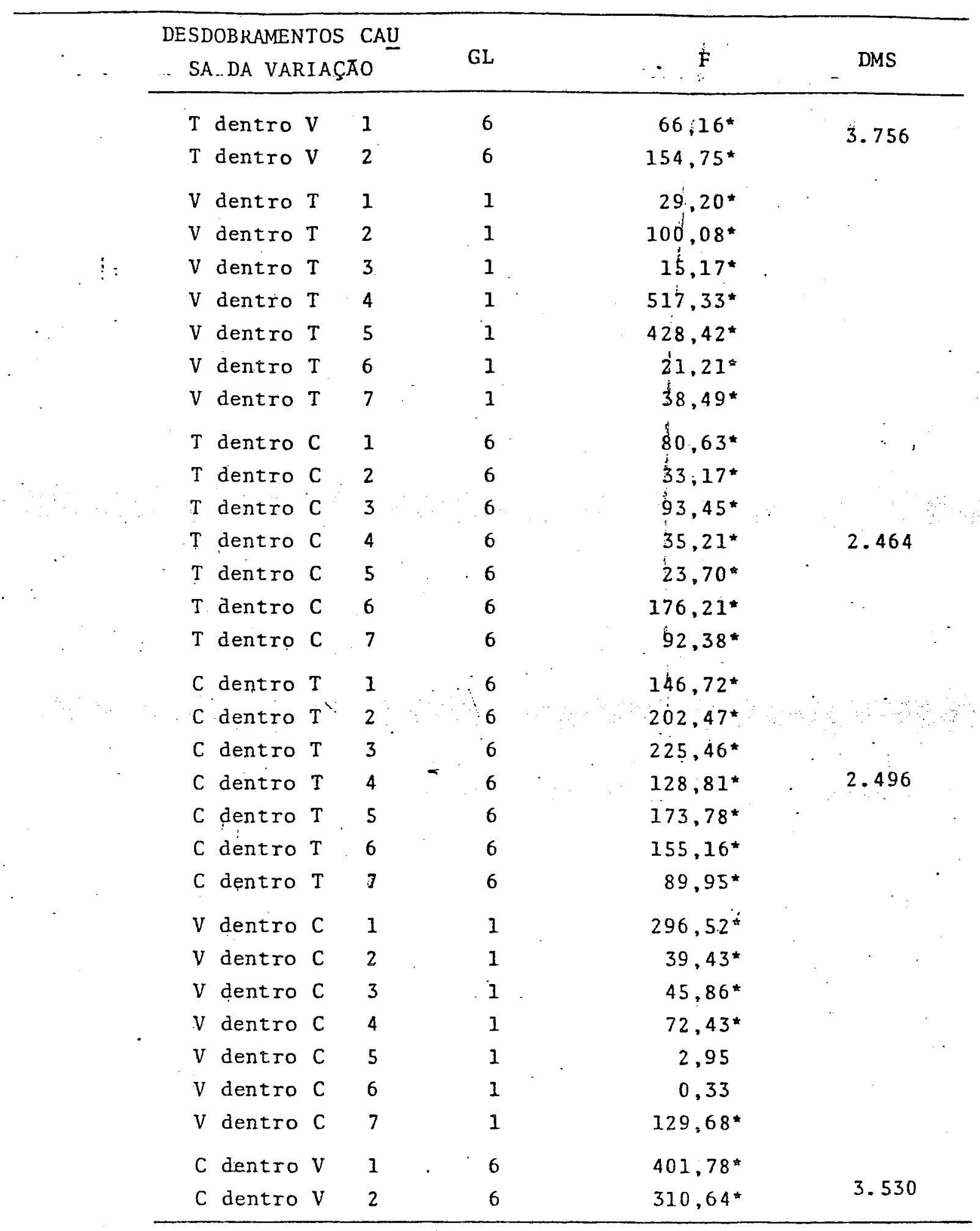


TABELA 12 - Valores de açúcares redutores $(\stackrel{\circ}{0})$ em bainhas de canas, das variedades IAC 48-65 e IAC 50-14, em LVa.

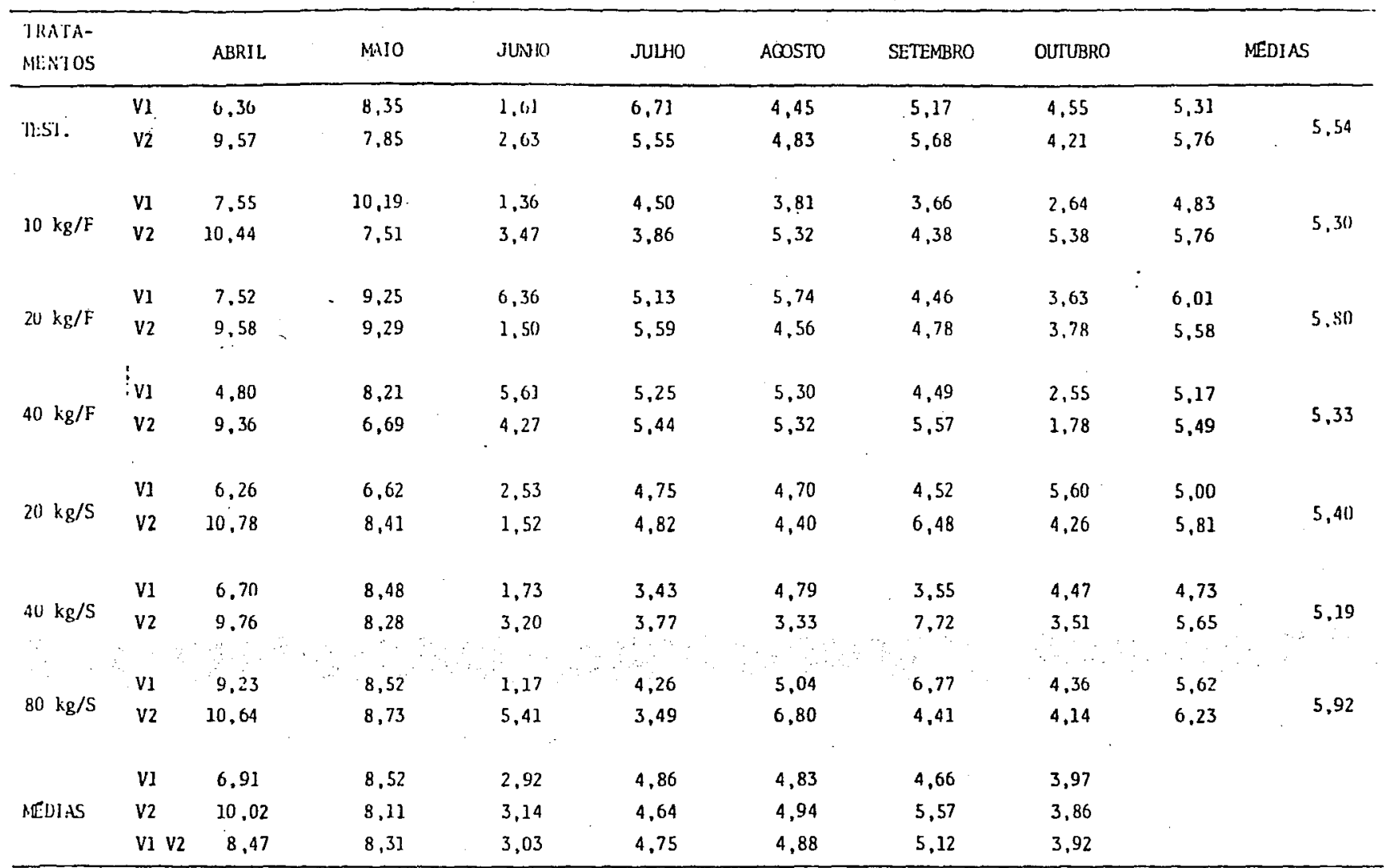

\begin{tabular}{|c|c|c|}
\hline Causas da Variaçāo & $\mathrm{GL}$ & . $F$ \\
\hline Blocos & 2 & 1,254 \\
\hline Tratamentos & 6 & $87,052 \%$ \\
\hline Resíduo A & 12 & \\
\hline Parcelas & 20 & \\
\hline Variedades & 1 & $343,143 *$ \\
\hline Interaçāo $T \times V$ & 6 & 71,080 \\
\hline Resíduo B & 14 & \\
\hline Sub-Parcelas & 41 & \\
\hline Coleta & 6 & $4.658,285 x$ \\
\hline Interaçāo $\mathrm{T} \times \dot{C}$ & 36 & 127,143 \\
\hline Interaçāo $V \times C_{C}$ & 6 & 277.374 \\
\hline Interaçāo $T \times V \times C$ & 36 & 146.109 \\
\hline Residuo $\mathrm{C}$ & 168 & \\
\hline Total & 293 & \\
\hline
\end{tabular}


TABELA 14 - Valores de açücares redutores ( $\%)$ em bainhas de canns, das variedades IAC 48-65 e IAC 50-14, em LR.

\begin{tabular}{|c|c|c|c|c|c|c|c|c|c|c|}
\hline $\begin{array}{l}\text { TRATA- } \\
\text { MENTOS }\end{array}$ & & ABRIL & MAIO & $J U N \mathbb{H} 10$ & ЛЛно & ACOSTO & SETEMBRO & OUTUBPD & & MEDIAS \\
\hline \multirow[b]{2}{*}{ TEST. } & v1 & 4.47 & 2,78 & 3.07 & 2,52 & 0.73 & 3,30 & 3,33 & 2,88 & \multirow{2}{*}{2,77} \\
\hline & 12 & 2,12 & 2,77 & 2.54 & 2.55 & 1.93 & 3,21 & 3,21 . & 3.47 & \\
\hline \multirow{2}{*}{$10 \mathrm{~kg} / \mathrm{F}$} & Vl & 2,48 & 2,62 & 1,75 & 2,66 & 1,73 & 3,62 & 3,59 & 2.63 & \multirow[b]{2}{*}{2,85} \\
\hline & $v_{2}$ & 2,21 & 2,43 & 2.95 & 3,59 & 1,78 & 4,32 & 4,17 & 2.63 & \\
\hline \multirow{2}{*}{$20 \mathrm{~kg} / \mathrm{F}$} & VI & 3,70 & 1.49 & 3,64 & 3,55 & 2.15 & 4.74 & 2,55 & 3,11 & \multirow{2}{*}{3,20} \\
\hline & $v_{2}$ & 3,57 & 3.27 & 3.37 & 3,30 & 1,66 & 4,45 & 3,37 & 3.28 & \\
\hline \multirow{2}{*}{$n i 1 \mathrm{~kg} / \mathrm{F}$} & v1 & 2,51 & 3.73 & 2.24 & 3,37 & 2,58 & 3,26 & 4,72 & 3,20 & \multirow{2}{*}{2,72} \\
\hline & $v_{2}$ & 2,19 & 2.12 & 2.10 & 3,25 & 1,23 & 1,68 & 2,75 & 2.23 & \\
\hline \multirow{2}{*}{$20 \mathrm{~kg} / \mathrm{s}$} & v1 & 3,81 & 3,54 & 1,76 & 3,59 & 2,08 & 3.38 & 5,38 & 3.36 & \multirow[b]{2}{*}{2,92} \\
\hline & v2 & 2,62 & 1,31 & 1,99 & 3.03 & 2.34 & 3,28 & 2,80 & 2,48 & \\
\hline \multirow{2}{*}{$40 \mathrm{~kg} / \mathrm{S}$} & vi & 3.58 & 2.83 & 3,05 & 2,57 & 1,55 & 4,20 & 2,67 & 2,93 & \multirow{2}{*}{2,83} \\
\hline & V2 & 2,71 & 328 & 1,32 & 4,61 & 1,81 & 3,16 & 2,25 & 2,73 & \\
\hline \multirow{2}{*}{$80 \mathrm{~kg} / \mathrm{S}$} & $\mathrm{Vl}$ & 3.67 & 3,41 & 3,42 & 2,65 & 1,75 & 1.32 & 3,66 & 2,84 & \multirow{2}{*}{2,97} \\
\hline & $\mathrm{v} 2$ & 3.45 & 2.97 & 2.57 & 3,24 & 2,43 & 3,40 & 3,54 & 3,10 & \\
\hline \multirow{3}{*}{ MEDIAS } & v1 & 3,46 & 2.91 & 2,70 & 2,99 & 1,80 & 3,40 & 3,70 & & \\
\hline & v2 & 2,69 & 2,63 & 2,40 & 3,36 & 1,88 & 3,38 & 3.19 & & \\
\hline & $V_{1} V_{2}$ & 3,08 & 2.77 & 2,55 & 3,18 & 1,84 & 3,39 & 3.44 & & \\
\hline
\end{tabular}

\begin{tabular}{|c|c|c|}
\hline Causas da Variaçāo & GL & $\mathrm{F}$ \\
\hline Blocos & 2 & 3,053 \\
\hline Tratamentos & 6 & $78,733 \nsim$ \\
\hline Resíduo A & 12 & \\
\hline Parcelas & 20 & . \\
\hline Variedades & 1 & $129,530 *$ \\
\hline Interaçāo $T \times V$ & 6 & 168,448 \\
\hline Residuo B & 14 & \\
\hline Sub-Parcelas & 41 & \\
\hline Coleta & 6 & $740,723 *$ \\
\hline Interaçāo $T \times C$ & 36 & 88,667 \\
\hline Interaçāo $V \times C$ & 6 & 73.084 \\
\hline Interaçāo $\mathrm{T} \times \mathrm{V} \times \mathrm{C}$ & 36 & 78.147 \\
\hline Resíduo C & 168 & \\
\hline Total & 293 & \\
\hline
\end{tabular}

$\mathrm{CV}$ (T) $2,068 \quad \mathrm{CV}(\mathrm{V}) 2.461 \quad \mathrm{CV}$ (C) 2,491 
Os resultados obtidos para açúcares redutores,, mostram-se inconsistentes, pois as variações ocorreram de forma aleatória, traduzindo eventualmente uma situação de momento, mas sem efeito de tratamentos, pois para cada coleta, destaca-se um dos tratamentos ou variedades. 
4.4. Sacarose

Os teores de sacarose foram determinados por dois métodos distintos para folhas, através da diferença de açūcares redutores com e sem inversão, usando o método propos to por NELSON (1944), e do colmo através do mëtodo de LOPEZ HERNANDES (1961). Em vista deste fato, serão apresentados para limbos e bainhas os resultados em $\mu \mathrm{g} / \mathrm{g}$ de sacarose, com posterior ' transformaçāo para porcentagem, e para colmos, diretamente em porcentagem. Como a transformaçăo não modificou a significân cia da análise, apresentam-se os resultados originais onde se fízeram as observações pertinentes.

Os resultados obtidos de microgramas de sacarose por grama de limbo, encontram-se na tabela 15 ; para canas cultivadas em LVa.

A anālise de variância apresentou significância para todas as variāveis, com destaque para os tratamentos 80 $\mathrm{kg} / \mathrm{ha}$ via solo e testemunha, para a variedade IAC 50-14 e para a primeira e segunda coleta. No entanto, também as interações foram significativas em todas as possibilidades, permi tindo a observação dos resultados, através dos desdobramentos das causas de variação.

$\mathrm{Na}$ variação dos tratamentos, dentro das variedades, destacou-se na variedade IAC $48-65$, os tratamentos 80 e $20 \mathrm{~kg} / \mathrm{ha}$ via solo e $40 \mathrm{~kg} / \mathrm{ha}$ via foliar, superando os demais; na variedade IAC 50-14, destacam-se os tratamentos testemunha' 
e $80 \mathrm{~kg} / \mathrm{ha}$ via solo, com os maiores valores e 20 e $40 \mathrm{~kg} / \mathrm{ha}$ ' via foliar,com, os menores. Porém,fixando-se os tratamentos' verifica-se que a IAC 50-14,predomina em todos os tratamentos, com exceçäo do $40 \mathrm{~kg} / \mathrm{ha}$ via foliar.

$\mathrm{Na}$ interação tratamentos $\mathrm{x}$ coletas, fixada a co leta, verifica-se que os melhores tratamentos variaram, tendo a testemunha apresentado maior valor na primeira e segunda co leta e sendo os menores valores apresentados pelos tratamentos $20 \mathrm{~kg} / \mathrm{ha}$ via foliar e $20 \mathrm{~kg} / \mathrm{ha}$ via solo, respectivamente, nas mesmas coletas; na terceira e quarta coleta, o maior valor foi no $80 \mathrm{~kg} / \mathrm{ha}$ via solo e o menor no $10 \mathrm{~kg} / \mathrm{ha}$ via foliar, que foi acompanhado, na quinta, pelo $40 \mathrm{~kg} / \mathrm{ha}$ via solo; tam bẻm na sétima coleta o maior valor foi do $80 \mathrm{~kg} / \mathrm{ha}$ via solo., mas o menor foi $20 \mathrm{~kg} / \mathrm{ha}$ via foliar; na quarta coleta o meThor foi $40 \mathrm{~kg} / \mathrm{ha}$ via solo e o menor o $40 \mathrm{~kg} / \mathrm{ha}$ via foliar; $\underline{\text { i }}$ nalmente, na sexta coleta, os destaques são para 20 e $40 \mathrm{~kg} / \mathrm{ha}$ ! via solo, com o teor mais elevado e a testemunha, com o menor. Fi xando-se os tratamentos, destaca-se a primeira coleta, seguida da segunda com os maiores teores e terceira coleta com os menores teores, na maioria dos tratamentos ou muito próximo' disto, nas demais.

Para a interação variedade x coleta, fixada a coleta, verifica-se que a variedade IAC 48-65 apresentou maior teor na. terceira e quinta coleta, enquanto a IAC 50-14 pre dominou nas demais, com exceção da sétima coleta que não apre sentou significancia, Por outro lado, ao se fixar a variedade, 
TABELA 15 - Valores de sacarose $(\mu \mathrm{g} / \mathrm{g}$ ) em limbos de canas, das variedades IAC 48-65 e IAC 50-14, ‘ em LVa.

\begin{tabular}{|c|c|c|c|c|c|c|c|c|c|c|}
\hline $\begin{array}{l}\text { IR:AL- } \\
\text { MLSWOS }\end{array}$ & & ABRIL & MAIO & JUN10 & ЈЧนН & AGOSTU & SETEMBRO & OUTUBKO & \multicolumn{2}{|c|}{ MEDIAS } \\
\hline \multirow[b]{2}{*}{$\mathrm{T}: \mathrm{ST}$. } & $V_{1}$ & 11.779 & 5.932 & 3.483 & 3.667 & 4.101 & 4.991 & 3.345 & 5.345 & \multirow[b]{2}{*}{7.414} \\
\hline & $v_{2}$ & 23.490 & 19.617 & 2.570 & 6.406 & 5.696 & 4.166 & 4.438 & 9.483 & \\
\hline \multirow{3}{*}{$10 \mathrm{~kg} / \mathrm{F}$} & v1 & 12.245 & 5.706 & 2.852 & 2.444 & 3.361 & 5.746 & 6.328 & 5.526 & \multirow{3}{*}{6.141} \\
\hline & $v_{2}$ & 14.782 & 9.401 & 976 & 9.274 & 3.448 & 7.335 & 2.070 & 6.755 & \\
\hline & & $\cdot$ & & & & & & & & \\
\hline \multirow{2}{*}{$20 \mathrm{~kg} / \mathrm{F}$} & v1 & 10.205 & 6.509 & 5.431 & 4.392 & 4.209 & 4.469 & 1.647 & 5.266 & \multirow{2}{*}{5.628} \\
\hline & $v_{2}$ & 10.498 & 9.444 & 2.250 & 5.556 & 4.303 & 8.245 & 1.637 & 5.990 & \\
\hline \multirow[b]{2}{*}{$40 \mathrm{~kg} / \mathrm{F}$} & v1 & 10.685 & 8.630 & 6.223 & 5.188 & 5.846 & 4.505 & 3.313 & 6.341 & \multirow{2}{*}{6.122} \\
\hline & v2 & 12.182 & 8.503 & 2.414 & 4.079 & 2.543 & 6.660 & 4.944 & 5.904 & \\
\hline \multirow[b]{2}{*}{$20 \mathrm{~kg} / \mathrm{s}$} & VI & 11.956 & 4.544 & 4.800 & 3.851 & 5.697 & 9.605 & 4.316 & 6.396 & \multirow{2}{*}{6.572} \\
\hline & $v_{2}$ & 15.066 & 7.145 & 2.244 & 9.224 & 2.595 & 7.813 & 3.151 & 6.748 & \\
\hline & & & $\cdots$ & & & $\because \quad \therefore$ & & & & \\
\hline \multirow{2}{*}{$40 \mathrm{~kg} / \mathrm{S}$} & v1 & 10.746 & 7.365 & 3.502 & 8.085 & 4.014 & 1.741 & 1.684 & 5.305 & \multirow{2}{*}{6.861} \\
\hline & $v_{2}$ & 11.079 & 14.316 & 3.610 & 8.767 & 2.496 & 15.180 & 3.469 & 8.417 & \\
\hline \multirow[b]{2}{*}{$80 \mathrm{~kg} / \mathrm{s}$} & v1 & 13.154 & 3.4 .38 & 5.842 & 4.319 & 6.418 & 6.469 & 5.270 & 6.414 & \multirow[b]{2}{*}{7.824} \\
\hline & $v_{2}$ & 12.237 & 16.496 & 6.316 & 9.032 & 6.010 & 8.304 & 6.236 & 9.233 & \\
\hline \multirow{3}{*}{ MEDIAS } & $\eta$ & 11.538 & 6.035 & 4.591 & 4.564 & 4.807 & 5.361 & 3.700 & \multirow{3}{*}{, } & \\
\hline & v2 & 14.191 & 12.132 & 2.911 & 7.477 & 3.870 & 8.243 & 3.706 & & \\
\hline & $V_{1} V_{2}$ & 12.864 & 9.083 & 3.751 & 6.020 & 4.338 & 6.802 & 3.703 & & \\
\hline
\end{tabular}

Tukey Tratamentos $=606$

Tukey Variedades $=328$

\begin{tabular}{|c|c|c|}
\hline Causas da Variaçāo & GL & $F$ \\
\hline Blocos & 2 & 1,440 \\
\hline Tratamentos & 6 & $79.750 \%$ \\
\hline Resíduo A & 12 & \\
\hline Parcelas & 20 & \\
\hline Variedades & 1 & $863,407 \%$ \\
\hline Interaçāo $T \times V$ & 6 & 118,393 \\
\hline Resíduo B & 14 & \\
\hline Sub-Parcelas & 41 & \\
\hline Coleta & 6 & $1.016 .122 *$ \\
\hline Interação $\mathrm{T} \times \mathrm{C}$ & 36 & 33,267 \\
\hline Interaçāo $V \times C$ & 6 & 167.175 \\
\hline Interação $\mathrm{T} \times \mathrm{V} \times \mathrm{C}$ & 36 & 38,117 \\
\hline Resíduo C & 168 & \\
\hline Total & 293. & \\
\hline
\end{tabular}

$\mathrm{CV}$ (T) $8,445 \quad \mathrm{CV}$ (V) $7,478 \quad \mathrm{CV}$ (C) 0.102 
.94 .

TABELA 15 (Continuaçāo) - Valores.de sacarose ( $\mu \mathrm{g} / \mathrm{g}$ ) em limbos de canas, das variedadés IAC 48-65 e IAC 50-14, em LVa.

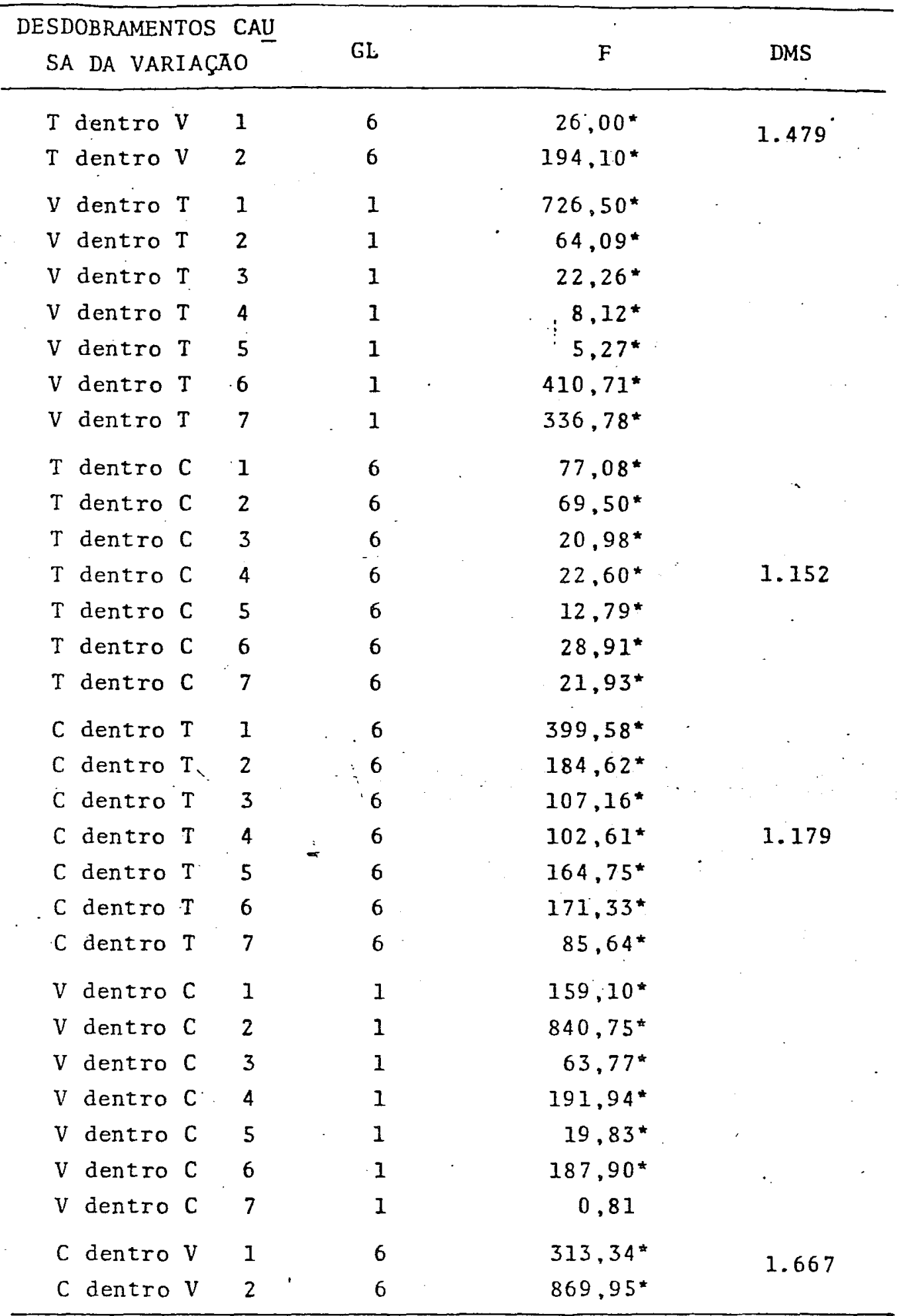


nota-se que na IAC 48-65 o maior teor encontra-se na prime ra coleta e o menor na sétima, enquanto na IAC 50-14 o maior também foi na primeira, mas o menor foi na terceira coleta.

Para LR os teores de sacarose em micrograma por grama de limbo, constam da tabela 17 .

A anālise de variancia demonstra significáncia' para todas as variáveis, com a melhor média sendo obtida pela variedade IAC 50-14, destacando-se ainda as médias : dos tratamentios testemunha, $10 \mathrm{~kg} / \mathrm{ha}$ via foliar e $20 \mathrm{~kg} / \mathrm{ha}$ via so 10; com a primeira e sétima coleta apresentando as melhores.' medidas. Porẻm,verifica-se que todas as interações foram sig nificativas, e a partir do desdobramento das causas de variação,pode-se fazer as observações descritas a seguir.

$\mathrm{Na}$ interação tratamento $\mathrm{x}$ variedade, ocorreram' significâncias quando se fixou as variedades, mas não em todos os casos quando se fixou os tratamentos. $\because$ Na primeira alter. nativa, na variedade IAC 48-65; destacou-se como maior média; o tratamento $20 \mathrm{~kg} / \mathrm{ha}$ via solo e como menor, otratamento $20 \mathrm{~kg} /$ ha via foliar; para a variedade IAC 50-14, a maior média $\because$ foi da testemunha, seguida de perto pelo $20 \mathrm{~kg} / \mathrm{ha}$ via foliar, e a menor do $20 \mathrm{~kg} / \mathrm{ha}$ via solo. Na segunda alternativa, com fixa çāo dos tratamentos, nota-se que a variedade IAC 48-65 foi ' maior no $20 \mathrm{~kg} / \mathrm{ha}$ via solo, a IAC 50-14 nos tratamentos teste munha, $20 \mathrm{~kg} / \mathrm{ha}$ via foliar e $40 \mathrm{~kg} / \mathrm{ha}$ via solo; enquanto nos outros não ocorrèram significâncias.

Para variaçāo de tratamentos dentro de coletas, não se obteve significância para a quinta e para as outras co 
letas, verificando-se: na primeira, a maior média foi de $10 \mathrm{~kg} / \mathrm{ha}$ via foliar e a menor $20 \mathrm{~kg} / \mathrm{ha}$ via foliar; na: segunda, foram 40 $\mathrm{kg} / \mathrm{ha}$ via foliar, juntamente com $20 \mathrm{~kg} / \mathrm{ha}$ via solo como maioj: res e $10 \mathrm{~kg} / \mathrm{ha}$ via foliar e $40 \mathrm{~kg} / \mathrm{ha}$ via solo, as menores; na terceira, os destaques foram $20 \mathrm{~kg} / \mathrm{ha}$ via solo, o maior, e $10 \mathrm{~kg} /$ ha via foliar, o menor; na quarta, o menor é $80 \mathrm{~kg} / \mathrm{ha}$ via solo e a maior, com pouca diferença $40 \mathrm{~kg} / \mathrm{ha}$ via solo; a testemu nha foi a maiộr na sexta, mas menor na sétima, sendo : $40 \mathrm{~kg} /$ ha via foliar,o menor na sexta e o $10 \mathrm{~kg} / \mathrm{ha}$ via foliar." a maior média da sétima coleta.

A variação de coletas dentro de tratamentos,foi significativa em todos os casos, com as seguintes situações:a primeira coleta foi a de maior média nos tratamentos, excetuando $020 \mathrm{~kg} / \mathrm{ha}$ via foliar em que houve inversão com a sétima coleta; os valores intermediários foram obtidos pela quarta e sétima coleta, tendo as demais próximas da quinta coleta, que foi a de menor média, excetuando-se o $20 \mathrm{~kg} / \mathrm{ha}$ via foliar, on de a menor média foi da terceira coleta.

A interação coletas $x$ variedades , fixada a coleta, apresentou a variedade IAC 48-65 como a de maior média. na quinta coleta, e a variedade IAC 50-14 maior na primeira e quarta coleta, com os demais sem significância. Fixada a va riedade, verifica-se que dentro da IAC 48-65, destaca-se como maior média a primeira: e a quinta coleta como menor.Pa ra a variedade IAC 50-14, a maior foi a primeira coleta; como intermediärias as sétima e quarta coleta e, sendo a menor,a 
TABELA 17 - Valores de sacarose $(\mu \mathrm{g} / \mathrm{g})$ em 1 imbos de canas, das variedades IAC 48-65 e IAC 50-14, em LR.

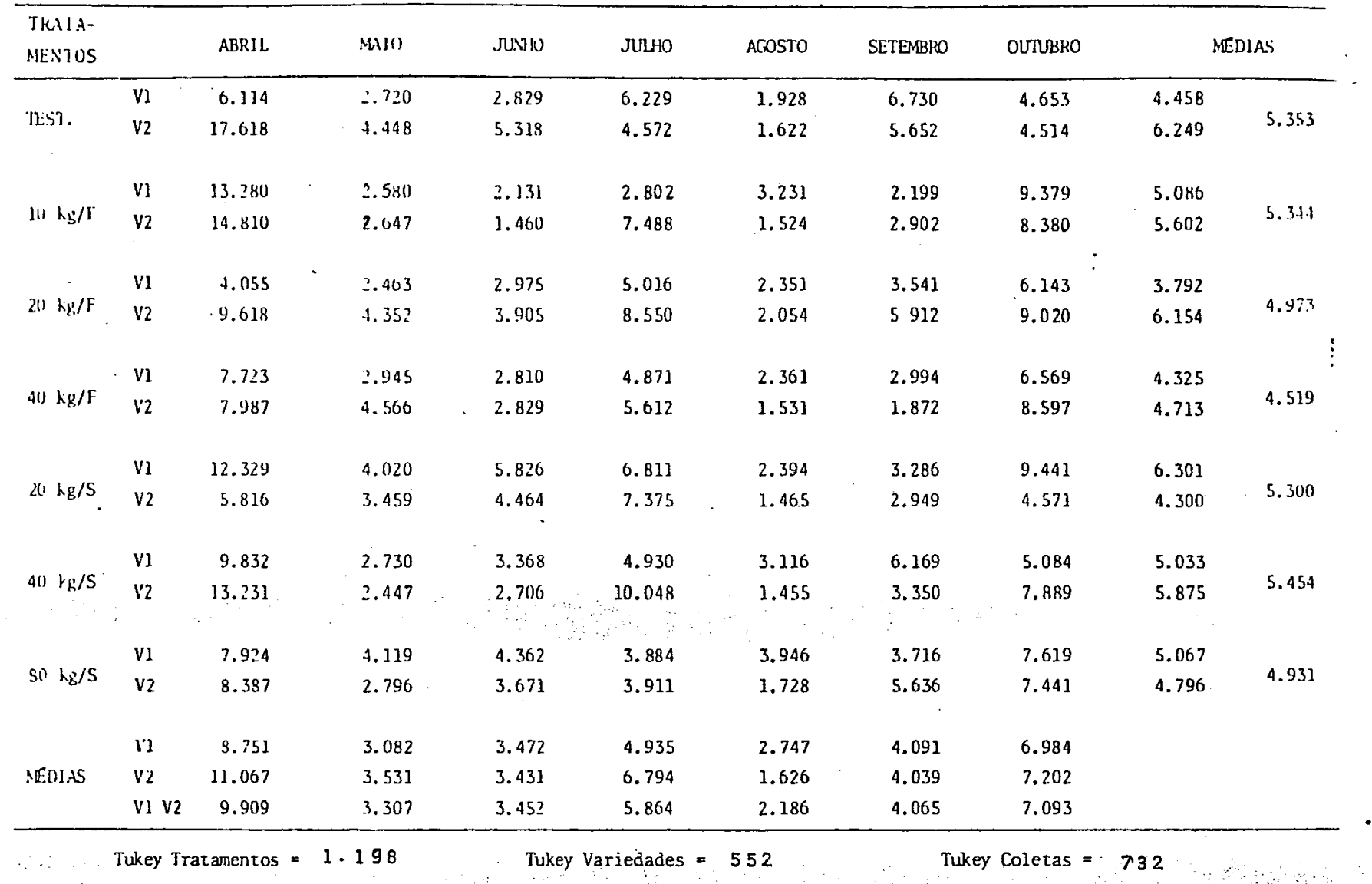

\begin{tabular}{|c|c|c|}
\hline Causa da Variaçāo & GL & $F$ \\
\hline Blocos & 2 & 0,404 \\
\hline Tratamentos & 6 & $3.793 \%$ \\
\hline Resíduo A & 12 & \\
\hline Parcelas & 20 & \\
\hline Variedades & 1 & $28,328 * *$ \\
\hline Interação $T \times V$ & 6 & 30,411 \\
\hline Resíduo B & 14 & \\
\hline Sub-Parcelas & 41 & \\
\hline Coletas & 6 & $481,603 \%$ \\
\hline Interaçāo $T \times C$ & 36 & 20,619 \\
\hline Interaçāo $v \times C$ & 6 & 23,559 \\
\hline Interaçāo $T \times V \times C$ & 36 & 14,965 \\
\hline Resíduo $\mathrm{C}$ & 168 & \\
\hline Total & 293 & \\
\hline
\end{tabular}

$\mathrm{CV}$ (T) 0,216

CV (V) 0,162

CV (C) $0: 154$ 
.98.

TABELA 17 (Continuação) - Valores de sacarose $(\mu \mathrm{g} / \mathrm{g}$ ) em limbos de canas; das variedades IAC 48-65 e IAC 50-14, em LR.

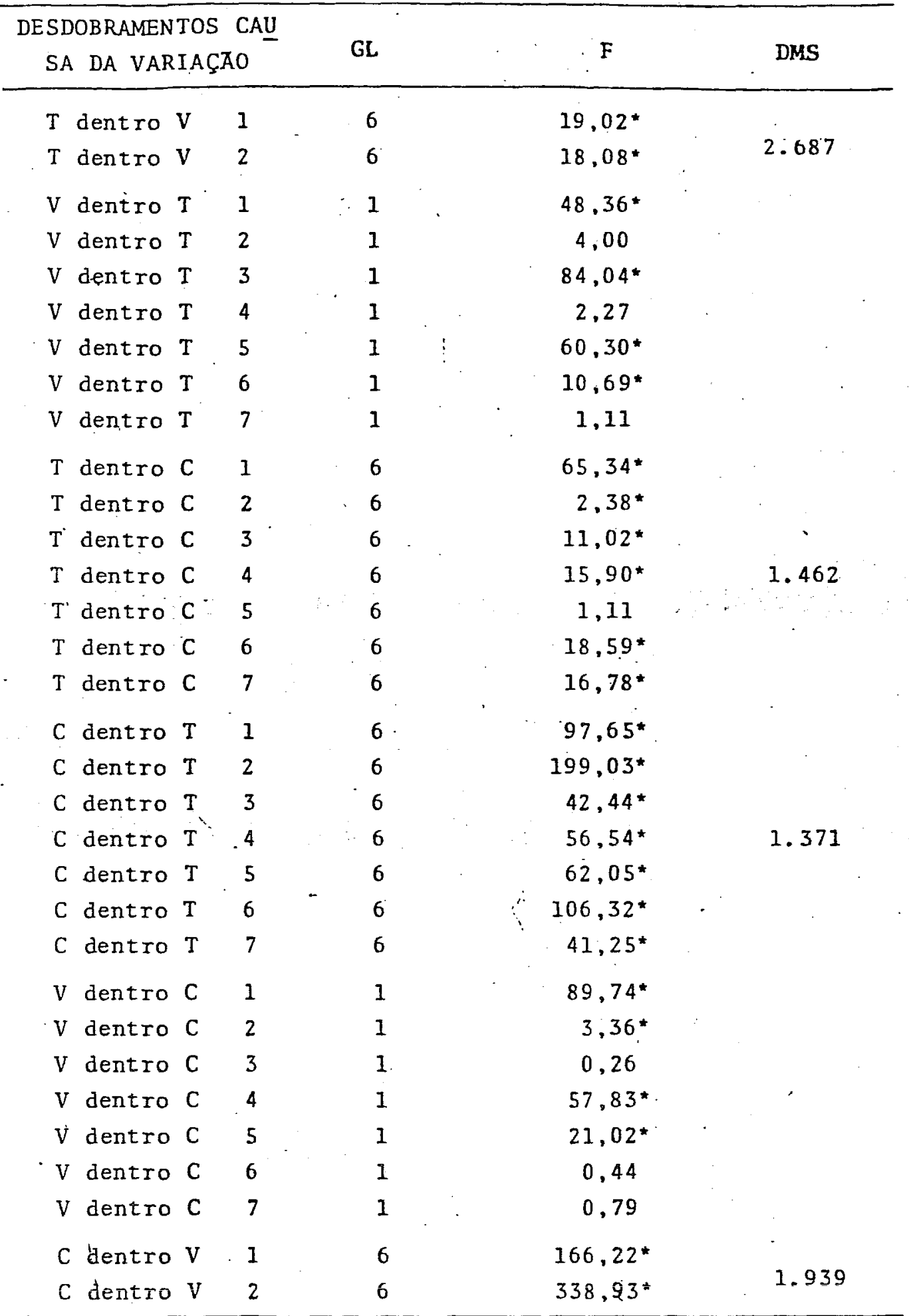


.99 .

TABELA 16 - Valores de sacarose ( $\left(\begin{array}{c}0 \\ 0\end{array}\right)$.em limbos de canas, das variedades IAC 48-65 e IAC 50-14, em LVa.

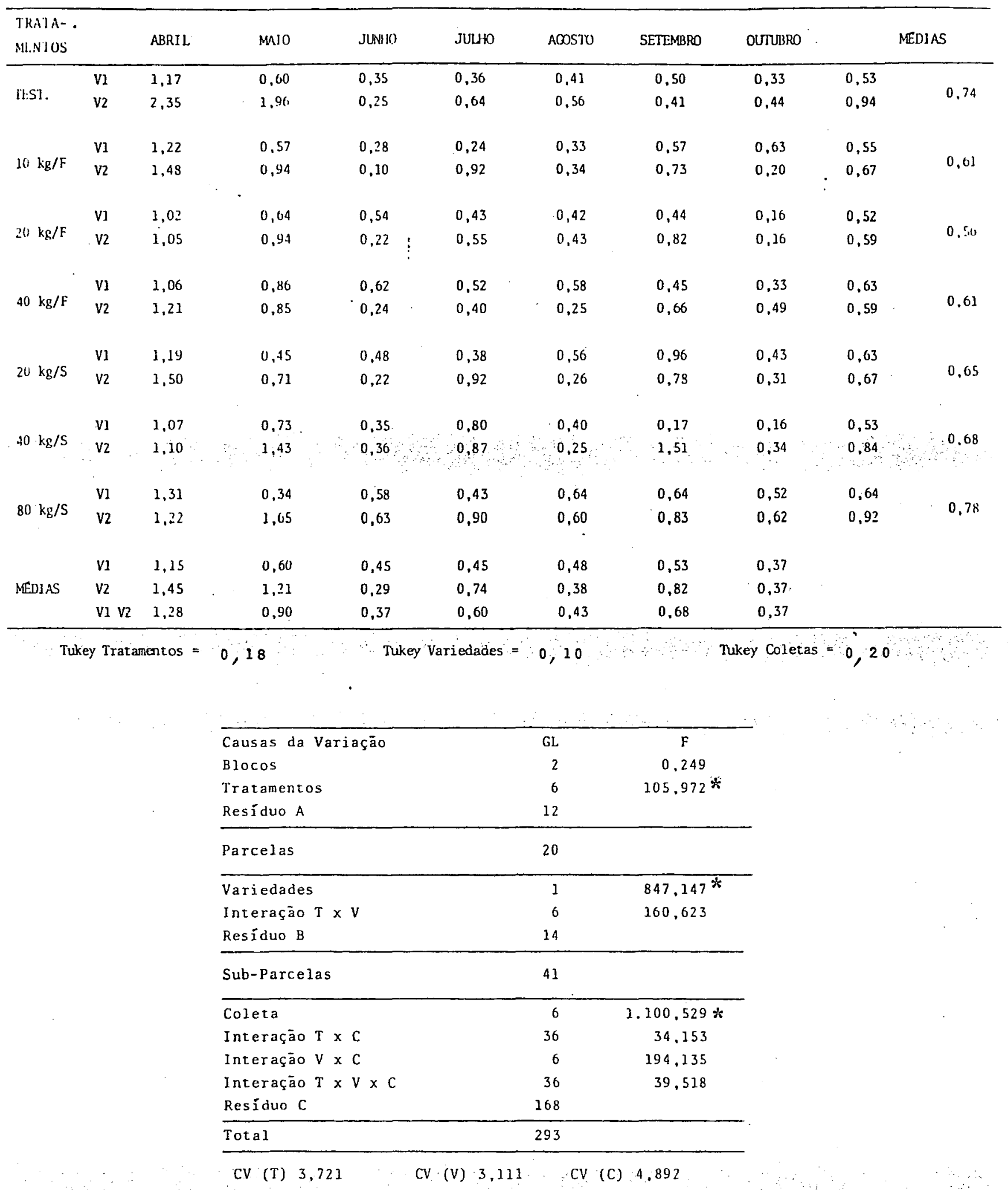


TABELA 18 - Valores de sacarose ( $\left(\frac{0}{0}\right)$. em limbos de canas, das variedades IAC 48-65 e IAC 50-14, em LR.

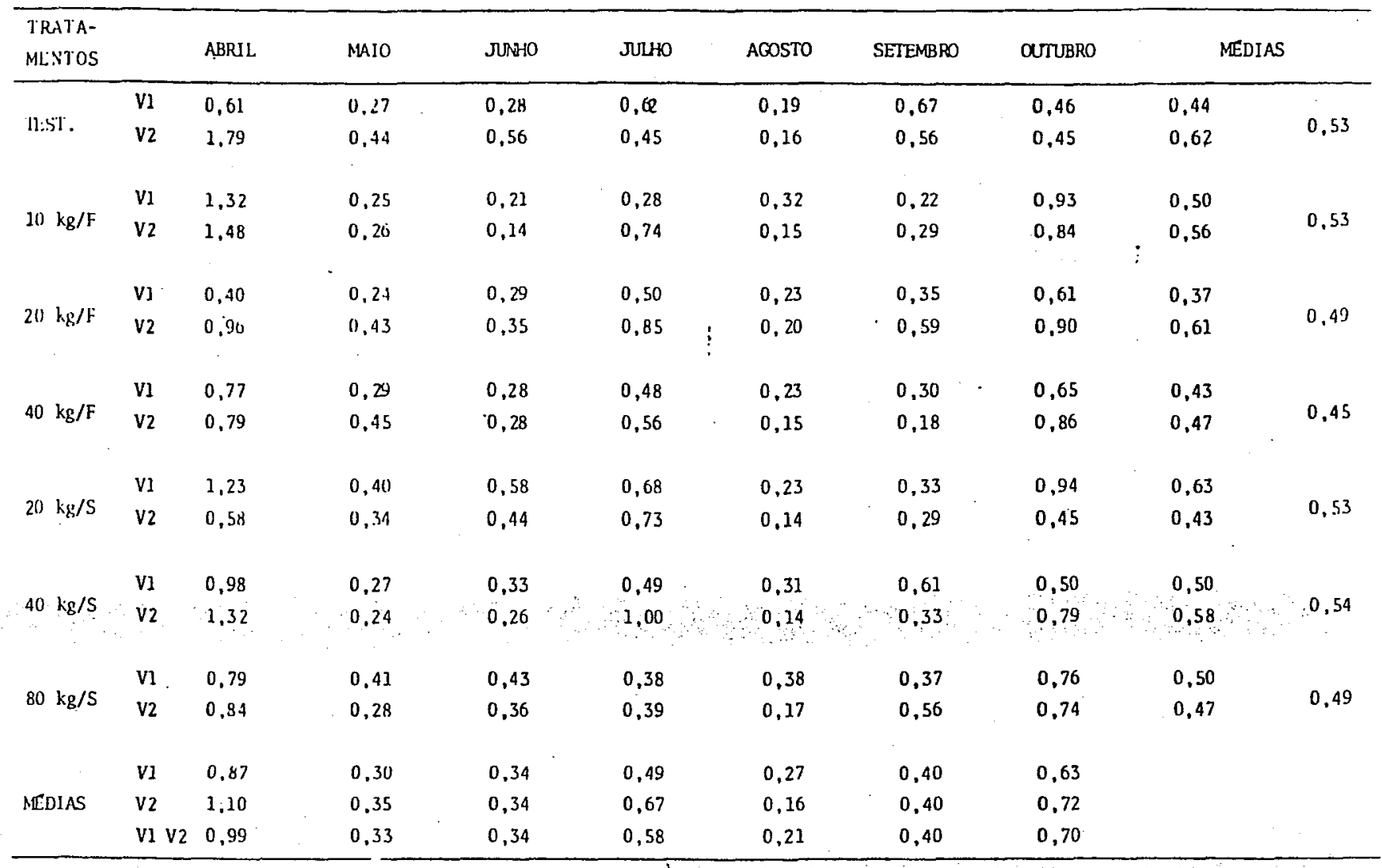

\begin{tabular}{lrc}
\hline Causas da Variação & GL & $\mathrm{F}$ \\
Blocos & 2 & 0,336 \\
Tratamentos & 6 & $3,450 *$ \\
Resíduo A & 12 & \\
\hline Parcelas & 20 & \\
\hline Variedades & 1 & $14,694 *$ \\
Interação T $\times V$ & 6 & 34,692 \\
Residuo B & 14 & \\
\hline Sub-Parcelas & 41 & \\
\hline Coleta & 6 & $475,875 *$ \\
lntcração T $\times \mathrm{C}$ & 36 & 18,564 \\
Interação V $\times \mathrm{C}$ & 6 & 24,433 \\
Interação T $\times \mathrm{V} \times \mathrm{C}$ & 36 & 11,214 \\
Residuo C & 168 & \\
\hline Total & 293 & \\
\hline
\end{tabular}

CV (T) $9.764 \quad C V(V) \&, 2.03 \quad$ CV (C) $7,7.57$


que corresponde a quinta coleta.

Os resultados transformados para porcentagem " de sacarose em limbos, encontram-se na tabela 16 para LVa e na tabela 18 para LR.

Os resultados para bainhas correspondentes a mi crogramas de sacarose, de canas cultivadas em LVa, encontram-se na tabela 19。

A anālise de variância apresenta significāncia' para as variáveis estudadas, com destaque para o tratamento' $40 \mathrm{~kg} / \mathrm{ha}$ via solo, para a primeira coleta, seguida da segunda e para a variedade IAC 48-65. As interações também foram todas significativas, e pelo desdobramento das causas de variação, foram feitas as observações a seguir.

A variação dos tratamentos dentro elas varieda ? des, mostra que na variedade IAC 48-65 destacam-se como os maiores valores os tratamentos $40 \mathrm{~kg} / \mathrm{ha}$ via solo e $20 \mathrm{~kg} / \mathrm{ha}$ ' via foliar e o menor valor no tratamento testemunha; na varie dade IAC 50-14 destaca-se o maior valor no tratamento 40 kg/ ha via solo e o menor no tratamento $20 \mathrm{~kg} / \mathrm{ha}$ via solo. Por outro lado, ao fixar-se os tratamentos, verifica-se que a varieda de IAC 48-65 apresentou maiores médias nos tratamentos 20 e $40 \mathrm{~kg} / \mathrm{ha}$ via foliar e $20 \mathrm{~kg} / \mathrm{ha}$ via solo; e nas demais, prevale ce. a variedade IAC 50-14.

$\mathrm{Na}$ interação tratamentos $\mathrm{x}$ coletas, fixada a co leta, obtiveram-se as seguintes relações: o tratamento $40 \mathrm{~kg} / \mathrm{ha}$ via solo apresenta a maior média na primeira e terceira coleta, onde as menores médias são, respectivamente, as dos trata mentos testemunha e $20 \mathrm{~kg} / \mathrm{ha}$ via solo; na segunda coleta la 
maior mëdia ē apresentada pelo tratamento $40 \mathrm{~kg} / \mathrm{ha}$ via solo, que tambẻm è maior na quarta e quinta coleta; enquanto as menores são dos tratamentos, $40 \mathrm{~kg} / \mathrm{ha}$ via foliar, $80 \mathrm{~kg} / \mathrm{ha}$ e $20 \mathrm{~kg} / \mathrm{ha}$ via solo, respectivamente para segunda, quarta e quinta coleta ; na sexta coleta,a maior média foi do tratamen to $10 \mathrm{~kg} / \mathrm{ha}$ via foliar, acompanhado do $20 \mathrm{~kg} / \mathrm{ha}$ via solo, e a menor do tratamento testemunha; jạ na sétima coleta, destaca ' ram-se os tratamentos $20 \mathrm{~kg} / \mathrm{ha}$ via solo of $40 \mathrm{~kg} / \mathrm{ha}$ via foliar; como a maior e menor média. Fixados os tratamentos, o compor tamento é mais uniforme, com as melhores médias sendo obtidas na segunda coleta,para os tratamentos testemunha e $40 \mathrm{~kg} / \mathrm{ha}$ ' via solo, e aparecendo nos demais tratamentos, a primeira coleta; as menores médias ocorreram na sétima coleta em todos os tratamentos.

No desdobramento da interaçāo variedade $\mathrm{x}$ coletas, quando fixada a coleta, verifica-se que a variedade IAC 50-14 predomina na segunda, quinta e sétima coleta, enquanto nas outras predomina a IAC 48-65; fixada a variedade, notam ' - se as maiores médias para a primeira coleta na variedade IAC 48-65, para segunda coleta na variedade IAC 50-14; as menores' médias foram na sétima coleta,para as duas variedades.

Para canas cultivadas em LR, foram obtidos os resultados constantes da tabela 21 .

Verifica-se significância, na anâlise de variân cia, para todas as variáveis estudadas, destacando-se como me lhores médias, os tratamentos testemunha e $10 \mathrm{~kg} / \mathrm{ha}$ via foliar, 
TABELA 19 - Valores de sacarose $(\mu \mathrm{g} / \mathrm{g})$ em bainhas de canas, das variedades IAC 48-65 e IAC 50-14 em LVa.

\begin{tabular}{|c|c|c|c|c|c|c|c|c|c|c|}
\hline $\begin{array}{l}\text { TRATA- } \\
\text { ME:VIOS }\end{array}$ & & ABRIL & MHIO & Ju:310 & JULHO & ACOSTO & SETEMBPD & OMUkKO & \multicolumn{2}{|c|}{ MEDIAS } \\
\hline \multirow{2}{*}{ ก:5T. } & v1 & 25.644 & $i .1135$ & 0.772 & 6.235 & 4.793 & 12.910 & 4.947 & $y .715$ & \multirow{2}{*}{34.145} \\
\hline & $\mathrm{v} 2$ & 17.365 & 39.1133 & 6.305 & 8.267 & 13.877 & 10.238 & 6.279 & 14.575 & \\
\hline \multirow[b]{2}{*}{$10 \mathrm{~kg} / \mathrm{F}$} & $\mathrm{Vl}$ & 33.057 & 12.5688 & 2.216 & 7.948 & 4.257 & 19.024 & 2.139 & 11.604 & \multirow[b]{2}{*}{12.519} \\
\hline & $v_{2}$ & 20.231 & $\therefore 5.916$ & 6.503 & 4.502 & 17.524 & 13.822 & 5.551 & 13.435 & \\
\hline \multirow[b]{2}{*}{$201 \mathrm{~kg} / \mathrm{F}$} & $v_{1}$ & 40.533 & $3 \ldots 1] 4$ & 9.914 & 9.116 & 9.553 & 16.945 & 2.859 & 16.433 & \multirow[b]{2}{*}{14.136} \\
\hline & v2 & 20.881 & 20.815 & 1.754 & 5.306 & 11.780 & 12.510 & 3.833 & 11.840 & \\
\hline \multirow[b]{2}{*}{$40 \mathrm{~kg} / \mathrm{F}$} & v1 & 39.958 & 16.789 & 8.805 & 8.587 & 9.509 & 15.308 & 1.031 & 14.284 & \multirow[b]{2}{*}{12.710} \\
\hline & $v_{2}$ & 28.328 & 15.600 & 7.617 & 3.575 & 10.990 & 10.005 & 1.845 & 11.137 & \\
\hline \multirow[b]{2}{*}{$20 \mathrm{~kg} / \mathrm{s}$} & $\mathrm{V} I$ & 20.640 & 20.923 & 4.167 & 8.698 & 6.147 & 15.310 & 6.611 & 12.638 & \multirow[b]{2}{*}{11.516} \\
\hline & $v_{2}$ & 20.312 & 13.662 & 4.134 & 2.499 & 8.063 & 17.488 & 6.607 & 10.395 & \\
\hline \multirow[b]{2}{*}{$40 \mathrm{~kg} / \mathrm{s}$} & VI & 38.952 & 33.471 & 5.382 & 9.740 & 13.217 & 13.472 & 1.400 & 16.520 & \multirow[b]{2}{*}{17.030} \\
\hline &.$v_{2}$ & 28.407 & 37.294 & 10.066 & $8.267^{\circ}$ & 20.035 & 15.874 & 2.916 & 17.551 & \\
\hline \multirow[b]{2}{*}{ j0 $\mathrm{hg} / \mathrm{S}$} & V1 & 38.773 & 18.789 & 10.228 & 3.249 & 6.255 & 13.433 & 2.832 & 13.366 & \multirow{2}{*}{13.562} \\
\hline & $v_{2}$ & 25.217 & 18.587 & 5.517 & 6.850 & 18.279 & 13.566 & 8.298 & 13.759 & \\
\hline \multirow{3}{*}{ MEDIAS } & $v_{1}$ & 34.794 & 19.384 & 6.783 & 7.649 & 7.676 & 15.153 & 3.120 & & \\
\hline & $v_{2}$ & 22.963 & 25.358 & 5.994 & 5.610 & 14.364 & 13.358 & 5.047 & & \\
\hline & $\mathrm{V}_{1} \mathrm{v}_{2}$ & 28.878 & 22.371 & 6.389 & 6.629 & 11.020 & 14.255 & 4.083 & & \\
\hline
\end{tabular}

\begin{tabular}{|c|c|c|}
\hline Causas da Variação & $\mathrm{GL}$ & $\mathbf{F}$ \\
\hline$B 10 \cos$ & 2 & 0,539 \\
\hline Trat amentos & 6 & $551,545 \%$ \\
\hline Resíduo A & 12 & \\
\hline Parcelas & 20 & \\
\hline Variedades & 1 & $16.718 *$ \\
\hline Interaçāo $T \times V$ & 6 & 356,616 \\
\hline Resíduo B & 14 & \\
\hline Sub-Parcelas & 41 & \\
\hline Coleta & 6 & $13.029 .668^{\text {* }}$ \\
\hline Interação $\mathrm{T} \times \mathrm{C}$ & 36 & 248.895 \\
\hline Interaçāo $V \times C$ & 6 & 1.484 .448 \\
\hline Interação $T \times V \times C$ & 36 & 178.014 \\
\hline Resíduo C & 168 & \\
\hline Total & 293 & \\
\hline
\end{tabular}

CV (T) $3.781 \quad C V(V) 4.181 \quad \therefore C V$ (V) 3.906 
TABELA 19 (Continuação) - Valores de sacarose ( $\mu \mathrm{g} / \mathrm{g}$ ) em bainhas de canas, das variedades IAC 48-65 e IAC 50-14, em LVa.

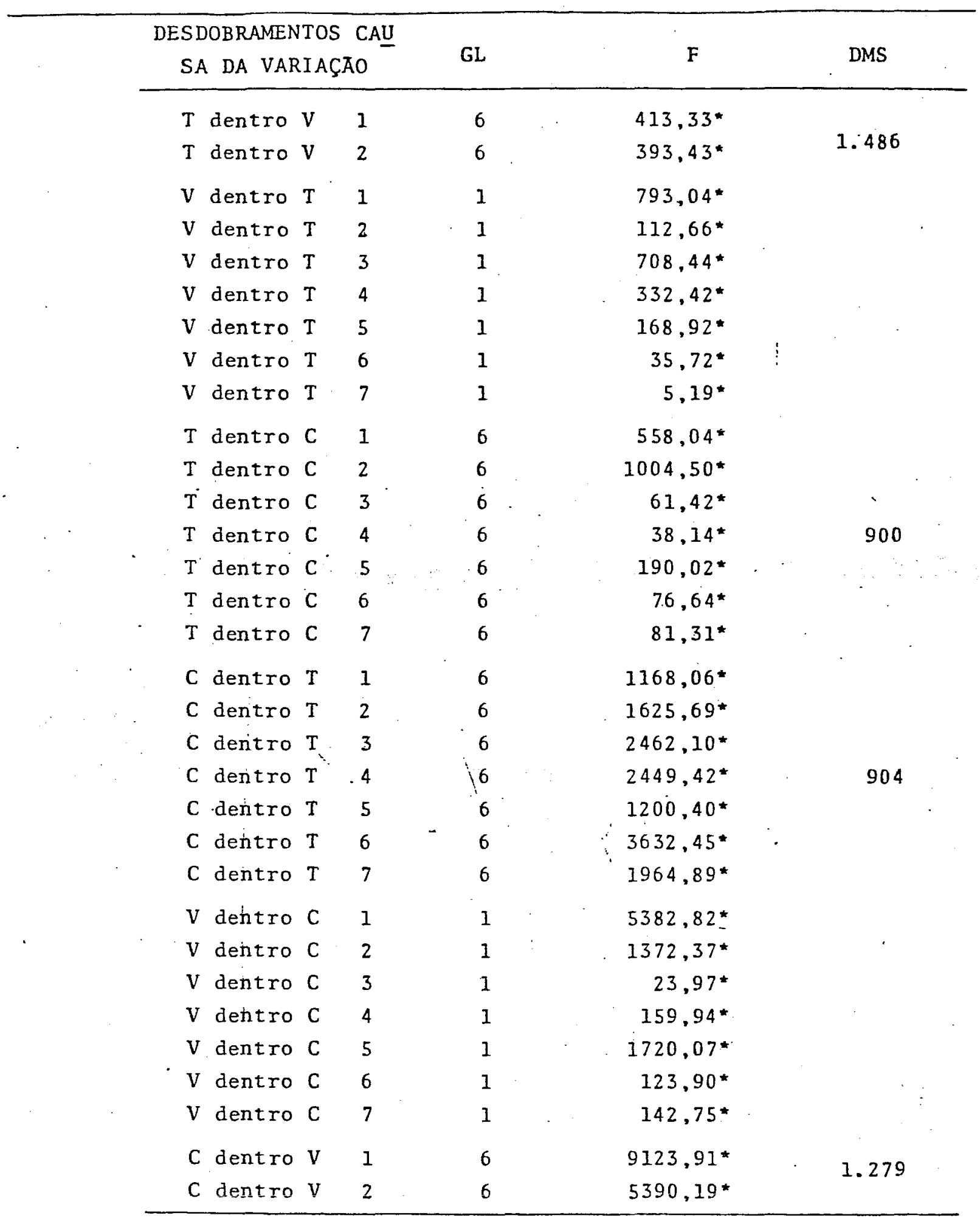


a quarta e sexta coleta e a variedade IAC 50-14. Tambëm nes te caso, ocorreram significâncias nas interações, que permi..' tem as observaçōes descritas a seguir.

Do desdobramento da interação tratamentos $\mathrm{x}$ vá' riedades, fixadas as variedades, verificou-se que a melhor mé dia è do tratamento $10 \mathrm{~kg} / \mathrm{ha}$ via foliar e a menor do tratamen to $40 \mathrm{~kg} / \mathrm{ha}$ via solo para a variedade IAC $48-65$, enquanto que no IAC 50-14 a maior média ocorreu ho tratamento testemunha e as menores nos tratamentos $80 \mathrm{~kg} / \mathrm{ha}$ via solo e $20 \mathrm{~kg} / \mathrm{ha}$ via' foliar. Ao fịxar-se os tratamentos, verifica-se que nāo ocor reu significância nos tratamentos $10 \mathrm{e} 20 \mathrm{~kg} / \mathrm{ha}$ via foliar e no $80 \mathrm{~kg} / \mathrm{ha}$ via solo, enquanto nos demais a variedade IAC 50-14 superou a IAC 48-65.

Para a interação coletas $x$ tratamentos, foram ' feitas as seguintes constatações, ao se fixar coletas: não houve significância na quinta coleta; nas três primeiras cole tas, a maior média foi da testemunha, enquanto as piores foram respectivamente, da primeira à terceira, os tratamentos 80 e $20 \mathrm{~kg} / \mathrm{ha}$ via solo e $20 \mathrm{~kg} / \mathrm{ha}$ via foliar; o tratamento $10 \mathrm{ka} / \mathrm{ha}$ via foliar apresentou o maior teor na quarta e sétima coleta, com os menores teores nos tratamentos 40 e $20 \mathrm{~kg} / \mathrm{ha}$ via solo; na sexta coleta, o maior valor foi do tratamento $20 \mathrm{~kg} / \mathrm{ha}$ via solo e o menor $80 \mathrm{~kg} / \mathrm{ha}$ via solo. Fixando-se os tratamentos, nota-se predominância da primeira coleta como maior média e da quinta com a menor no tratamento testemunha; no tratamento $10 \mathrm{~kg} / \mathrm{ha}$ via foliar,bem como no $80 \mathrm{~kg} / \mathrm{ha}$ via solo, as 
TABELA 21 - Valores de sacarose $(\mu \mathrm{g} / \mathrm{g})$ em bainhas de canas, das variedades IAC 48-65 e IÁC 50-14, em LR.

\begin{tabular}{|c|c|c|c|c|c|c|c|c|c|c|}
\hline $\begin{array}{l}\text { TRATA- } \\
\text { MENTOS }\end{array}$ & & ABRIL & MA10 & JRN 10 & ЈULHO & ACOSTO & SETEMBRO & OUTUHPO & \multicolumn{2}{|c|}{ MEDIAS } \\
\hline \multirow{2}{*}{ TEST. } & V1 & 5.920 & 2.676 & 12.118 & 8.550 & 2.459 & 4.877 & 8.056 & 6.380 & \multirow{2}{*}{7.202} \\
\hline & $v_{2}$ & 14.019 & 7.434 & 6.356 & 5.673 & 3.513 & 13.637 & 5.544 & 8.025 & \\
\hline \multirow[b]{2}{*}{$10 \mathrm{~kg} / \mathrm{F}$} & V1 & 6.407 & 3.148 & 4.080 & 14.869 & 3.338 & 7.522 & 9.781 & 7.021 & \multirow{2}{*}{7.146} \\
\hline & $v_{2}$ & 8.651 & 3.396 & 7.788 & 9.860 & 3.665 & 10.607 & 6.934 & 7.727 & \\
\hline \multirow[b]{2}{*}{$20 \mathrm{~kg} / \mathrm{F}$} & V1 & 9.919 & 3.218 & 2.421 & 12.196 & 2.149 & 7.209 & 7.612 & 6.388 & \multirow[b]{2}{*}{6.388} \\
\hline & $v_{2}$ & 4.446 & 4.604 & 5.483 & 10.204 & 4.232 & 10.177 & 5.577 & 6.389 & \\
\hline \multirow[b]{2}{*}{$40 \mathrm{~kg} / \mathrm{F}$} & $v 1$ & 7.468 & 3.417 & 7.052 & 8.765 & 3.223 & 7.444 & 5.165 & 6.080 & \multirow[b]{2}{*}{6.380} \\
\hline & $v_{2}$ & 11.655 & 3.366 & .4 .706 & 6.449 & 3.872 & 10.539 & 6.181 & 6.681 & \\
\hline \multirow{2}{*}{$20 \mathrm{~kg} / \mathrm{s}$} & $V 1$ & 9.925 & 922 & 4.111 & 13.211 & 2.393 & 9.729 & 4.266 & 6.365 & \multirow{2}{*}{6.796} \\
\hline & V2 & 9.222 & 2.630 & 4.700 & 9.031 & 5.412 & 14.710 & 4.875 & 7.226 & \\
\hline \multirow[b]{2}{*}{$40 \mathrm{~kg} / \mathrm{S}$} & V1 & 5.018 & 1.067 & 6.558 & 5.420 & 2.594 & 8.966 & 5.611 & 5.033 & \multirow[b]{2}{*}{5.862} \\
\hline & $v_{2}$ & 7.728 & 3.186 & 3.917 & 9.115 & 4.609 & 12.016 & 6.268 & 6.691 & \\
\hline \multirow[b]{2}{*}{$80 \mathrm{~kg} / \mathrm{S}$} & V1 & 5.101 & 4.334 & 6.442 & 11.803 & 2.773 & 5.348 & 9.427 & 6.384 & \multirow{2}{*}{6.358} \\
\hline & $v_{2}$ & 3.739 & 3.784 & 6.420 & 9.055 & 6.078 & 9.783 & 5.459 & 6.331 & \\
\hline \multirow{3}{*}{ MEUIAS } & $V 1$ & 7.108 & 2.606 & 6.112 & 10.688 & 2.704 & 7.298 & 7.134 & & \\
\hline & $v_{2}$ & 8.494 & 4.057 & 5.624 & 8.484 & 4.483 & 11.638 & 5.834 & & \\
\hline & V1 V2 & 7.801 & 3.331 & 5.868 & 9.586 & 3.594 & 9.468 & 6.484 & & \\
\hline
\end{tabular}

\begin{tabular}{|c|c|c|}
\hline Causas da Variaçāo & GL & $F$ \\
\hline Blocos & 2 & 0,982 \\
\hline Tratamentos & 6 & $14.510 *$ \\
\hline Resíduo A & 12 & \\
\hline Parcelas & 20 & \\
\hline Variedades & 1 & $35,677 *$ \\
\hline Interaçāo $T \times V$ & 6 & 5,241 \\
\hline Resíduo B & 14 & \\
\hline Sub-Parcelas & 41 & \\
\hline Coletas & 6 & $227.873 \%$ \\
\hline Interação $T \times C$ & 36 & 12,977 \\
\hline Interaçāo $v \times C$ & 6 & 42,956 \\
\hline Interaçāo $\mathrm{T} \times \mathrm{V} \times \mathrm{C}$ & 36 & 9,898 \\
\hline Residuo $\mathrm{C}$ & 168 & \\
\hline Total & 293 & \\
\hline
\end{tabular}

$\mathrm{CV}$ (T) $0,124 \quad \cdots \mathrm{CV}$ (V) $0,154 \quad \mathrm{CV}$ (C) 0,165


.107.

TABELA 21 (Continuaçāo) - Valores de sacarose $(\mu \mathrm{g} / \mathrm{g}$ ) em bainhas de canas, das variedades IAC 48-65 e IAC 50-14 em LR.

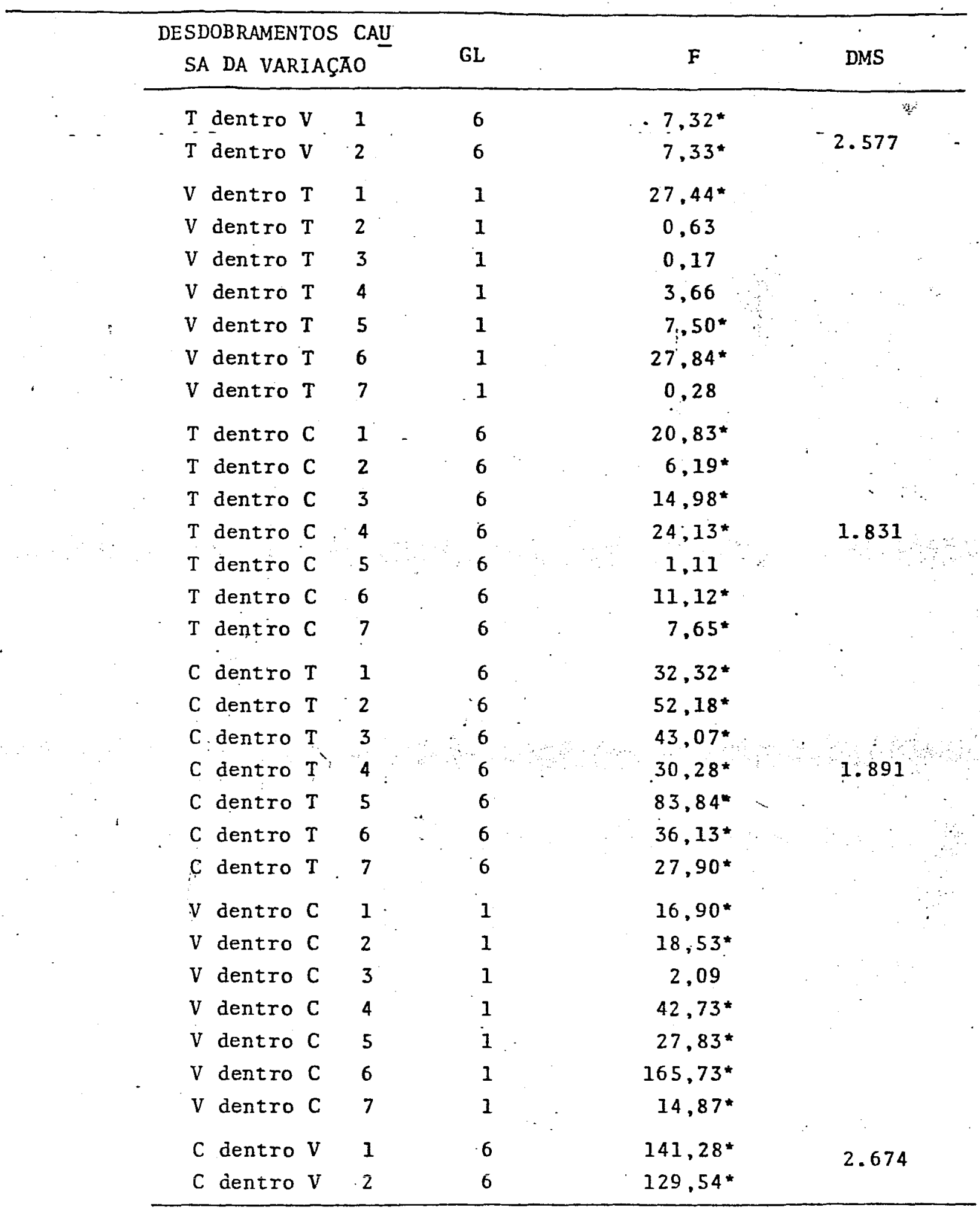


TABELA 20 - Valores de sacarose $(\stackrel{\circ}{0})$ em bainhas de canas, das variedades IAC 48-65 e IAC 50-14, em LVa.

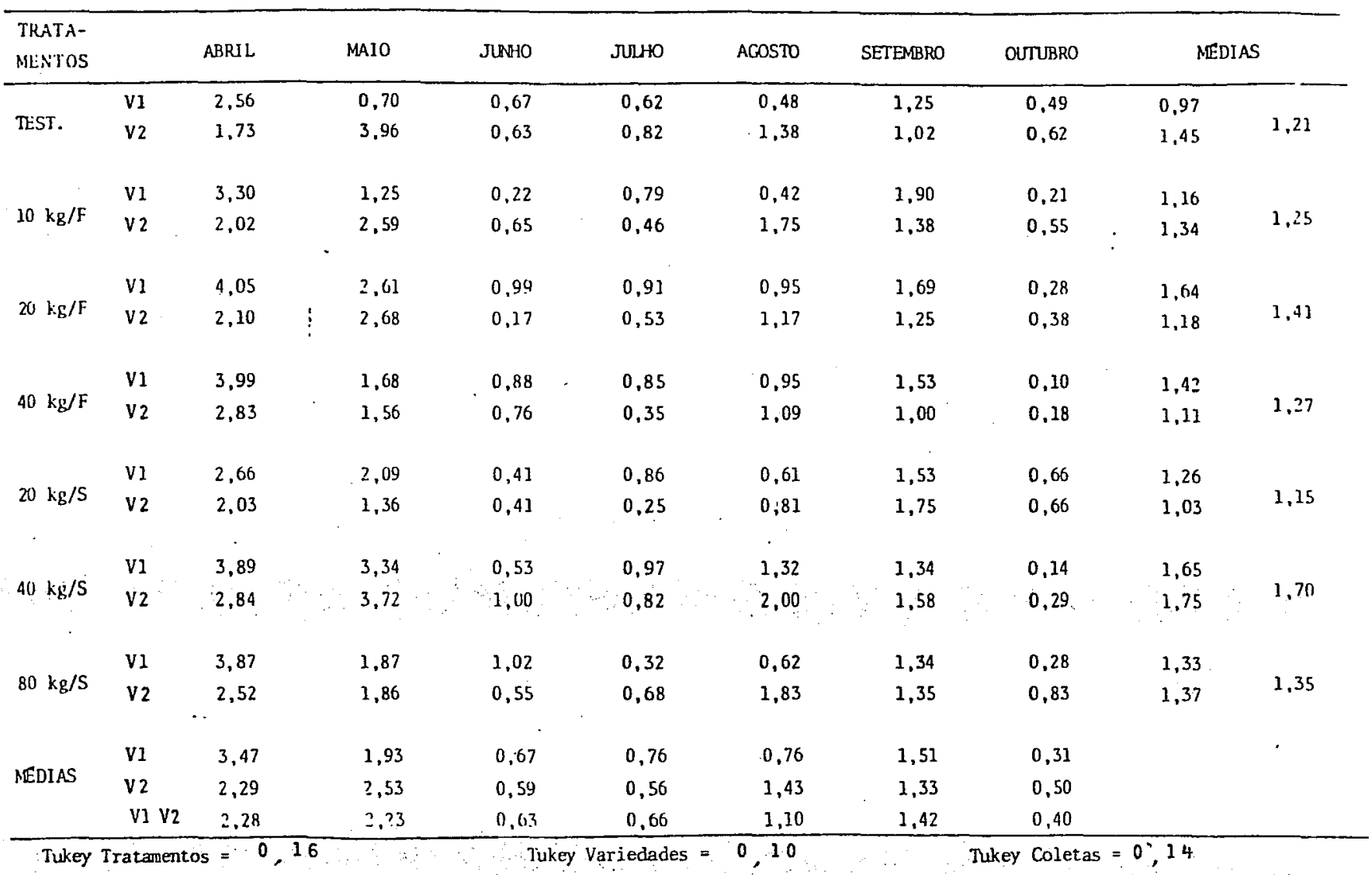

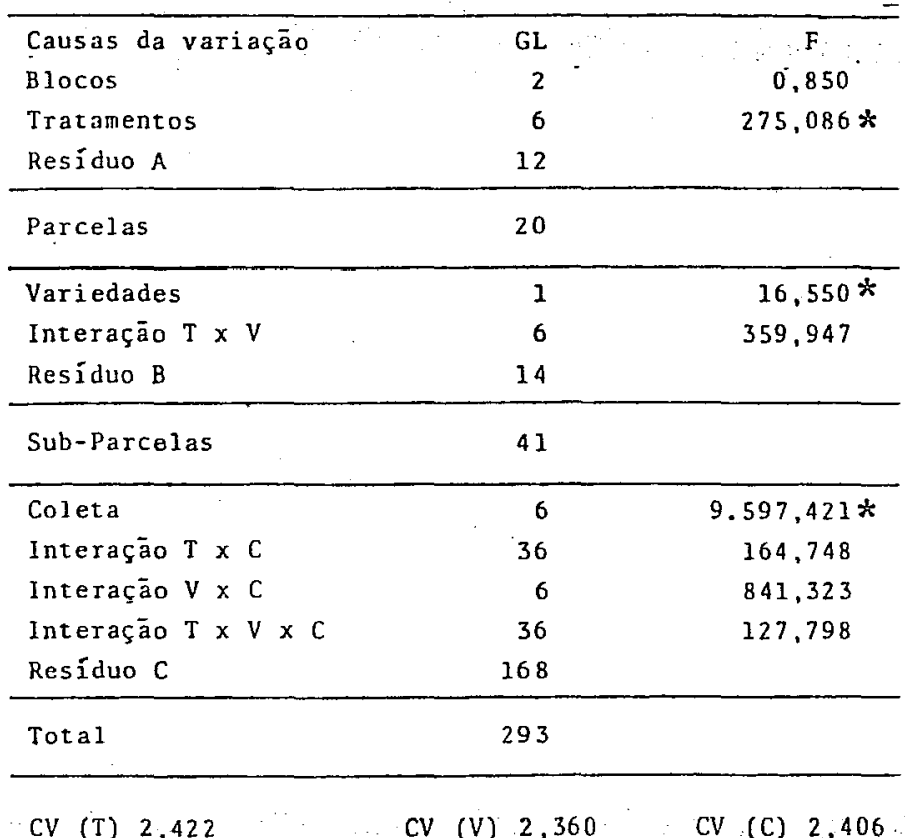


TABElA 22 - Valores de sacarose $(\stackrel{0}{0})$ em bainhas de canas, das variedades IAC 48-65 e IAC 50-14, em LR.

\begin{tabular}{|c|c|c|c|c|c|c|c|c|c|c|}
\hline $\begin{array}{l}\text { IRTA- } \\
\text { MLNIOS }\end{array}$ & & ABRIL & MAIO & $J N H$ & JULHO & ACOSTO & SETEMBRO & QUTUBRO & & MEDIAS \\
\hline \multirow{2}{*}{ TEST. } & $\mathrm{V} 1$ & 0.59 & 0.27 & 1,21 & 0,85 & 0,24 & 0,48 & 0,80 & 0.63 & \multirow{2}{*}{0.72} \\
\hline & v2 & 1,40 & 0.74 & 0.63 & 0,56 & 0,35 & 1,36 & 0,55 & 0,80 & \\
\hline \multirow[b]{2}{*}{$10 \mathrm{~kg} / \mathrm{F}$} & v1 & 0,64 & 0.31 & 0.40 & 1,48 & 0,33 & 0,75 & 0,97 & 0,70 & \multirow[b]{2}{*}{0,71} \\
\hline & v2 & 0,86 & 0.33 & 0.78 & 0,98 & 0,36 & 1,06 & 0,69 & 0,77 & \\
\hline \multirow[b]{2}{*}{$20 \mathrm{~kg} / \mathrm{F}$} & $\mathrm{v}$ & 0,99 & 0,32 & 0,24 & 1,22 & 0,21 & 0,72 & 0,76 & 0.63 & \multirow[b]{2}{*}{0,63} \\
\hline & $v_{2}$ & $\dot{0}, 44$ & 0,46 & 0,55 & 102 & 0,42 & 1,05 & 0,55 & 0.63 & \\
\hline \multirow[b]{2}{*}{$40 \mathrm{~kg} / \mathrm{F}$} & $\mathrm{v}$ & 0,74 & 0,34 & 0,70 & 0,87 & 0,32 & 0.74 & 0,52 & 0,60 & \multirow[b]{2}{*}{0,63} \\
\hline & $v_{2}$ & 1,16 & 0,33 & 0,47 & 0.64 & 0,38 & 1,05 & 0,61 & 0,66 & \\
\hline \multirow[b]{2}{*}{$20 \mathrm{~kg} / \mathrm{F}$} & VI & 1,02 & 0,09 & 0,41 & 1.32 & 0,23 & 0.97 & 0,42 & 0,63 & \multirow[b]{2}{*}{0.67} \\
\hline & v2 & 0,92 & 0.26 & 0,47 & 0,90 & 0.54 & 1,46 & 0.49 & 0,72 & \\
\hline \multirow[b]{2}{*}{$40 \mathrm{~kg} / \mathrm{F}$} & v1 & 0,50 & 0,11 & 0,65 & 0,54 & 0,26 & 0,89 & 0,56 & 0,50 & \multirow[b]{2}{*}{0,58} \\
\hline & v2 & 0,77 & 0,31 & 0,39 & 0,91 & 0,46 & 1,19 & 0,62 & 0,66 & \\
\hline \multirow[b]{2}{*}{$80 \mathrm{~kg} / \mathrm{F}$} & $\mathrm{v} 1$ & 0,51 & 0,38 & 0,64 & 1,17 & 0,27 & 0,53 & 0,94 & 0.63 & \multirow{2}{*}{0.63} \\
\hline & v2 & 0,36 & 0,39 & 0,65 & 0,88 & 0,61 & 0,99 & 0,53 & 0,63 & \\
\hline \multirow{3}{*}{ MEDIAS } & $v 1$ & 0,71 & 0,20 & 0,61 & 1,06 & 0,27 & 0,72 & 0,71 & & \\
\hline & v2 & 0,84 & 0.40 & 0,56 & 0.84 & 0,44 & 1,16 & 0,58 & & \\
\hline & V1 V2 & 0,78 & $0,33$. & 0,58 & 0,95 & 0,35 & 0,94 & 0.64 & & \\
\hline \multicolumn{11}{|c|}{ Tukey Coletas $=0,32$} \\
\hline & & & Causas da Var & i açāo & & $\mathrm{GL}$ & $\mathrm{F}$ & & & \\
\hline & & & Blocos & & & 2 & 0,221 & & & \\
\hline & & & Tratamentos & & & 6 & $16.915 *$ & & & \\
\hline & & & Residuo A & & & 12 & & & & \\
\hline & & & Parcelas & & & 20 & & & & \\
\hline & & & Variedades & & & 1 & $68,160^{\frac{1}{x}}$ & & & \\
\hline & & & Interaçāo $T x$ & v & & 6 & 5,762 & & & \\
\hline & & & Resíduo B & & & 14 & & & & \\
\hline & & & Sub-Parcelas & & & 41 & . & & & \\
\hline & & & Coleta & & & 6 & $303.720 *$ & & & \\
\hline & & & Interaçāo $T x$ & C & & 36 & 15.252 & & & \\
\hline & & & Interaçāo $V x$ & $\mathrm{C}$ & & 6 & 43,368 & & & \\
\hline & & & Interaçāo $T x$ & $V \times C$ & & 36 & 11,541 & & & \\
\hline & & & Residuo C & & & 168 & & & & \\
\hline & & & Total & & & 293 & & & & \\
\hline & & & $\mathrm{CV}$ (T) 5,650 & & $\mathrm{CV}$ (V) 7,201 & $\mathrm{CV}(\mathrm{C})$ & $7.74]$ & & & \\
\hline
\end{tabular}


maiores médias foram da quarta coleta e as menores da segunda; no tratamento $20 \mathrm{~kg} / \mathrm{ha}$ via foliar o maior teor foi também da quarta coleta, mas o menor foi da quinta; a primeira coleta' föi maior no tratamento $40 \mathrm{~kg} / \mathrm{ha}$ via foliar, que teve o menor valor na segunda; finalmente,nos tratamentos 20 e $40 \mathrm{~kg} / \mathrm{ha}$, via solo, as maiores médias foram da sexta coleta e as meno. res da segunda.

$\mathrm{Na}$ interaçāo variedades $\mathrm{x}$ coletas, fixada a co-

leta,verifica-se que não ocorreu significância na terceira co leta, enquanto na quarta e sétima coleta as maiores médias' são da IAC 48-65, e nas demais coletas, predomina a IAC 50-14. Fixando-se as variedades, verifica-se a maior média na quarta coleta e a menor na segunda, para a variedade IAC 48-65; na IAC 50-14 a maior foi da sexta coleta e a menor da segunda.

os resultados transformados para porcentagem de sacarose, em bainhas de canas cultivadas em LVa encontram-se na tabela 20 , e na tabela 22 , para as canas plantadas em LR.

Os resultados para colmos, da porcentagem de sacarose em LVa, encontram-se na tabela 23. Da análise de va riância, depreende-se que não existem diferenças significativas entre tratamentos e variedades, só ocorrendo como o esperado, diferenças significativas entre coletas, com os maiores valores ocorrendo no final do ciclo, tendo pico na sexta cole ta, e o menor na primeira coleta. 
Tambēm não foram verificadas significâncias pa$\mathrm{ra}$ as interações, mas no intuito de se determinar tendências, com diferenças mínimas de $0,5^{\circ}$, procedeu-se ao desdobramento' das causas de variação, que depois de analisadas apontaram as observações abaixo descritas.

Fixando a variedade, na interação tratamentos $x$ coletas, verifica-se que os tratamentos tiveram diferentes com portamentos, embora não significativos nas duas variedades . $\mathrm{Na}$ IAC 48-65, as melhores médias gerais foram da testemunha e do tratamento $20 \mathrm{~kg} / \mathrm{ha}$ via solo, enquanto os tratamentos folí ares apresentaram as menores mëdias; mas na IAC 50-14, 'trës' tratamentos se aproximam ${ }_{G}$ a seguinte ordem: testemunha, 20 $\mathrm{kg} / \mathrm{ha}$ via foliar e $20 \mathrm{~kg} / \mathrm{ha}$ via solo, como as de maior média, enquanto a menor média foi do tratamento $40 \mathrm{~kg} / \mathrm{ha}$ via foliar, repetindo o comportamento da outra variedade. Fixando-se o tratamento, verifica-se diferença maior que $0,5 \%$, apenas no tratamento $20 \mathrm{~kg} / \mathrm{ha}$ via foliar, com predominância da IAC 50-14. Para a interação tratamentos x coletas, fixando - se as coletas, não se verifica nenhuma significância;: no entanto, a testemunha desponta com a maior média na primeira,tex ceira e sétima coleta. 0 tratamento $20 \mathrm{~kg} / \mathrm{ha}$ via solo aparece como o melhor na segunda e quinta coleta, acompanhando o $40 \mathrm{~kg} / \mathrm{ha}$ via solo na quarta, restando a sexta coleta, em que não existe destaque. Fixando-se os tratamentos, no tam-se valores crescentes da primeira até a quinta coleta, com significâncias em todos os tratamentos, com os teores má- 
TABELA 23 - Valores de sacarose $\left(\frac{0}{0}\right)$ em colmos de canas, das variedades IAC 48-65 e IAC 50-14, em LVa.

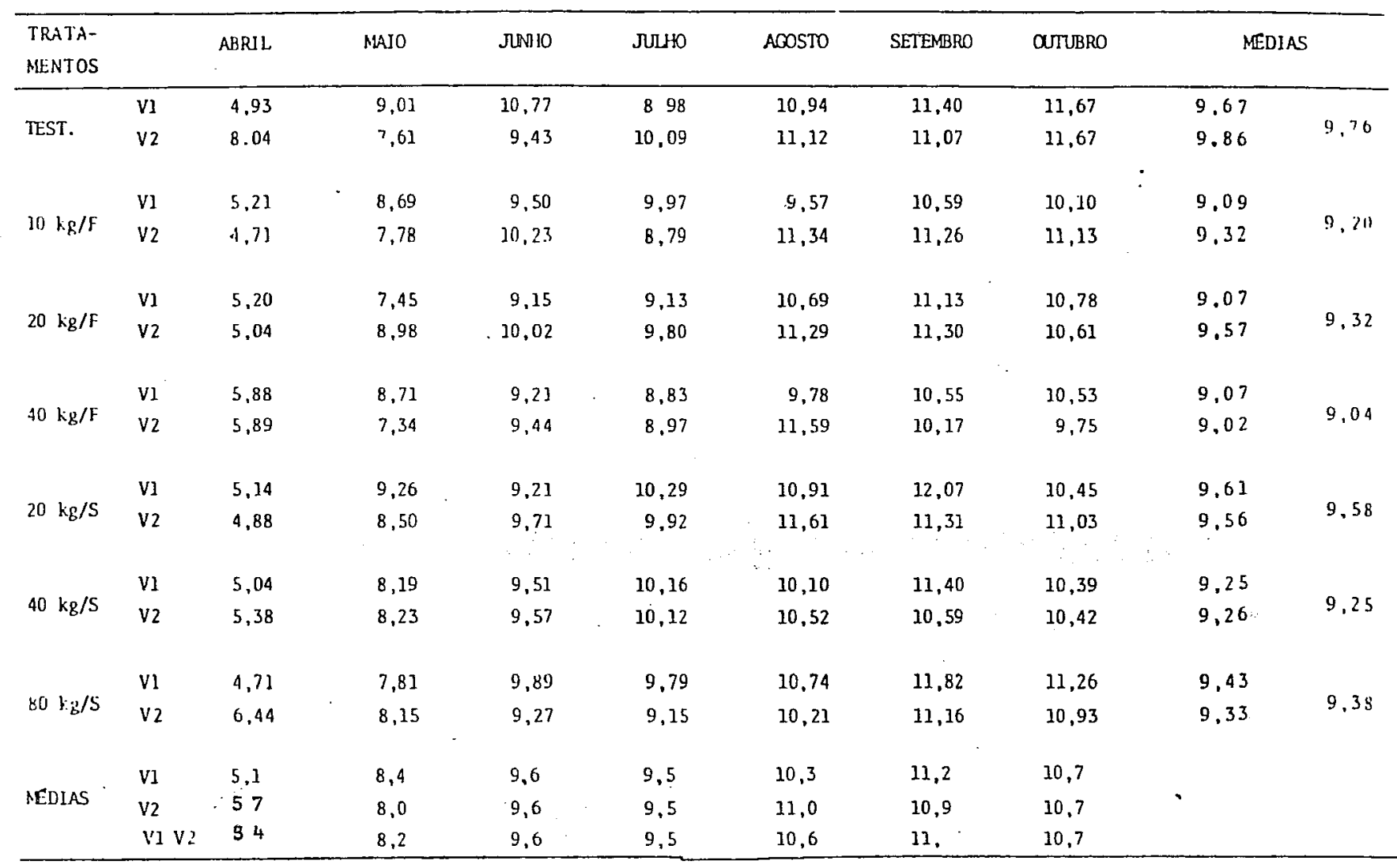

\begin{tabular}{lrc}
\hline Causas da variaçāo & GL & $F$ \\
Blocos & 2 & 2,340 \\
Tratamentos & 6 & 1,510 \\
Residuo A & 12 & \\
\hline Parcelas & 20 & \\
\hline Variedades & 1 & 1,467 \\
Interação T $\times V$ & 6 & 0,570 \\
Resíduo B & 14 & \\
\hline Sub-Parcelas & 41 & \\
\hline Coleta & 6 & $142,608 *$ \\
Interação T $\times C$ & 36 & 0,616 \\
Interação V $\times C$ & 6 & 1,514 \\
Interaçāo T $\times V \times C$ & 36 & 1,083 \\
Resíduo C & 168 & \\
\hline Total & 293 & \\
\hline
\end{tabular}

CV (T) 6.415

CV (v) 5,364

CV (C) 6,474 
.113.

TABELA 23 (Continuaçāo) - Valores de sacarose ( $\left(\begin{array}{l}0 \\ 0\end{array}\right)$ em colmos de canas, das variedades IAC 48-65 e IAC 50-14 em LVa.

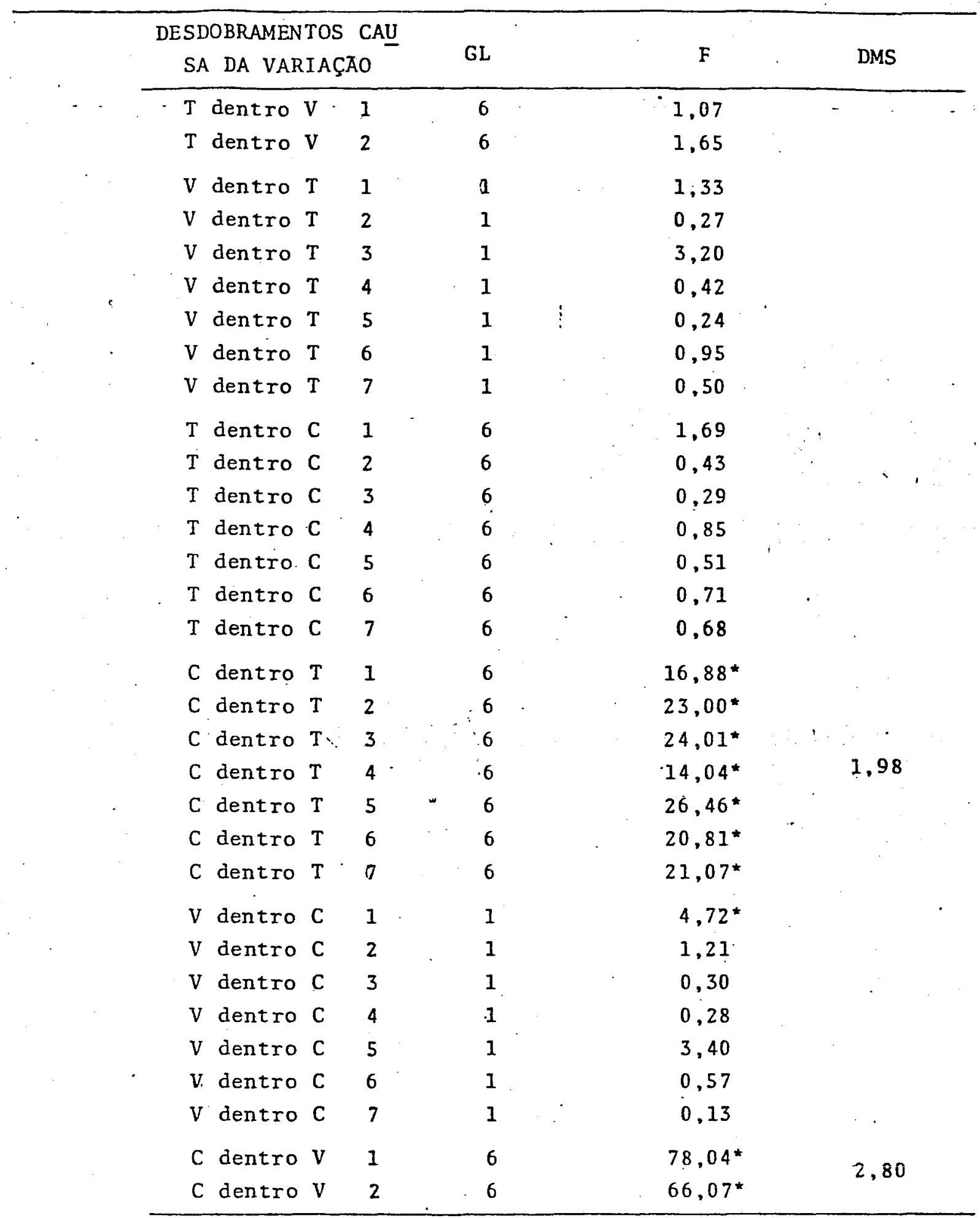


ximos ocorrendo nas três ültimas coletas. o pico ocorreu na quinta coleta, no tratamento $40 \mathrm{~kg} / \mathrm{ha}$ via foliar; ocorreu na sexta coleta para os tratamentos 10 e $20 \mathrm{~kg} / \mathrm{ha}$ e em todos os tratamentos via solo; o teor mäximo do tratamento $40 \mathrm{~kg} / \mathrm{ha}$ ' via foliar foi o mais precoce, ocorrendo na quinta coleta.

$\mathrm{Na}$ interação variedades $\mathrm{x}$ coletas, fixada coletas, existiria significância apenas na primeira coleta com a variedade IAC 50-14 superando a IAC 48-65; na segunda coleta a IAC 48-65 è superior, enquanto na quinta a maior é a IAC 50-14, nas demais, não ocorrem diferenças dignas de nota.

Para canas cultivadas em LR, os resultados rela tivos à porcentagem de sacarose em colmos, encontram-se na ta bela 24. Da análise de variância depreende-se significância' para variedades e coletas, bem como para as interações tratamentos $x$ variedades e variedades $x$ coletas, sem contudo ocorrer significância para tratamentos. Tambëm neste caso, serão verificadas as interações não significativas, à procura de tendências. De modo geral, as melhores médias são as dos tra tamentos testemunha, 40 e $80 \mathrm{~kg} / \mathrm{ha}$ via solo; a variedade de maior média fọi a IAC 48-65 e a melhor coleta foi a sexta.

Da decomposição das causas de variação, nas diferentes interações, pode ser observado, o abaixo descrito.

$\mathrm{Na}$ interação tratamentos $\mathrm{x}$ variedades, com os tratamentos fixados, com significância para todos, menos testemunha e $20 \mathrm{~kg} / \mathrm{ha}$ via foliar, observa-se que a variedade 
IAC 48-65 apresentou maiores médias em todos os tratamentos.' Já com a fixação das variedades, mesmo não ocorrendo significância, nota-se que na IAC 48-65, os melhores tratamentos foram 80 e $40 \mathrm{~kg} / \mathrm{ha}$ via solo, sendo o pior. $40 \mathrm{~kg} / \mathrm{ha}$ via folir ar: Para a variedade IAC 50-14, apenas os tratamentos testemu nha e $20 \mathrm{~kg} / \mathrm{ha}$ via solo, diferem em $0,5 \%$, com o primeiro supe rando o segundo.

Para a interação tratamentos $x$ coletas, não se detecta significância quando se fixam as coletas, nāo ocorren do diferenças dignas de nota, na segunda e sétima coleta; na primeira e sexta coleta:, destacam-se apenas valores baixos ' em $10 \mathrm{~kg} / \mathrm{ha}$ via foliar para a primeira e $20 \mathrm{~kg} / \mathrm{ha}$ via solo na sexta; na terceira,ocorre destaque positivo para $80 \mathrm{~kg} / \mathrm{ha}$ ' via solo e negativo para $20 \mathrm{~kg} / \mathrm{ha}$ via foliar; na quarta coleta,o tratamento $20 \mathrm{~kg} / \mathrm{ha}$ via foliar alcança a maior média, enquanto a menor $\overline{\mathrm{e}} \quad 20 \mathrm{~kg} / \mathrm{ha}$ via solo.. Finalmente, na quinta, o maior valor é ém $40 \mathrm{~kg} / \mathrm{ha}$ via solo, sendo o maior em $10 \mathrm{~kg} / \mathrm{ha}$ via foliar. Quando fixa-se os tratamentos, verifica-se que ' em todas as coletas são significativos, sendo os valores crescentes até a sexta coleta, diminuindo levemente na sētima, excetuando -se os tratamentos $40 \mathrm{~kg} / \mathrm{ha}$ via foliar e $20 \mathrm{~kg} / \mathrm{ha}$ via solo, on de o maior valor ocorre na sétima coleta.

$A$ interação coletas $x$ variedades, apresentou significância, onde fixando-se veriedades, na observação do desdobramento, verifica-se que o comportamento das coletas é semelhantes nas duas variedades,alcançando a maior média 
TABELA 24 - Valores de sacarose $\left(\frac{0}{0}\right)$ em colmos de canas, das variedades IAC 48-65 e IAC 50-14, em LR.

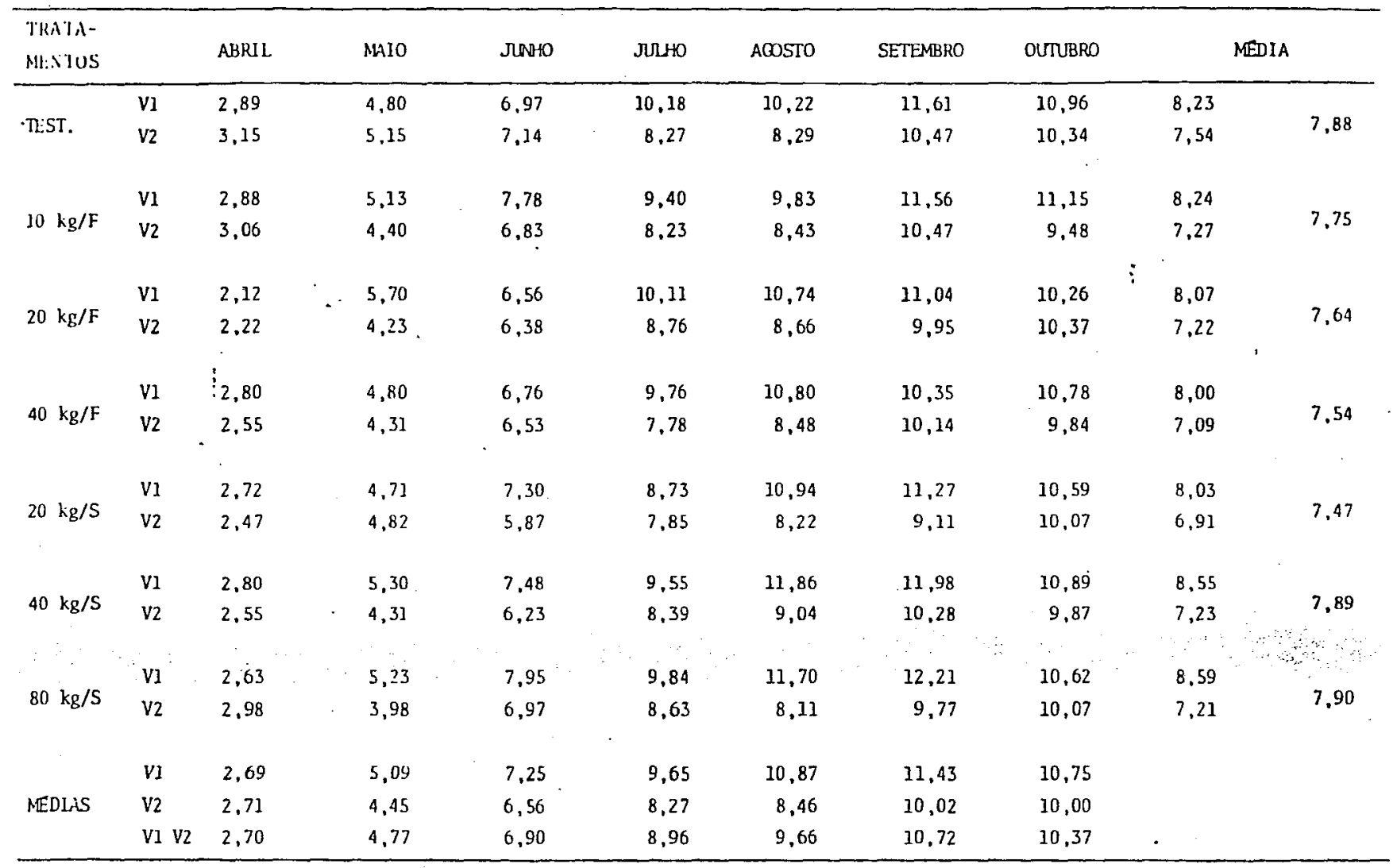

\begin{tabular}{lrc}
\hline Causas da Variacāo & GL & F \\
Blocos & 2 & 5,848 \\
Tratamentos & 6 & 1,005 \\
Residuo A & 12 & \\
\hline Parcelas & 20 & \\
\hline Variedades & 1 & $39,746 *$ \\
Interação T $\times V$ & 6 & 0,392 \\
Resíduo B & 14 & \\
\hline Sub-Parcelas & 41 & \\
\hline Coleta & 6 & $591,854 *$ \\
Interação T $\times \mathrm{C}$ & 36 & 0,739 \\
Interação V $\times \mathrm{C}$ & 6 & 6,288 \\
Interacão T $\times \mathrm{V} \times \mathrm{C}$ & 36 & 0,633 \\
Resíduo C & 168 & \\
\hline Total & 293 & \\
\hline
\end{tabular}

$\mathrm{CV}$ (T) $7,695 \quad \mathrm{CV} \cdot(\mathrm{V}) 8,886 \quad \mathrm{CV}$ (C) 6.139


TABElA 24 (Continuaçāo) - Valores de sacarose $\left(\begin{array}{l}0 \\ 0\end{array}\right)$ em colmos de canas, das variedades IAC $48-65$ e IAC 50-14,em LR.

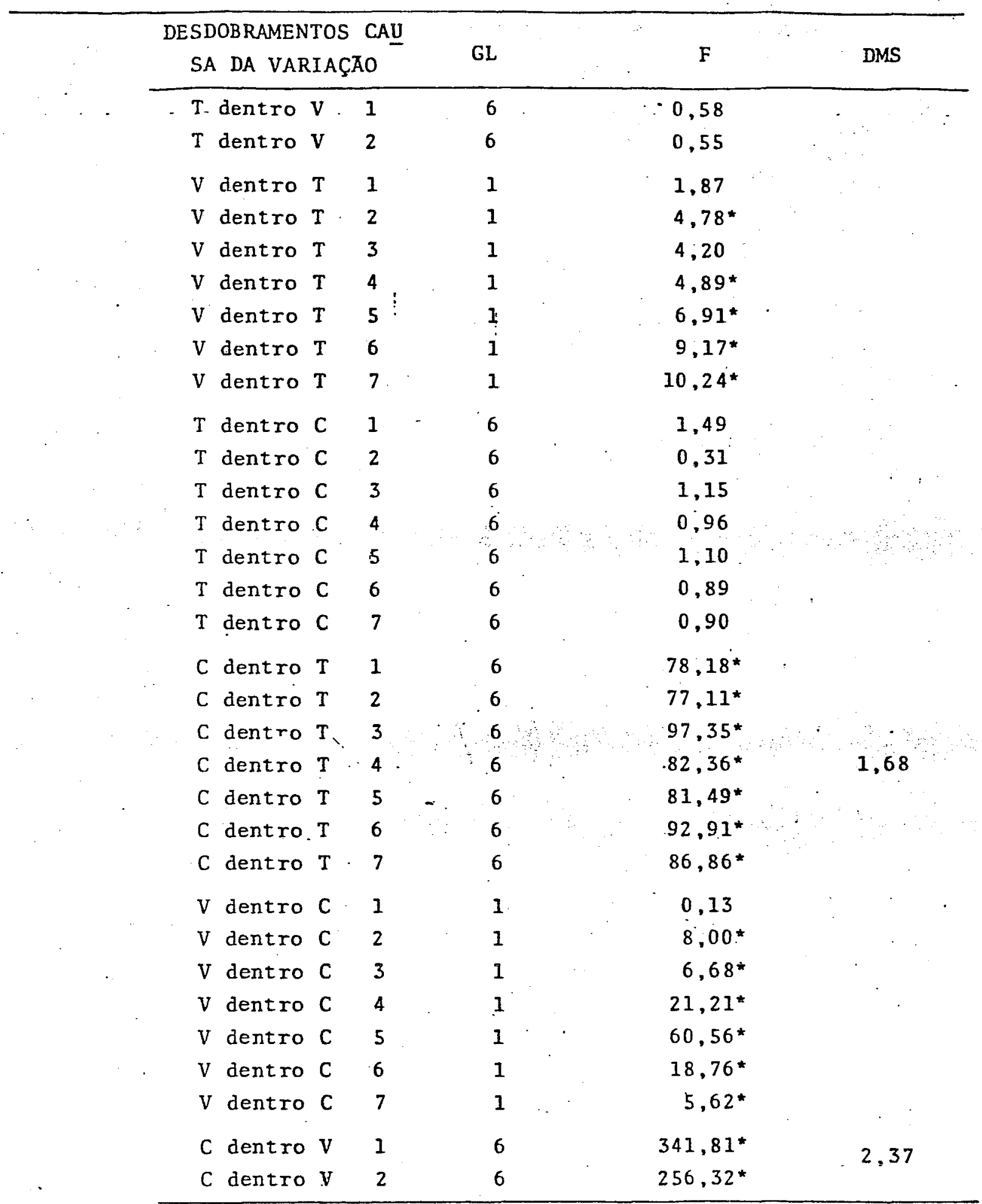


sexta coleta, depois de um crescimento gradativo. Fixando-se coletas, nota-se que só não houve significância entre as variedades, na primeira coleta; nas demais, observa-se que a variedade IAC 48-65 supera a IAC 50-14.

Os resultados de sacarose obtidos para colmos? são consistentes com os trabalhos desenvolvidos no Brasil por ESPIRONELO et alii (1976); NEPTUNE et alii (1965) e PEDRAS (1981) em cana-de-açūcar, quer seja cana planta de ciclo de 12 ou 18 meses, quer seja cana soca. Concordam ainda com trabalhos desenvolvidos por WALLACE (1947) e por SAMUELS et alii (1952) de que aplicaçōes de boro não incrementam o teor : de. sacarose em plantas tratadas, chegando inclusive, em alguns tratamentos, a deprimir o acúmulo.

Verifica-se tambẻm que a sugestão apresentada ' por PEDRAS (1981), não se confirmou, no concernente à expecta tiva de que plantas de cana cultivadas em ciclo de 12 meses ' viessem a responder a aplicações de microelementos.

Esta idéia, baseada em MAGALHAES e MONERAT (1978) de que as aplicações de boro deveriam ser feitas mais frequentemente, em vista da sua imobilidade, bem como em ORLANDO Fi et alii (1980) de que as plantas acumulam maior.' quantidade de boro na fase final do ciclo.

os resultados, parecem pois confirmar o já ex ' posto por INFORZATO e ALVAREZ (1957) de que a cana-de-açūcar, apresenta habilidade de absorver a quantidade necessária de 
boro do substrato, quer pelo seu excelente sistema radicular, quer por menor necessidade deste elemento (EVANS, 1959).

Em relação aos teores relativos de sacarose, ve rificam-se valores crescentes das folhas para os colmos: atra vès da bainha, confirmando o proposto por BURR et alii (1957) de haver armazenamento temporário de polissacarídeos nas bainhas, durante a noite e auxiliando no transporte de açūcar da lâmina para o colmo. 


\section{CONCLUSOES}

Baseado nos resultados e discussōes apresentaai dos, pode-se destacar as seguintes conclusões, a respeito do efeito fisiológico do boro sobre a cana-de-açücar, nas condições estudadas.

1. Em relação ao teor de boro:

1.1. Em limbos, para LVa não se verificaram efeitos entre os tratamentos ou variedades, ocorrendo apenas para coletas nos tratamentos de $10 \mathrm{~kg} / \mathrm{ha}$ via foliar e $80 \mathrm{~kg} / \mathrm{ha}$ via solo; e ainda nesses dois tratamentos ' para variedades, na primeira coleta. Em LR não se' verificou significância para nenhuma das variedades.

1.2. Em bainhas, para LVa não se verificaram efeitos para tratamentos ou variedades, ocorrendo singnificâncias entre coletas, com a segunda maior que a primeiranos tratamentos testemunha, 20 e $40 \mathrm{~kg} / \mathrm{ha}$ via foliar e $80 \mathrm{~kg} / \mathrm{ha}$ via solo. No LR, também só se verificaram' significāncias entre coletas, com a primeira superando a segunda no tratamento $80 \mathrm{~kg} / \mathrm{ha}$ via solo. 
1.3. Em colmos não se verificou qualquer efeito em LVa. Em LR, a média da segunda coleta superou a primeira.

1.4. Os teores foliares de boro, foram iguais ou maiores' que o nivel crítico para cana-de-açūcar.

1.5. Os dois solos, nas condiçōes do ensaio, apresentam bo ro disponível em quantidades suficientes, para aten ' der as necessidades da cana-de-açücar.

2. Em relação ao teor de açūcares redutores, não se verificou comportamento padronizado, com variações aleatórias dos re sultados, o que não permitiu conclusões consistentes a res peito do efeito do boro sobre este parâmetro.

3. Em relação ao teor de sacarose:

3.1. Em limbos, para LVa verificou-se significância em todas as variáveis, destacando-se o tratamento $80 \mathrm{~kg} / \mathrm{ha}^{\prime}$ via solo na variedade IAC 48-65, mas sem significância : sobre a testemunha, e do tratamento testemunha e:80 kg/ ha via solo na variedade IAC 50-14. Para LR, tambëm ocorreram significancias nas variáveis; a testemunha' superou os demais tratamentos na IAC 50-14 e na. IAC 48-65 o melhor tratamento foi o $20 \mathrm{~kg} / \mathrm{ha}$ via solo.

3.2. Em bainhas, para LVa verificaram-se significâncias nas variāveis, com destaque para o tratamento $40 \mathrm{~kg} / \mathrm{ha}$ via solo na IAC 50-14 e no IAC 48-65 juntamente com o 20 $\mathrm{kg} / \mathrm{ha}$ 女ia foliar. Em LR, tambèm ocorreu significân..' cia das variäveis, com predominância da testemunha so bre os demais e com a variedade IAC 50-14 superando a IAC $48-65$. 
.122.

3.3. Em colmos, para LVa não se verịficaram diferenças significativas a não ser em relação a coletảs, com as três últimas superando as demais. Em LR;verificou-se significância para interação vari edades $x$ coletas; na IAC 48-65 houve predomínio da sexta, mas sem diferir da quinta ou sétima; na IAC 50-14 a sexta e sétima predominam sobre as demais. 
LITERATURA CITADA

ALBERT, L.S., 1965. Ribonucleic acid content, boron deficien-. cy symptom and elongation of tomato root tips.

Plant Physiol., 40:649-652.

ALVAREZ, R. e A.C.P. WUTKE, 1963. Adubação da cana-de-açúcar. IX. : Experimentos preliminares com micronutrientes. Bragan tia, $22: 647-650$.

ANDREW, C.S: Influence of nutrition on nitrogen fixation and growth of legumes. In: HUNLAY, B. 1962. A review of nitrogen in the tropics with particular reference to pastures. Comm. Bur. Past. Fed. Crop Bull., 46:130-146. AUGSTEIN, H. e EICHLORN, M. 1976. Biochemistry and physiolo gy of boron in plants. Biol. Reund., 14:268-285. AZEREDO, D.F. e J. BOLSANELLO, 1981. Efeito de micronutrientes na produção e qualidade da cana-de-açúcar no Rio de Jä neiro, Espirito Santo e Minas Gerais (Zona da Mata). Estudo Preliminar. Brasil Açucareiro, 98(3)9-17. BAKER, J.E.; H.G. GAUCH e W. DUGGER Jr.. 1956. Effects of boron on the water relations of higher plants. Piant Physiol., 3?: $35-93$. 
BIBLE, B.B.; JU, H.Y. e CHONG, C.. 198I. Boron deficiency in relation to growth and thiocyanate toxin content in radish. Scientia Horticulturae, 15:201-205.

BIELESKI, R.L. 1960.' The physiology of sugar-cane. III. Cha racteristics of sugar uptake in slices of mature and immature storage tissue. Australian J. Biol. Sc1. 13:203-220. BIELESKI, R.L. 1960\%. The physiology of sugar-cane.

Effects of inhibitars on sugar accumulation in storage tis sue slices. Australian J. Biol. Sci. 13:221-231.

BINGHAM, F.T.; A. ELSEEWI E J.J. OERTILI, 1970. Characteristics of boron absorption by excised barley roots. Soil. Sci. Soc. Amer. Proc., 34(4):613-617.

BOHNSACH, C.W. E L.S. ALBERT, 1977. Early effects of boron deficiency on indolacetic acid oxidase levels of squash root tips. Plant Physiol., 59:1047-1050.

BONILLA, I.; CADAHIA, C.; CARPENA, 0 ; e HERNANDO; V. 1980 . Effects of boron on nitrogen metabolism and sugar levels, on sugar beet. Plant and soil. $57(1): 3-9$.

BOWEN, J.E., 1968. Borate absorption in exeised sugarcane leaves.Plant and Cell Physiol., $\underline{9}(3): 467-478$. BOWEN, J.E'., 1969. Some physiological effects of variable boron and zinc levels on sugar cane. Sugar News. 205-209. BOWEN, J.E., 1969a. Absorption of borate ionic species by Saccharum officinarum. Plant Cell Physiol.. 10(1)227-230. BOWEN, J.E., 1970. Boron deficiency and toxicity in sugarcane. journal of the Hawaii Agricultural Experiment Station $n^{8}$ 1176.

BOWEN, J.E., 1977. Boron. Crops \& Soil Magazine, 29(9)12-14. 
BRASIL SOBRINHO, M.0.C., 1965. Levantamento do teor de boro em alguns solos do Estado de São Paulo. Piracicaba, USP/ ESALQ, $135 \mathrm{p}$. (Tese de Livre-Docéncia).

BRASIL SOBRINHO, M.D.C.; A. ESPIRONELO $\mathrm{e}^{-}$T. IGUE, 1976. Efe to do boro em cana-de-açúcar cultivada em alguns solos no Municipio de Piracicaba. II. Cana soca. Bragantia, 35 Nota $n^{8} 17$.

GRASIL S , M.O.C. e D. FREIRE. 1979. Boro em alguns solos do Estado de São Paulo. Avaliaçāo por métodos químicos. Revista da Agricultura. 55: 83-105.

BRASIL S*, M.O.C. e D. FREIRE. 1980. Boro em alguns solos do Estado de São Paulo. Avaliação por métodos biológicos.Revista da Agricultura. 55: $115-126$.

BRIEGER, F.O.e S.B...PARANHOS, 1964. Técnica cultural." In: Cultura e adutação de cana-de-açūcar. São Paulo. Instituto Brasileiro de Potassa. Cap. 5, p 139-190. BUCHANAN, J.G... 1953. The path of carbon in photosynthesis. XIX. The identification of sucrose phosphate in sugar beet leaves. Arch. Biochem. Biophys. 44:140 BUCKMAN, H.O. e N.C. BRADY, 1967. Natureza e Propriedades dos

Solos. Rio de Janeiro, Freitas Bastos. 594 p. BURR, G.O.; C.E. HARTT; H.W. BRODIE; T.TANIMOTO; H.P. KORTSCHAK; D. TAKAHASHI; F.M. ASHTON E R.E. COLEMAN. 1957.: The sugarcane plant. Ann. Rev. Plant Physiol. ㅇ: 275-308. BURR, G.O. 1974. Informação pessoal. Experiment station of. the Hawaiian Sugar Planters' Association. Honolulu-Hawaii. BUSSLER, W. I960. In: MENGEL, K.: E KIRKBY, E.A. 1978.

Principles of Plant Nutrition. Bern. International Potash Institute. $593 p$. 
CHRISTOFOLETTI, J. C.. 1872. Adajtaçäo em pulverizador costal para pressão canstante para fins experimentais. Botuca tu, F.C.M.B.B.. Ilp. (mimeografado).

CLEMENTS, H.F.; J.P. MARTIN E S. MORIGUCHI. I941. Composition of sugar cane plant grown in deficient nutrient solution. Hawailan PI. Res., 45:227-239.

COMISSÃO DE SOLOS. 1960. Lovantamento e reconhecimento dos' solos do Estado de São Paulo. B. Servi. Nac. Pesq. Agron.., Rio de Janeiro, (12): 1-634.

DE, R. ER. SINGH, 1960. Effects of micronutrient elements on growth, yield, and chemical composition of sugar cane. Soil Sci.: 89:97-100.

DIBLE, W.T.; E. TRUOG e K.C. BERGER. 1954. Boron determination in soils and plants. Simplified curcumin procedure. Anal. Chem. 26: 418-421.

DUGGER, W.M. $e$ T.E. HUMPHREYS, 1960. Influence of Boroan on Enzimatic Reactions Associated with Biosyntesis of sucrose. Plant Physiol. $35(4): 523-530$.

DUGGER, W.M., Jr.; T.E. HUMPHREYS e B. CALHOUN. 1957. The Influence of Boron on Starch Phosphorylase and its Signifi cance in Translocation of Sugars in Plants. Plant Physiol. $\underline{32}: 364-370$.

ESPINDOLA, C.R., 1979. Pedogënese em äreas basälticas de reverso de "cuesta" do médio curso do Rio Tieté. Botucatu,fCAl UNESP, 213 p. (Tese de Docéncia).

ESPIRONELO, A., 1972. Estudos sobre efeitos de boro na conade-açūcar (Saccharum sp.). Cultivada em alguns solos do municipio Município de Piracicaba. Piracicaba, ESALQ/USP. 94 p. (Tese de Doutoramento). 
ESPIRONELO, A. e H. OLIVEIRA, 197.2. Orientação geral para a adubaçāo de cana-de-ąúcar no Estado de São Paulo. Bol. Inst. Agron. Campinas. 201:1-16.

ESPIRONELO, A.; M.S.C. BRASIL SOBRINHO E T. IGUE, 1976. Avaliação do boro assimilável e provas de respostas, pelo mé todo biolágico do girassol, à administração desse elemento a alguns solos cultivados com cana-de-açúcar. Bragantia, $\underline{35},(20): 221-236$.

ESPIRONEL.O, A.; M.D.C. BRASIL SOBRINHO e T. IGUU, 1970 a. Efeitus dos boro em cana-de-açúcar cultivada em alguns soIos do Município de Piracicaba. Bragantia, 35(18)191-2l1. ESPIRONELQ; A.; M.O.C. BRASIL SOBRINHO E R.S. MORAES, 1976 b. Efeito do boro em cana-de-açúcar cultivada em vasos conten do solo. Bragantia, 35(23) 259-272.

EVANS, H., 1959. Elements other than nitrogen, potassion and phosphorus in the mineral nutrition of sugar cane. Proc. 10 th Congr. ISSCT. Hawaii, 473-508.

GALLO, J.R.; R. HIROCE e.R. ALVAREZ, 1969;. Levantamento do estado nutricional de canaviais de São Paulo, por análise foliar. Bragantia, 27:365-382.

GAUCH, H.G. E W.M. DUGGER, 1953. The role of boron in the translocation of sucrose. Plant Physiol., 28:457-465. GAUCH, H.G. e W.M. DUGGER Jr.. 1954. The physiological role of boron in higher plants: a review and interpretation. Univ. Maryland Agr. Exp. Sta. Tech. Bull. A.80. GEIGER, D.R.; GIAQUINTA, R.T.; SOVONICK, S.A. e FELLOWS, R.J. 1973. Solute Distribution in sugar Beet Leaves in Relation 
to Phlogm Loading and Translociation.

(6): $585-589$.

GJUL'AHMEDOV, A.N. E J.M. PEJSAHUV, 1969. Effect of boron on

the yield and quality of grapes. Hort. Abs., 39(4)779.

GLASZIOU, K.T. 1960. Accumulation and transformation of su-

gars in sugar cane stalks. Plant Physiol. 35:895-901.

GLASZIOU, K.T. 1961. Accumulation \& transformation of sugars

in stalks of sugar cane. Origin of glucose 8 fructose in

the inner space. Plant Physiol.: 36:175-179.

GLASZIOU, K.T. e K.R. GAYLER. 1972. Storage of sugars in

stalks of sugar cane. Botanical Review. 38:471-492.

HAAG, H.P., 1965. Estudos de nutriçäo mineral na cana-de-açü car em solução nutritiva. Piracicaba, ESALq/USP. I4l p. (Te se de Livre-Docēnciaj.

HARTT, C.E. 1940. The synthesis of sucrose by excised bla des of sugar cane. Haw. Plant Rec. 44:89-116.

HARTT, C.E. 1943. The synthesis of sucrose in the sugar cane plant - IV. Concerning the mechanism of sucrose synthesis in the sugar cane plant. Haw. Plant Rec. 47:3l-43.

HARTT, C.E.. 3943. The synthesis of sucrose in the sugar cane plant - I. Haw. Plant Rec. 47:113-132.

HARRT, C.E.; H.P. KORTSCHAK; A.J. FORBES E G.O. BURR. I962. Trans Iocation of $\mathrm{C}^{14}$ in Sugarcane. Plant. Physiol. 37:305-318. HATCH, M.D. e K.T. GLASZIOU. 1964. Birect evidence for tirans location of sucrose in sugarcane leaves and stems. Plant Physiol. 39:180-184. 
HULL, R.J. e LERMANN, S.L. 1972. Photosynthate distribution In boron deficient bean leves. Plant Physiol., 49:22. HUMBERT, R.P., 1974. El cultivo de la cana de azucar. C. Mé xico. Compañia Editorial Continental, S.A. 719 p. IVANOVA, V.I., i965: The effect of $B$ and $M n$ on the yield and sugar content of sugar beets. Chem. Abs., $63 n^{8} 18980$. KANWAR, R.S., 1960. Some preliminary studies on the germination and tillering of sugar cane as influenced by minor el $\equiv$ ments. Indian Sugar., 9 : 563-569.

KIBALENCO, A.P., 1966. Effect of boron on carbohidrate metabolism im plants. Chem. Abs.. 64(9)13106.

KIBALENCD, A.P., 1970. Effect of boron on the structure and function of sugar beet chioroplasts., C.A. 고 (23) n8 119765. KISE, I.R., 1966. Effect of molybdenum, boron and copper on yield and biochemical composition of vegetable crops. Soils Fert., 29(4)382.

KOUCHI, H. E K. KUMAZAWA, 1975.' Anatomical responses of root tip to boran deficiency. I. Effect of boron deficiency on elongation of root tips and their morphological characte ristics. Soil Sci.\& Plant Nutr., 2l(1)21-27. KOUCHI, H. e KUMAZAWA, K. 1975a. Anatomical response of root tips to boron deficiency. 11. Effect of boron deficiency on the cellular growth and development in root tips. Soil Sci. Plant Nut., 21:137-150.

KOUCHI, H. E KUMAZAWA, K. 1976. Anatomical responses of root tips to boron deficiency. III. Effect of boron deficiency on subcellular structure of root tips, 
particulary on morphology of çell wall and its related organeIles. Soll. Sci. Plant Nut., 22:53-71.

LAL, K.N. E H. SHRIVASTAVA, 1949. Studies in crop physiology. Nutrient effects upon development and vegetative vigour of sugar cane. Proc. Indian Acad. Sci. B., 29:iog.

LEE, S. e S. ARONOFF, 1967. Boron ir plants. A biochemical role. Science, 158: 798-799.

LINSKENS, H.F. 1974. Informaçăo pessoal. Uni. Nigmegen, Ho Ianda.

LOPEZ HERNANDEZ, J.A. 196I. Accion de las sales de boro sobre el poder rotatorio de los azucares. Boln. Estac. exp... agríc: Tucumán, (71). 17 .

LOTT, W.L.; A.C. MCCLUNG; R. VITTA e J.R. GALLO, 196I. Levan. tamento de cafezais..pela análise foliàr em são Raulo e Paranā. São Páulo, IBEc Res. INSTITUTE.. 69 p. (Boletim 26). LUIT, B. Van, 1970. Prevention of boron deficiency in sugar beet by fertilising on spraying. Soils Fert., 33 (4)422. MAgALHÃES, J.R. e P.H. MONNERAT, 1978. Aplicäção foliar de boro na prevençāo de deficiēncia e na composição mineral do tomateiro. Pesq. Agropec. Bras., 13[4]73-80.

MALAvOLTA, E.; H.P. HAAG; F.A.F. MELlo e M.O.C. BRAsil SOBRINHO, 1964. La nutriciōn mineral de algunas cosechas tropi cales. Berna Instituta Internacional de la Potasa. 163 p. MALAvolta, E. e H.P. HAAG, 1964. Nutrição e Adubação. In: Cultura e adubação de cana-de-açúcar. São Paulo, Inst. Bras. Potassa, cap. 9, p 237-278. MARTIN, J.P.. 1934. Symptoms of malnutrition manifested by 
sugar cane plant when grown in.culture solution from which certain essential elements are omited. Haw. Plant Rec.., 3 B: 330.

MARTIN-LEAKE, H., 1949. The sugar cane in Australia. 48 th Ann Rep. Bureal Sugar Exp. Sta. 1947-48. The International Sugar J. June. 156-157.

MARTIN; T.; M. GEORGESCU E A. CIOFU, 196. The effect.. of spray applications of manganese, boron and cobalt to grape vine. Soils Fert., 29:108.

MASON, T.G. e E.T. MASKELL, 1928. Studies on tae transport' of carbohydrates in the cotton.plant... I. A study of diurnal variation in the carbohydrates of. leaf, bark, and wood, and of the effects of ringing. Ann. Botany. 42:189253.

MEADE, G.P., 1963. Analysis of the juice. In: Cane Sugar handbook. 9 ed. New York, Wiley. P.543-551. MEADE, G.P., 1963a. Chemical control. In: Cane Sugar handbook. 9 ed. New York, Wiley: p.628-670. MENGEL, K. e KIRKBY, E.A. 1978. Principles of Plant nutrí ' tion. International Potash Institute. 593p. MoILRATH, W.J. e J. SKOK. 1964. Boron nutrition and lignifí cation in sunflower and tabaco stems. Botan. Gaz. 125:268271.

MITCHELL, J.W.; W.M. DUGGER E H.G. GAUCH, 1953. Increased translocation of plant growth modifying substances due to application of boron. Science, 118 . 
MOGILNER, I. 1960. Funcion del Microelemento Boro en el organismo Vegetal. Bonplandia. T.l. pag. 38-50.

MUKHERJEE, K.L., 1968. Effect of microelement fertilization on the yield and juice quality of sugar cane. Sci. and Cult., $34: 125-126$.

NELSON, N. 1944. A photometric adaptation of Somogyi method' for the determination of glucose. J. Biol. Chem.. 153:375380.

NELYUBOVA, G.L. e L.A. DOROZHKINA, 1969. Effect of boron an sugar distribution in sugar beet and carrot roots. C.A. 20 (5) $n^{8} 17601$.

NELYUBOVA, G.L. E L.A. DOROZHKINA, 1970. Effect of boron on sugar accumulation in sugar beet and carrot. Soils fert.. $\underline{33}(\dot{5}) 515$.

NEPTUNE, A.M.L:; O. J. CROCOMO; O. VALSECHI; E.R. OLIVEIRA; J.P. STUPI ELLO; A. CAMPANELLI e A. COBRA. NETO, 1965. Influéncịa do boro sobre o teor de sacarose em cana-de-açúcar (Variedade CB41/76) e sua interação com potássio e cálcio em presença' de nitrogènio e fósforo. Anais do X Congresso Brasileiro de Ciéncias do Solo.

QERTLI, J.J. E W.F.RICHARDSON, i970. Mechanism of boron imo-. bility in plants. Physiol. Plant., 23:108-116.

D'KELLEY, J.C., 1959. Boron and plant growth. New Biol., 30 : $103-111$.

ORLANDO F', J. e S. RUGAI, 1974. Nutriçāo mineral de cana-de -açúcar no Brasil. Brasil Açúcareiro, 84(3):12-21. 
ORLANDO F., J. e E. ZAMBELLO F8 ę H.P. HAAG, 1980. Efeito do solo e da idade da planta na absorção de boro pela canade-açücar CB 4176. Brasil Açucareiro, 96(1):31-41.

ORTII, B.V., 1968. Normal values of nutrients in sugarcane. Bol. Azucar. Mex., 26:28-34.

PEDRAS, J.F: 1981. Efeitos do boro sobre algumas cáracterú ticas agroindustriais em duas variedade de cana-de-açúcar' (Saccharum spp.). Piracicaba. ESALQ/USP. 90p. (Tese de li? Mestrado].

PIMENTEl Gomes, $F$; 1963. Curso de Estatistica. 2a. ed. PI racicaba, Nobel. $384 p$.

POLLARD, A.S.; PARR, A.S. B. BRIAN, B.C. 1977. Boron in relation to membrane function in higher plants. 5. Exp. Bot., 23: $831-841$.

PRICE, C.A.; CLARK, H.E. P FUNKHOUSER, E.A. Functions of micronutrient in plants. In: MERIVEDT, J.J.; GIORDAND,P. M. \& LINSDAY, W.L. 1972. Micronutrient in Agriculture.. Madison, Soil Science Society of America. Inc. 600p. RAB, F., 1969. Location and translocation of.boron in sugar beet plants. [...., ?I(3.3) $n^{8} 57616$.

RAO, P.J.M., 1977. Soil and foliar diagnosis in sugar factory laboratories for determining macro \& micro nutrients requi red for sugercane growth. Indian Sugar, 27(10)671-685.

RIBEIRO, M.E.M., 1978. Caracterizą̧ão de sintomas de : defí ciência de boro em pepino, elface, alho, beterraba, cebola e rabanete. Viçosa, UFV, 48p. (Tese de Mestrado). 
ROREM, E.S., H.G. WALKER JI. E R.M. MCCREADY. 19.59. B105Ynthesis of sucrose and sucrose-phosphate by suger beet leaf extracts. Plant Physiol. 34:269-272.

SAAKDV, V.S. 1965. Influéncia de B a Mn sobre a dinämica de movimentaçāo e distribulção de glucose-1,6-C 14 em plantas. Palestra da Acad. de Sci. da CCCP. Tom l62, $n^{8} 2$, pg. 465467.

SACHER, J.A., M.D. HATCH e K.T. GLASZIOU. 1963. Sugar accumulation cycle in sugar cane. III. Physical \& metabolic.' aspects of cycle in immature storage tissues. Plant Physiol 38: $348-354$.

SAMUELS, G.; M.A. LUGO-LOPEZ E F. LANDRAU JUIIIOR, 1952. Influence of fertilizers on sucrose content of sugar cane. Sugar. $47: 49-5 I$.

SARIN, M.N. e SADGOPAL, A. 1965. Studies on the effect of boron deficiency in tomate seedling. I. Growth and anatomical response. Indian J. Plant Physiol., 8: 119-129. SERRA, G.E., 1973. Efeitos da adubação fósfatada sobre algumas características agro-industriais do caldo de cana-deaçücar, variedade CB 4176. F..C.M.B.B. I04 p. (Tese de Dou toramento.

SERVAITES, I.C. e GEIGER, D.R. 1974. Effects of Light Inten sity and oxygen on Photosynthesis and translocation in sugar Beet. Plant Physol: 54(4):575-578.

SHAFFER, P.A. e M. SOMOGYI. 1933. Copper lodametric reagents for sugars determinations. J. Biol. Chem. 100: 695-713. 
SIMS, J.R. eF.7. BINCHAM, 1968. Retention of boron by leyer silicates, sesquioxides, ond soij materiajs. IIJ. Iron and aluminium coated layer silicates and soil materials. Sodil. Sci. Soc. Amer. Proc., (32):369-373.

SIQUEIRA, J.O.; J.F. SILVEIRA \& G.A.A. GUEDES, 1979. Efeito de micronutrientes na presença e auséncia de calcário no rendimento agrícola e qualidade do caldo de cana de açūcar (cana planta): Brasil Açuciareiro, 94(5):77-80.

SISLER, E.C.; W.M. DUGGER e H.G. GAUCH, 1956. The role of boron in the translocation of organic-compounds in plant. Plant Physiol. 31: 11-16.

SKOK, J., 1941. Effect of boron on growth and development of the radisti. Bot. Gaz., I03:280-294.

SOMOGYI, M. 1937. A Reagent for the copper-iodometric de: termination of very small amounts of sugar. J. Biol. Chem. $117-771$.

SOMOGYI, M. 1952. Notes on sugar determination. J. Biol.! Chem. 195: 19-23.

SOVONICK, S.A.; GEIGER, D.R. E FELLOWS, R.J. I974. Evidence. for Active Phloem Loading in the Minor Veins of sugar Beet. Plant Physiol. 54(6): 886-891.

STRLCKMEYER, B.E., I968. Effects of inadequate suplies of magnesium, calcium and boron on foliar symptoms and leaf Enatomy of geranium. Phyton, 25(2)143-150.

SULTANUM, E., 1974. Considerações sobre a sintomatologia de micronutrientes em cana-de-açúcar no Nordeste do Brasil. Brasil Açucareiro, B3 (2). Encarte. SWANSON,C.A. E E.D.H. EL-SHISHINY. 1958. TransIocation of sugars in the concord grape. Plant Physiol., 33: 33-37. 
SWANSON, C.A., 1965. Translocation of organic soluts. In: STEWARD, F.C., ed. Plant Physiology a Treatise., 2:481-551. TANAKA, H., I967. Short comunication: boran adsorption : by plant roots. Plant \& Soil, (2):300-302.

TANAKA, H., 1967 a. Effect of boron on the sugar composition of sunflower leaves. Role of boron in the sugar metabolism of higher plants. I. J. Sci. Soil Manure, 37:558-572.

TRIP, P. e P.R. GORHAM. 1968. Translocation of radiative su ! gars in vascular tissue of soybeans plants. Can. J. Botany. 46: $1129-1133$.

VAN DILLEWIJN, C., 1960. Botanique de la canne e sucre. Wa geningen, Hollande, H. Veenman e Zonan N.V. 391 P. VENTER, H.A. \& CURRIER. H.B. 1977. The effect of boron deficiency on callose formation and ${ }^{14} \mathrm{C}$ translocation in bean (Phaseolus vulgaris L.) and cotton (Gossipium hirsut. tum L.J. Am. J. Bot., 64:861-865.

VLASYUK, P.A., 1967. The effect of trace elements on the increase of sugar content and the improvement of technological properties of sugar beet: C.A., 67(1):2444.2444. WALLACE, L.G., 1947. Soil fertility trials. Cane Growers Quartely Bull. Queensland. 10:145-151.

WARINGTON, K. 1923. The effect of boric acid on the broad, bean and certain other plants. Ann. Batany: 37:629-672. WHITTINGTON, W.J., 1959. The rale of boron in plant growth. II. The effect on growth of radicle. J.Exp.Bot..10:93-103. ZIMMERMANN, M.H. 1957. Translocation of organic substances' in trees. I. The nature of the sugars in the sieve tube, exudate of trees. Plant Physiol. 32:288-291. 
.137

ZIMERMANN, N., 1960. Transport in the phloem. Annual Review of Plant Physiol., $11: 167-190$. 